Portland State University

PDXScholar

$1-1-2011$

\title{
Countering Structural Violence: Cultivating an Experience of Positive Peace
}

Carrie E. Stiles

Portland State University

Follow this and additional works at: https://pdxscholar.library.pdx.edu/open_access_etds Let us know how access to this document benefits you.

\section{Recommended Citation}

Stiles, Carrie E., "Countering Structural Violence: Cultivating an Experience of Positive Peace" (2011). Dissertations and Theses. Paper 210.

https://doi.org/10.15760/etd.210

This Thesis is brought to you for free and open access. It has been accepted for inclusion in Dissertations and Theses by an authorized administrator of PDXScholar. Please contact us if we can make this document more accessible: pdxscholar@pdx.edu. 
Countering Structural Violence: Cultivating an Experience of Positive Peace

by

Carrie E.T. Stiles

A thesis submitted in partial fulfillment of the requirements for the degree of

\author{
Master of Arts \\ in \\ Conflict Resolution
}

Thesis Committee:

Harry Anastasiou, Chair

Patricia Rumer

Tom Hastings

Portland State University

2011 


\begin{abstract}
This thesis considers some conflicts involving indigenous peoples that arise from the universal standardization of Intellectual Property Rights (IPRs) over Plant Genetic Resources (PGR). My study presents the research problem of how to include indigenous peoples in dialogue as a prerequisite for conflict transformation. To better understand this problem, and potential solutions, I conducted participatory action research (PAR) through an ethnographic case study of Himalayan farmers working with the grassroots network Navdanya. The study explores the research question: how do Garhwali farmers experience grassroots mobilization for biodiversity and indigenous knowledge (IK) conservation? This question is intended to generate data for conflict resolution analysis on how to engage indigenous peoples in dialogue on the subject of IPRs over PGR. I discuss five themes that emerge from the data collected including: experiences and strategies in grassroots mobilization, culture and sharing, the seed, climate change and women. My research is divided into three separate, but interrelated elements. Firstly, I discuss my methodological choices and experiences. Secondly, I present the ethnographic research, thematic data analysis and draw conclusions. Finally, I frame the literature in the context of the theory of structural violence to explain the significance of conflicts arising from IPRs over PGR in the context of the erosion of IK systems and biodiversity.
\end{abstract}




\section{Table of Contents}

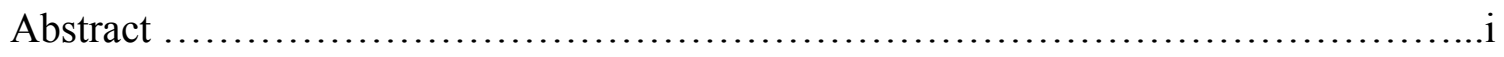

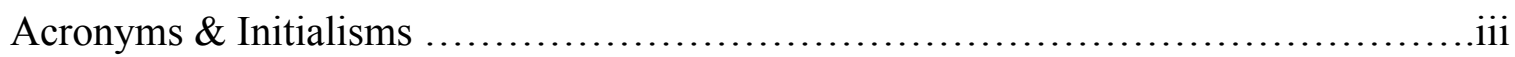

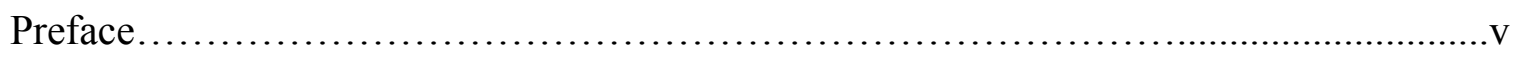

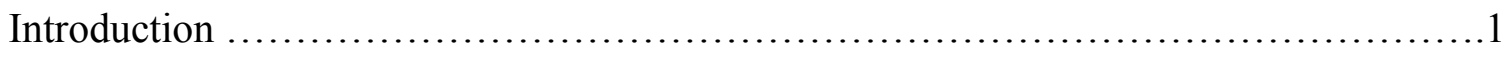

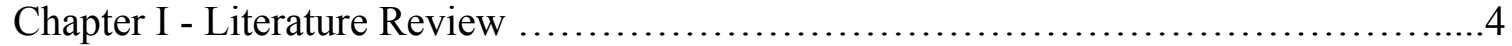

Part I - Structural Violence .............................................4

Part II - Impacts on biodiversity and indigenous knowledge...................11

Part III - A tale of three treaties and one exemption: TRIPS, CBD, ITPGRFA,

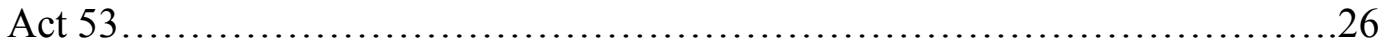

Part IV - International Rights..........................................50

Part V - Impacts on epistemology and socio-cultural factors..................54

Part VI - Reciprocity and the Selfish Model.............................62

Chapter II - Methodologies..................................................67

Part I - Participatory Action Research.....................................68

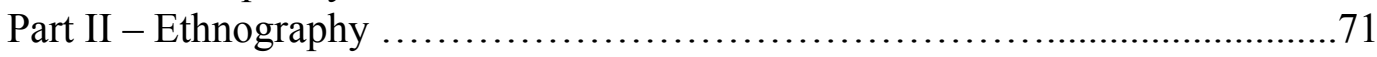

Part III - Data collection and analysis.................................. 74

Part IV - The Role of the Researcher .................................. 80

Chapter III - Analysis ....................................................... 82

Part I - Setting . ................................................... 83

Part II - Actors.......................................................... 85

Part III - Events.................................................. 89

Part IV - Processes................................................... 88

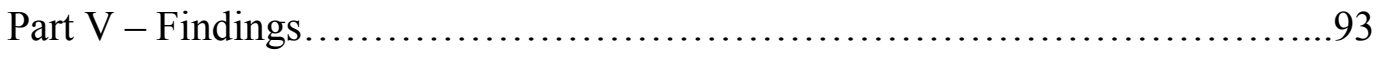

Chapter IV - Overall Conclusion.......................................... 133

References............................................................. 140 


\title{
Acronyms \& Initialisms
}

\author{
ABS - Access and Benefit Sharing \\ CBD - Convention on Biological Diversity \\ CEO - Chief Executive Officer \\ CR - Conflict Resolution \\ ETC - Action Group on Erosion, Technology and Concentration \\ FAO - Food and Agriculture Organization we \\ IFAD - International Fund for Agricultural Development \\ IK - Indigenous Knowledge \\ ILO - International Labor Organization \\ IPR - Intellectual Property Rights
}

ITPGRFA - International Treaty on Plant Genetic Resources for Food and Agriculture

PAR - Participatory Action Research

PGR - Plant Genetic Resources

PIC - Prior Informed Consent

PRA - Participatory Rural Appraisal

RFSTE - Research Foundation for Science Technology and Ecology

SHG - Self Help Groups

TRIPS - Trade Related Intellectual Property Rights

UN - United Nations

UNEP - United Nations Environmental Program

UNU - United Nations University

US - United States 
USPTO - United States Patent Office

WHO - World Health Organization

WIPO - World Intellectual Property Rights Organization

WTO - World Trade Organization 


\section{Preface}

This study is premised on the salience of engaged dialogue and relationship building in the interest of non-violent, conflict transformation. In this study I present Participatory Action Research (PAR) to explore the conflict resolution problem of how to include indigenous peoples in dialogue regarding IPRs over PGR. Existing studies of how to engage indigenous peoples in dialogue on this issue emerge from grassroots literature, anthropology, international politics and international rights in theory and practice. To understand the research problem, and explore possible solutions, I have investigated the question: how do Garhwali farmers experience grassroots mobilization to conserve biodiversity and IK?

In this thesis I present the hypothesis that indigenous peoples experience a greater degree of positive peace when they are recognized and included, through a dialogic relationship, in the process of biodiversity and IK conservation. To evaluate this hypothesis I collected data during a six-month research period with the non-governmental organization Navdanya, which is the largest organic, fair-trade network in India. I analyze the data I collected to understand the methods and meanings of grassroots mobilization that engage local people in dialogue regarding the impacts of IPRs over PGR.

Through data analysis I reveal some local concerns and how people experience and strategize to build positive peace and counteract structural violence. In the literature review section (Chapter III) I apply the countervailing conflict resolution theories of positive peace and structural violence to evaluating my hypothesis. With my literature review I explain in detail how a specific case of structural violence impacts a local 
population. I present the case in the context of Indigenous, Cultural and Farmer's Rights to highlight the precedence for conflict transformation. 
Introduction

No man is wise enough by himself

Roman playwright Plautus

(254-184 BC)

Currently, $75 \%$ of the world's poorest 1.2 billion people inhabit rural areas and rely on small-scale farming for their livelihoods (Andersen, 2006, p. 4). According to the International Fund for Agricultural Development (IFAD) there are at least 300 million indigenous peoples living in over 70 countries, the majority of whom live in poverty (2003, p. 5). Indigenous peoples in poor countries are heavily dependent on seeds increasingly controlled by developing countries through the universal standardization of Intellectual Property Rights (IPRs) over Plant Genetic Resources (PGR) (Fowler et al., 2001).

This thesis explores the impacts of IPR regimes on indigenous peoples when these regimes seek to govern PGR. IPR regimes are a common topic of debate, in a large body of literature, spanning several fields including: ecology, environmental science, political science, international studies, ethnobotany and anthropology. IPR regimes operate through a vast network consisting of various treaties, rules, institutions, interests and relationships. The World Trade Organization (WTO) and developed countries are the main advocates of IPR regimes.

The United States (US) has been a key proponent and leader in promoting intellectual property protection in agriculture (Shiva, 2005). Primarily, IPRs over PGR restrict indigenous farmers access to seeds and criminalize the traditional practice of seed saving. IPR regimes promote the commercialization of PGR for food and agriculture. IPR regimes seek to govern over PGR by promoting the rights of the biotechnology industry 
and transgenic seed corporations to expand private sector IPRs.

The agreement on Trade Related Intellectual Property Rights (TRIPS) is at the center of debates pertaining to the negative impacts of the universal standardization of life form patenting. TRIPs require member states in the WTO to conform their IPR legislation, regulations and procedures to universalize life form patenting of PGR or be subjected to sanctions (Godbole-Chaudhuri, Srikantaiah \& Van Fleet, 2008). Patents on PGR have proliferated exponentially since the establishment of the TRIPS regime. Life patents over PGR have had different socio-cultural, ecological and economic impacts including: criminalization of the traditionally pivotal practice of seed, the restriction of farmer's access to seed, the emergence of the phenomenon known as biopiracy and the increased erosion of biodiversity and IK.

The emerging field of conflict resolution (CR) has not focused on transforming conflicts arising from life form patenting over PGR. The limited CR participation in addressing this specific, yet hugely consequential problem is regrettable because of the urgent need to engage peace scholars in advocating for marginalized communities living in poverty. However, the countervailing conflict resolution theories of structural violence and positive peace are exceedingly relevant to the topic of indigenous marginalization in the context of IPRs over PGR.

The field of conflict resolution has advanced the concept of positive peace to better understand how to transform conflict. Positive peace requires peace-building efforts to manifest social relationships and social structures that meet basic human needs and fulfill human rights. The avoidable nature of violence emphasized by Galtung means that space; opportunities and strategies for conflict resolution need to be created by concerned parties 
(Ho, 2007). Creating opportunities for marginalized stakeholders to participate in the empowerment of their communities is an essential component of positive peace building. Inclusive research processes and innovative tools that create opportunities for constructive dialogue are also needed to build positive peace (Krishna, 2009).

Social justice and positive peace are intimately related. In short, the concept of positive peace means peace as more than the absence of war (negative peace), but rather the experience of advanced states of mind and society such as justice and equity (Barash \& Webel, 2009). Positive peace exists when oppression and structural violence are minimized, or eliminated, through the existence of supportive and sustainable relationships between different groups across a range of boundaries. The experience of positive peace includes the experience of a just society (Barash \& Webel, 2009). Positive peace is the exemplary outcome of social interactions because citizens may experience a greater degree of social harmony. Characteristics of a society experiencing positive peace include improved health, effective implementation of justice initiatives and socioeconomic equity.

This thesis is premised on the fact that conflict transformation requires that marginalized people be engaged in dialogue regarding issues that impact their survival. The purpose of this thesis is to amplify the voices of Garhwali farmers in the context of IPRs over PGR because their knowledge is in need of conservation. I analyze the experiences of Garhwali farmers as they mobilize from the grassroots to protect their knowledge, culture and biodiversity. My overall intention is to consider the indigenous perspective in the debate over IPRs over PGR. 


\section{Chapter I - Literature Review}

\section{Part I - Structural Violence}

"The poor remain in poverty not because they want to, but because of the many barriers deliberately built around them by those who benefit from their poverty."

- Nobel Laureate Mohammad Yunus

My literature review presents multiple legal and regulatory frameworks, international agreements and national laws pertaining to IPRs over PGR. Furthermore, I present literature that explores the relational impacts of restricting farmer's access to seed, the erosion of IK and depletion of genetic resources. I reviewed three general topics to assess the impacts of these legal and regulatory frameworks on indigenous peoples. The first topic explains the impact of the commercialization of IK on biodiversity and indigenous peoples including erosion and biopiracy. The second topic of study focuses on international rights and sustainability. The third topic presents epistemological and sociocultural differences between western proponents of IPR regimes and IK systems.

This literature review aims to provide substantive content towards clarifying the illdefined concept of structural violence. Theoretical understandings of violence have progressed slowly over time while violence has increased exponentially. The relationship between oppressive structures and the struggle of marginalized groups to balance global power relations are under-theorized (Parsons, 2007). The theory of structural violence has struggled to rectify this deficit by allowing for a more nuanced analysis of violence through examination of the indirect causes of avoidable harms. Structural violence has largely been described in vague terms in the existing literature. Analyzing structural violence has proven challenging for scholars and practitioners. 
Structural violence is a central concept in peace theory. Norwegian peace researcher Johan Galtung first proposed the theory of structural violence (Barash \& Webel, 2009). Galtung is considered the contemporary founder of peace and conflict studies and has contributed greatly to initiating and articulating discourses of peace and violence. Galtung constructed a typology of violence with three categories: personal, cultural and structural (1990). Galtung defines violence as the avoidable disparity between the potential ability to fulfill basic needs and their actual fulfillment.

Köhler and Alcock found in 1976 that structural violence occurs when poverty and unjust socio-political and economic institutions, systems and structures harm, or kill people. Hoivik wrote in 1977, "We know that social structures kill and maim as surely as the bullet and the knife" (p. 59). Galtung (1969) explains that structural violence is indirect, avoidable violence built into structures where there is unequal power and consequently unequal life chances. Structural violence is an oppressive framework that operates through powerful associations, organizations and institutions that guarantees privilege amongst its leaders, prioritization of their political agenda, and an enforcement of their methods and ideologies. The power imbalances indirectly result in injury towards others through exclusion and exploitation.

The loss of life resulting from inequality is a consequence of structural violence. Originally, scholars reduced the phenomena of structural violence by measuring it through comparisons of national average life expectancy rates. Alcock and Köhler (1979) and Hoivik (1977) measured structural violence based on the premise that a country with a high life expectancy rate, like Sweden, is subjected to less structural violence than a country with a low life expectancy rate, like Mali. 
Experts created the "human suffering index" in 1991 to analyze human welfare measures such as life expectancy and political freedom (Farmer, 1996). The index categorized 27 of 141 countries as experiencing "extreme human suffering". The "human suffering index" is a more advanced method of quantifying the symptoms of structural violence compared to the rudimentary approach of conflating life expectancy with structural violence. However, suffering is problematic to quantify because the quality of each person's experience is unique and subjective. Farmer points out that the experience of suffering is not effectively conveyed by statistics or graphs and that not all suffering is equal. Thus, it is necessary to immerse research in human experiences to understand structural violence rather than depend on graphs and models.

Parsons (2007) accuses Galtung of oversimplifying structural violence by applying it as an 'umbrella concept'. He writes that structural violence is often used as an umbrella concept for other types of injustice such as oppression, marginalization, inequality, exploitation, domination, and repression. However, an overly broad definition of structural violence ignores significant opportunities and possibilities for conflict transformation.

Essentially, Parsons (2007) critiques Galtung's explanation of structural violence because it is too general. Parsons asserts that Galtung's explanations of peace and violence lack normative clarity and sufficient analysis and thus cannot adequately explain violent power relations. Additionally, Galtung's application of structural violence as an umbrella concept does not always translate in the international context. Instead, Parson's asserts that a multi-faceted analysis and approach to understanding and reducing structural violence will serve to legitimate the concept of structural violence in the 
international sphere.

Galtung (1969) negates the need to trace structural violence back to its source because that would not be 'meaningful'. While Galtung (p. 170) calls for a precise definition of the term 'peace' in his influential article, Violence, Peace and Peace Research he writes about structural violence that, “...if people are starving when this is objectively avoidable, then violence is committed, regardless of whether there is clear subject-action-object relations... as in the way world economic arrangements are organized today." The lack of clear subject-action-object relations when elaborating at theory of structural violence is problematic.

Starvation is the most extreme form of malnutrition. Dutta et al. (2004) found that nearly half of the Garhwali populations in the mid and high hills suffer from malnutrition. Through data analysis I found that Galtung's direct correlation between starvation and structural violence is problematic because many factors converge to create the conditions for suffering and marginalization. Starvation can be a form of direct violence, cultural violence or nonviolent resistance, for example in the forms of capitol punishment, anorexia or hunger strikes respectively. In the case of the Garhwal issues such as severe agro-climatic variations, the big dam projects, and climate change need to be included in an exploration of extreme malnutrition.

In order to transform structural violence it is necessary to render a complex and dynamic picture of the conflict. However, clarifying the action-subject-object relation when correlating malnutrition and structural violence need not be a strenuous undertaking. Sen (2005) provides a simple, yet illuminating example in writing about a lethal confusion of food politics. He points out the shocking fact that although India 
suffers from worse hunger and malnutrition than sub-Saharan Africa the government keeps the largest unused food stock in the world.

Sen (2009) calls for clear articulation and reasoned scrutiny when describing a case of injustice. He writes that, "The identification of redressable injustice is not only what animates us to think about justice and injustice, it's also central ... to the theory of justice" (p. VII). Furthermore Sen explains that:

The impossibility of remaining silent on a subject is an observation that can be made about many cases of injustice that move us to rage in a way that is hard for our language to capture. And yet any analysis of injustice would also demand clear articulation and reasoned scrutiny. (p. 1)

Following Sen, in order to situate structural violence as a case of injustice it is necessary to articulate, scrutinize and clarify a subject-action-object relation.

Alcock and Köhler wrote in 1979 that, "Eventually, we should be able to formulate a comprehensive, empirically validated theory of structural violence which would explain variations and changes in the magnitudes of structural violence. Such a theory is a long way off however" (p. 255). Thirty years later Farmer (1996, p. 274) reflects on structural violence and asks the question, "Can we devise an analytic model, one with explanatory and predictive power, for understanding suffering in a global context?" Farmer calls for fine-grained, systemic analyses of power and privilege that is geographically broad and historically deep in discussions of structural violence and suffering.

Investigating the social 'axes' within the larger social matrix is essential to deducing what Farmer calls a 'political economy of brutality' (1996, p. 282). He explains most importantly that:

As the twentieth century draws to a close, the world's poor are the chief victims of structural violence - a violence which has thus far defied the analysis of many 
seeking to understand the nature and distribution of extreme suffering. Why might this be so? One answer is that the poor are not only more likely to suffer, they are also more likely to have their suffering silenced (p. 283).

To break this silence it is necessary to amplify the voices of those suffering from poverty and marginalization. Furthermore, it is necessary to hold the forces that create suffering accountable by charting the larger social matrix in which experiences of suffering are embedded. Creating a system of accountability requires tracing experiences of suffering back to specific sources in a global context.

The basis of many social movements hinges on tracing structural violence back to a source and holding those sources accountable through creative, innovative methods. It is not that structural violence exists when things are not clear, but rather where there is complexity of social forces. The complexity of social forces must be rendered comprehensible for constructive conflict resolution to mitigate structural violence. Furthermore it is the role of conflict resolution practitioners and scholars to better understand the subject-action-object relations to create the space necessary for constructive dialogue.

Elaborating a theory of structural violence demands that we design a system of accountability by mounting evidence rather than accepting the illusive character of suffering. The example of IPR regimes over PGR illuminates an example of the complex forces that converge to generate structural violence. In this study I have analyzed the action-subject-object relations that converge to create structural violence in order to render the conflict presented more comprehensible. My study explores the relationship between Garhwali people (subject), life form patenting (action) and PGR or seeds (object). Through analysis of the research problem and research question I seek to 
articulate a case of injustice by clarifying the subject-action-object relation negated by Galtung. 


\section{Part II - Impacts on biodiversity and indigenous knowledge}

\section{Understanding Indigenous Knowledge Systems}

Understanding the many facets and faces of indigenous peoples and their knowledge systems is integral to reconciling the conflict between IK systems and the universal standardization of IPRs over PGR. Article 1 of the 1989 Convention concerning Indigenous and Tribal Peoples in Independent Countries, No. 169, adopted by the International Labour Organization (ILO) provides a working definition of indigenous communities, peoples and nations stating that:

Indigenous communities, peoples and nations are those which, having a historical continuity with pre-invasion and pre-colonial societies that developed on their territories, consider themselves distinct from other sectors of the societies now prevailing on those territories, or parts of them. They form at present nondominant sectors of society and are determined to preserve, develop and transmit to future generations their ancestral territories, and their ethnic identity, as the basis of their continued existence as peoples, in accordance with their own cultural patterns, social institutions and legal system. (UN Department of Economic and Social Affairs, 2004, p. 2)

The forces of colonialism and the global market economy have eroded the cultural patterns, social institutions and legal systems created by indigenous peoples (Shiva, 1997).

Indigenous peoples' knowledge is central to millions of people's lives in developing countries (Shiva, 2002). Indigenous peoples have argued that IK is inseparable from the biological, environmental, territorial, cultural, spiritual, legal and epistemological context (Tobin, 2009). Ellen and Harris (2000) outline ten facets of IK: (1) localness, (2) oral transmission, (3) origin in practical experience, (4) emphasis on the empirical rather than theoretical, (5) repetitiveness, (6) changeability, (7) being widely 
shared, (8) fragmentary distribution, (9) orientation to practical performance, and (10) holism.

The World Intellectual Property Rights Organization (WIPO) (2005, p. 4) defines IK as, "traditional know-how, innovations, information, practices, skills and learning of traditional knowledge systems such as traditional agriculture, environment or medical knowledge.” Furthermore, the United Nations Environmental Program more broadly defines IK as encompassing:

... all forms of knowledge... that enable the community to achieve stable livelihoods in their environment. IK is ... embedded in community practices, institutions, relationships and rituals... It is a set of experiences ... It therefore represents all the skills and innovations of a people and embodies the collective wisdom and resourcefulness of the community.

Indigenous peoples' experiences of community practices, institutions, relationships and rituals and their skills and innovations are all part of IK systems. IK is vital in the pursuit of poverty alleviation through the promotion of sustainable livelihoods.

IK is widely identified in the literature as holistic and collectively owned in an intergenerational context (Berson, 2010; Brush, 2007; Calle, 1996, Chowdhury, 2004; Fernando, 2003; Godbole-Chaudhuri, Srikantaiah \& Van Fleet, 2008; Marinova \& Raven, 2006; Mein, 2009; Miller, 2010; Sillitoe, 2010; Singaporia, 2007; Sulula, 2006; Vermeylena, 2007). The World Health Organization (WHO, 2001) has explained that, although IK is intergenerational, it is not static and every generation contributes to the knowledge system. As the Japanese writer Nakashima (as cited in WIPO, 2010, p. 1) has said:

Traditional knowledge is not merely learned by rote and handed down from one generation to the next. Inherently dynamic, it is subject to a continuous process of 
verification, adaptation and creation, altering its form and content in response to changing environmental and social circumstances.

An example of the dynamic processes described by Nakashima is genetic resources because they too result from the continuous process of adapting seeds through selective breeding to environmental conditions.

Indigenous models of subsistence living may be better understood through the relationship ethnic communities have with their ecosystems (Calle, 1996). For the purposes of this thesis the term IK primarily refers to elements of indigenous peoples knowledge that is relevant to biodiversity. The special relationship between IK and biodiversity conservation is sometimes referred to as traditional ecological knowledge or traditional environmental knowledge.

Indigenous peoples are an ecological ethnicity. Apffel-Marglin and Parajuli (2000, p. 292-312) define the social category of an "ecological ethnicity" to explain the significance of traditional environmental knowledge. An ecological ethnicity refers to groups of people who have evolved a sustainable relationship with nature such as peasant communities. However, most peasant communities have been marginalized by development and environmental modernization. Ecological ethnicities have:

... a commitment to creating and preserving a technology that interacts with the place and its nonhuman collectivity in a sustainable manner... the practices of the rural peoples of the subcontinent who are heavily dependent for their livelihood and survival on their immediate environment (and on its biomass) share a great deal in common, despite differences at the level of articulated "beliefs" or "worldviews" (p. 296-297).

The authors explain that 'ecosystem peoples' are commonly dependent on the environment and guided by a 'scientific and moral ecology' and a 'moral economy'. 
During an assessment of the relationships between culture and biodiversity the Action Group on Erosion, Technology and Concentration (ETC) found that developing countries have $86 \%$ of identified larger (vascular/higher) plants, $99 \%$ of the world's indigenous populations and $96 \%$ of the world's farmers (Singaporia, 2007, p. 15). A study published in Conservation Biology in 2006 used satellite data to demonstrate that deforestation and forest fire were 1.7 to 20 times more likely outside of indigenous inhabited reserves (Cardinato et al., 2007, p. 69). Di Falco and Perrings (2003) have demonstrated that voluntary collective farms use more plant biodiversity than do private farms. Indigenous communities on collective farms recognize the public value of having many varieties and so protect biodiversity without profit incentives.

\section{Biodiversity and Indigenous Knowledge}

Many scholars have expressed concern over the rapid erosion of biodiversity in relation to IK as a consequence of the universal standardization of PGR patenting (Andersen, 2006; Berson, 2010; Brush, 2007; Calle, 1996, Chowdhury, 2004; Eyzaguirre \& Dennis, 2007; Greene, 2004; Godbole-Chaudhuri; Kate \& Laird, 2000; Hamilton, 2006; Marinova \& Raven, 2006; Mein, 2009; Miller, 2010; Posey, 1996; Reid, 1993; Sharma, 2005; Sillitoe, 2010; Srikantaiah \& Fleet, 2008; Sulula, 2006; Vermeylena, 2007). Krishna provides a definition of biodiversity, "The term biodiversity refers to all living natural resources, fauna, flora and microorganisms and their inter-relationships in different ecosystems, forests, wetlands, desserts and so on" (2009, p. 140). India is one of twelve mega-biodiversity areas of the world and has $6.5 \%$ of the world's recorded species of plants and animals (45,000 plants and 81,000 animal species). The wealth in 
biodiversity is reflected by a vast socio-cultural diversity of natural resource-based livelihoods and knowledge systems.

Biodiversity is a public good with benefits including: environmental health, maintaining food cultures, productivity, minimizing risks, attenuating shocks, and providing insurance against volatile and imperfect markets (Eyzaguirre \& Dennis, 2007). Biodiversity also has tremendous ethical, symbolic and cultural value (Dankelman et al., 2005, p. 1). McNeely et al. (1990) classified values of biodiversity as both direct and indirect. Direct values include Consumptive Use Value (non-market value of firewood, fodder, water, medicine, game, etc) and Productive Use Value (commercial vale of timber, fish, crops, etc). Indirect values include Non-consumptive Use Value (scientific research, recreation, etc), Option Value (value of maintaining options available for the future) and Existence Value (value of ethical feeling of existence of nature, etc.).

Biodiversity loss (or genetic erosion) threatens IK systems and results in ecological and economic instability (Thrupp, 2003). Biodiversity loss increases susceptibility to insect and pest diseases, reduces nutritional health due to the decline in cultivated varieties, decreases adaptation possibilities to changing environmental conditions and accelerates loss of local agricultural knowledge. Biodiversity acts as insurance for farmers against climate change (Bhatt \& Shiva, 2009, p. 29). Mixed biodiverse crops outperform modern monoculture cropping systems by two to three times. Traditionally Indian farmers plant mixed cropping systems as insurance in several combinations of seven, nine and twelve crops.

Around 7,000 plant species have been cultivated since the beginning of agriculture (Bhatt \& Shiva, 2009, p. 23). Today, only fifteen species and eight animal species 
provide $90 \%$ of the global food supply. Modern agricultural practices have eroded the genetic foundation of most cultivated crops such as rice, wheat and maize by replacing biodiversity with a few modern varieties. Furthermore, wild relatives of crops are needed to inter-breed with cultivated varieties to evolve new traits that can withstand climate change. However, the large-scale extinction of species presents a problem to the possibility of evolving new traits that can adapt to changing environmental conditions.

The increasing need to adapt to changing conditions in society, the environment and the market highlight the urgent need for biodiversity conservation (Pimbert, 1999). Biodiversity conservation is important for future generations because of the need to conserve useful genetic traits such as drought resistance. Traditional crops bred by farmers are the major source of traits for climate resistance. However, powerful transnational seed/agrochemical corporations have patented these traits as explained by Syngenta chief executive officer (CEO) Michael Mack in April 2010, "Farmers around the world are going to pay hundreds of millions of dollars to technology providers in order to have this feature [drought- tolerant maize] (ETC Group, 2010, p. 4)."

Since the beginning of the industrial revolution biodiversity loss has accelerated exponentially. The extinction rate is now an estimated 40,000 times higher than ever before in the Earth's history (Dankelman et al, 2005, p. 3). Until the mid-1960s Indian farmers continued to practice ecological sustainable agriculture using mixed cropping, traditional seeds, organic inputs and adapted seeds to particular bioregions (Miller, 2010, p. 1). These techniques have been tested over five thousand years and are part of a sociocultural and economic tradition.

Biodiversity conservation requires open-access to crop varieties (Eyzaguirre \& 
Dennis, 2007). When farmers have access to genetic resources the cultivation of local varieties and adaptation of new varieties increases. According to the WHO (2001):

... for traditional communities and individual healers to continue preserving biodiversity, it is important that they be allowed to continue to access and use (medicinal) plants; failure to ensure this will ultimately lead to erosion of their knowledge. Once this knowledge has vanished, plants become 'anonymous', lose value and -because of neglect- are at a higher risk of extinction.

Restricting farmer's access to seed leads to the erosion of traditional knowledge. The loss of indigenous knowledge is of great concern because of indigenous peoples' capacity for biodiversity conservation.

\section{Green Gold}

Indigenous ecological knowledge is commonly referred to as "green gold" because if it's contributions to advancements in ecology, health and environmental sciences (Dei et al., 2000; Norton et al., 1998; Shankar \& Venkatasubramanian, 2005; Singaporia, 2007; Yuam \& Lin, 2000). Indigenous communities have a wealth of knowledge to offer which has proven to be valuable to the biotechnology industry. Herbal medicines are the most profitable type of traditional medicine. The world market for herbal medicine has reached forty three billion dollars in revenue. An estimated 4 billion people, $80 \%$ of the global population, currently use herbal medicine as a part of their primary health care (WHO, 2001).

IK is the foundation of considerable product development in a variety of industries such as medicine. An important fact presented by the WHO (2001) is that of 119 plant-derived pharmaceutical medicines, about $74 \%$ are used in modern medicine in ways that directly correlate with their traditional uses as plant medicines by native 
cultures. Biological compounds in plants used for medicinal purposes can easily be isolated by Western chemists and patented as a new "cure" for an ailment. Shiva comments on the isolation of genetic sequences by Western scientists saying that, "Society is the source of knowledge" and not an individual claiming rights over an “epistemologically petty, but technologically powerful tinkering” (1997, p. 72).

During the course of research and development companies depend on IK to determine non-toxicity (Siganporia, 2007). IK is also a widely used marketing tool. Many industries rely on the traditional knowledge provided by indigenous communities to sell their products and profit. However, indigenous communities have not been recognized, included or compensated by the market economy. According to the United Nations University (UNU), the total annual global market for all products derived from genetics is 500-800 billion dollars. Kate and Laird (2000), qualify that these genetic resources have been evolved by indigenous knowledge systems over many centuries through the traditional practice of seed saving. These facts and figures provoke the question: why have indigenous peoples not shared in benefits considering the economic viability and usefulness of indigenous knowledge to the biotechnology industry?

\section{Bioprospecting and Biopiracy}

Bioprospecting includes IK and is related to the rights of local and indigenous communities (Siganporia, 2007). Developing countries have demanded that benefits and profits generated from bioprospecting must be shared with the original providers of genetic resources. The WHO (2001) describes bioprospecting as the, 'systematic search for, and the development of, new resources of chemical compounds, genes, micro and 
macro-organisms and other valuable biological products.... So, in brief, bioprospecting means looking for ways to commercialize biodiversity." Bioprospecting products include pharmaceuticals, botanical medicines, agricultural biotechnology, horticulture, cosmetics, and personal care productions (Kate \& Laird, 2004).

One problem associated with bioprospecting with regard to IK is that bioprospectors are granted patent rights over their final products and processes without any due recognition of the initial contributors (Siganporia, 2007). Other problems associated with bioprospecting include environmental exploitation, knowledge appropriation and other social and economic problems related to unfair (or the total absence of) benefits sharing. The WHO (2001) mentions the tendency of bioprospectors to disrespect the rights, knowledge and dignity of local communities. Scholars commonly refer to the phenomenon of biopiracy in relation to the erosion of biodiversity and IK systems.

Bioprospecting often leads to the phenomenon commonly referred to as biopiracy. Indigenous peoples see IPRs as a form of biopiracy (Tobin, 2009). Biopiracy occurs when corporations and scientists from rich countries claim property rights over indigenous cultural knowledge (Godbole-Chaudhuri, Srikantaiah \& Fleet, 2008). Scholars and activists have described the phenomenon of biopiracy as the theft of IK without any compensation for the use of culturally embedded genetic resources (Mgbeoji, 2006; Shiva, 1997). Industries dependent on patent protection have been accused of misappropriating IK about plants without recognizing the centuries of selective breeding and seed saving that have created the plant genetic diversity on which these industries directly depend (Berson, 2010; Brush, 2007; Calle, 1996, Chowdhury, 2004; Mein, 2009; 
Miller, 2010; Posey and Dutfield, 1996; Sillitoe, 2010; Vermeylena, 2007).

Marinova and Raven (2006, p. 1) define Biopiracy as, "the non-consensual extraction of traditional knowledge, biological resources and/or proprietary rights, converting them into one's own 'inventions' and not sharing the benefits". According to Gupta (2005, p. 153), biopiracy is the, "manipulation of intellectual property rights by those intent on gaining exclusive control over genetic resources without giving adequate recognition or remuneration to the original possessors of these resources." Finger and Schuler (2004) write that biopiracy results in business in developed countries becoming wealthy off impoverished people's knowledge at the expense of developing countries stability (p. 160).

Indian people have extensive knowledge about plant classifications and botanical medicinal properties that support the survival and livelihoods of the impoverished rural masses (Sarangapani, 2003). Several case studies of high-profile patents show that the scientific and technical interests of patent holders were supported by publicly available IK (Marinova \& Raven, 2006). Neem and turmeric are popular and striking examples of biopiracy in India. The commercial benefits to Indian farmers resulting from the neem and turmeric patents have been indirect and minimal. However, the socio-cultural, spiritual and daily value of neem and turmeric to the lives of small-scale farmers and indigenous peoples is incalculable. Biopiracy is particularly troubling because the original purveyors of knowledge are prevented from using their original technologies. Thus, biopiracy epitomizes the misappropriation of knowledge and culture.

The burden of evidence and legal pursuit to reclaim knowledge ownership is forced onto indigenous communities (Godbole-Chaudhuri, Srikantaiah \& Van Fleet, 
2008). The patent of neem as a pesticide is one of the most well known cases of indigenous peoples challenge to biopiracy (Greene 2004; Marinova \& Raven, 2006; Finger \& Schuler, 2004). Indian farmers have traditionally used neem as a fungicide. Neem's properties are mentioned in Indian texts written over 2,000 years ago. Since 1976 the US Patent Office (US PTO) has granted 255 patents for products based on the properties of the neem tree such as gels, anti-wrinkle treatments, insect repellents, disinfectants, fungicides, asthma treatment and wood preservatives.

Similarly, the healing benefits of the spice turmeric traditionally used in Indian cooking, medicine and popular rituals such as the wedding ceremony have been documented and known for centuries (Marinova \& Raven, 2006). The medicinal properties include anti-oxidant, anti-inflammatory, anti-bacterial and anti-fungal properties. Yet, there are 580 US patents based on the properties of turmeric for medicinal uses and cooking products.

The Research Foundation for Science Technology and Ecology (RFSTE) successfully led three legal battles over biopiracy on neem, basmati rice and Nap Hap Indian wheat (Navdanya). The RFSTE, the International Federation of Organic Agriculture Movements (IFOAM) of Germany and Ms. Magda Alvoet (former Green Member of the European Parliament) filed legal opposition against the USDA and WR Grace Patent on the fungicidal properties of neem (no. 436257 B1) in the European Patent Office (EPO) at Munich, Germany. The EPO revoked the neem patent in May 2000 (reconfirmed March 2005) because there was "no inventive step" involved in the fungicide patent, which confirming the "prior art" of the use of neem. In 2001, the US PTO revoked a large section of the US corporation RicTec Inc.'s patent on basmati rice 
(Patent No. 5663484). In 2004, the EPO revoked Monsanto's patent on the Indian wheat (EP 0445929 B1) variety 'Nap Hal'.

\section{Patenting and Intellectual Property Rights}

The concept of Intellectual Property Rights (IPRs) originated in Florence, Italy in the early 1400s (Mgbeogi, 2006). Since this time, legal frameworks have evolved to protect the right to ownership over inventions, ideas and concepts (Godbole-Chaudhuri, Srikantaiah \& Van Fleet, 2008). IPRs typically provide monopolistic rights over the production, use, sale and profit of unique creations for a specified period of time (Marinova \& Raven, 2006). The intention of IPRs is to generate incentive for invention and innovation through temporary knowledge monopolies.

A monopoly is a market distortion designed to compensate for the market failure of underinvestment in innovative knowledge (Siganporia, 2007). In short, patents have three functions: they grant the 'right to exclude', they recognize ingenuity and they allow for a monopoly over economic benefits. According to Marinova and Raven (2006) IPR regimes have failed to equally apply these functions to IK even though IK systems result from ingenuity and creativity, and should generate economic benefits.

The very existence of IK, whether documented or oral, should serve as a strong prompting for the anticipation of unprecedented inventions (Chowdhury, 2004). The failure of IPR regimes to recognize and include indigenous peoples facilitates false claims of innovation and the misappropriation of IK (Eyzaguirre \& Dennis, 2007). The two central provisions of patenting, namely, recognition of authorship and protection of economic benefits have not included indigenous peoples (Marinova \& Raven, 2006). 
Characteristics of IK systems pose obstacles to its valuation and protection within IPR regimes. The granting of IPRs depends on proof that the innovation is novel and nonobvious (Godbole-Chaudhuri, Srikantaiah \& Van Fleet, 2008; May \& Sell, 2006). IK is collectively owned and intergenerational and therefore difficult to identify and isolate as a specific 'discovery' (Oguamanam, 2004). Innovations in genetic resources are often the product of long-term collective efforts of local communities through selective breeding, seed saving and exchange (Howard \& Nabanoga, 2007). According to Brush (2007) and Salazar et al. (2007) no single person can claim to be owners or originators of the innovation process that results in genetic resources.

\section{The Life Patent and the Life Science Industry}

The "life science industry" resulted from corporate mergers of pharmaceuticals, biotechnology, agribusiness, food, chemicals and cosmetics (Bongo, p. 19). Mergers and acquisitions by the life science industry in 1998 were valued at 2.4 trillion dollars. The enormous shifts in capital are attributed to "the new world currency": the life patent. According to Flint (cited in Bongo, p. 100), the life patent is a, "piece of property information relating to a biological process and generally takes the form of a piece of genetic code or genetic engineering that has been subject to intellectual property laws of the first world." Life patents grant so-called 'gene giants' the legal right to determine who gets access to genetic resources and at what price. Hence, the current private sector reflects a monopoly of a few firms dominating the world market in seed commercialization.

Critical scientists, local industries and nongovernmental organizations (NGOs) in 
India, who oppose the concentration of plant and animal breeding rights, accuse the biotechnology industry of threatening biodiversity and IK (Dankelman et al, p. 8). The biotechnology industry, supported by various governments, intends to genetically engineer uniform plants and animals on a large scale. The impact of distributing largescale uniformity in a small-selection of seeds that do not reproduce themselves, but need external inputs, creates the conditions necessary for biodiversity loss and indigenous marginalization.

Khor (2003) claims that patenting is leading to an even greater concentration in a few global corporations of control over the world's food crops such as maize, potato, soybean and wheat, giving them enormous economic power. Six transnational agrochemical/seed corporations (DuPont, BASF, Monsanto, Syngenta, Bayer and Dow) and their biotech partners (Mendel Biotechnology and Evogene) control 201 or $77 \%$ of the 262 patent families (both issued patents and applications). Three companies DuPont, BASF, Monsanto - account for 173 or $66 \%$. The public sector has only $9 \%$. These companies also monopolize the research and output in the field of transgenic plants (Sahai, 2004).

The impacts of the universalized standardization of life form patenting of PGR is central to contemporary debate over indigenous rights, corporate accountabilities and ethical scientific research (Hayden, 2003). Godbole-Chaudhuri, Srikantaiah and Van Fleet (2008) raise salient questions including: whose interests do IPRs serve to protect and to what degree should rights over knowledge be extended? Siganporia (2007, p. 10) answers the question in writing that IPR regimes serve to protect the interests of corporations and exclude indigenous communities: 
Corporations make tremendous profits from commercializing indigenous resources, yet they share no benefits with the indigenous communities who are the purveyors of these knowledge systems. The exclusion of indigenous cultures through IPR regimes is detrimental to the welfare of these communities.

Siganporia's asserts that exclusion has a negative impact on indigenous peoples. The issue of exclusion leads to the problem of how to engage indigenous peoples in dialogue regarding IPR regimes over PGR.

Shiva (2011, Right Livelihood Award) has commented extensively on the monopoly control over PGR:

The primary threat to nature and people today comes from centralising and monopolising power and control. Not until diversity is made the logic of production will there be a chance for sustainability, justice and peace. Cultivating and conserving diversity is no luxury in our times: it is a survival imperative.

The conservation of diverse cultures and biodiversity is intimately linked to sustainability, peace and justice. According to Shiva, the monopoly on seeds has created conditions that threaten the survival of 'nature and people'. 


\section{Part III -}

\section{A tale of three treaties and one exemption: TRIPS, CBD, ITPGRFA, Act 53 Trade-Related Aspects of Intellectual Property Rights}

The agreement on Trade Related Intellectual Property Rights (TRIPS) universally standardized IPRs in 1999 (Siganporia, 2007). The agreement was negotiated over seven years following the transformation of the General Agreement on Tariffs and Trade (GATT) into the World Trade Organization (WTO) during the Uruguay Round. The TRIPS Agreement mandates that WTO member states enforce revenue collection mechanisms for the use of protected IPR (Marinova \& Raven, 2006).

TRIPS require member states in the WTO to conform their IPR laws, regulations and procedures to universalize life form patenting (Godbole-Chaudhuri, Srikantaiah \& Van Fleet, 2008). TRIPS reduce the flexibility of countries to design their own appropriate laws (WHO, 2001). Violation of TRIPS makes member states vulnerable to trade sanctions through the WTO's dispute settlement system. Thus, TRIPS may easily be described as a coercive force.

TRIPS are based on US patent laws (Siganporia, 2007). The US PTO defines patents as 'the right to exclude others from making, using, offering for sale, or selling the invention throughout the United States or importing the invention into the United States' (US PTO, 2005) or any other territory covered by the patent law. The 1980 US Supreme Court ruling on Diamond V Chakrabarty allowed for the first patenting of life forms (Diamond V Chakrabarty 447 US., 303). The judgment stated that, "Anything under the sun that is made by man" and "things of nature that occur by man's handiwork" are patentable. 
According to leading US lawyer Andrew Kimbrell (as cited in Shiva, 1997, p. 1920), "In coming to its precedent-shattering decision, the court seemed unaware that the inventor himself had characterized his creation of the microbe as simply 'shifting' genes, not creating life." Shiva (p. 20) elaborates on the question of life form patenting stating that universities and corporations do not create genes, but shuffle genes. The recombinant DNA technique is a biochemical manipulation and an adjustment to the biological process. It intervenes in the normal processes by which the strains of bacteria exchange genetic information. When biologists claim patents on genetic they declare that $95 \%$ of DNA is “junk DNA", which means that it's function is unknown.

Another problem associated with basing universal IPR regimes on US laws is that US law allows for a distortion on the interpretation of what constitutes "prior art" (Shiva, 2000b). Discoveries made in the US are filed regardless of other patents that exist and are applied in other parts of the world. The non-recognition of "prior art" in U.S. patent laws facilitates the phenomenon of biopiracy.

TRIPS Article 27,5,3(b) mandates that signatory countries permit patenting of micro-organisms and micro-biological and plant varieties. This article is widely criticized by developing countries because it is seen to negate substantial ethical, ecological and economic consequences associated with patenting life forms (Marinova \& Raven, 2006; Siganporia, 2007). Shiva (2000b, p. 89) says the article is seen to discount “ “.. the differences in ethics and value systems of Third World nations, where life is sacred and exempt from patenting." According to Shiva, TRIPS has been at the heart of worldwide resistance to the WTO. 
The EU and US have coercively imposed the patenting of biological resources through forced alterations in national patent laws (GRAIN, 2007). When the Indian government did not implement TRIPS due to parliamentary protests the US initiated a WTO dispute and ruled in 1998 that India's non-compliance was illegal according to GATT (Shiva, 2000b). Shiva (p. 89) comments on the ruling saying that, "This ruling ... is in essence a decision against Indian democracy."

Developing countries have demanded revision of the article that mandates life form patenting to create a more balanced IPR system (Shiva, 1997). However, the effort to enact the right to review (incorporated in TRIPS), that may lead to TRIPS amendment, has been blocked by the US and EU. The Indian government submitted a discussion paper to the TRIPS council in Geneva that explained:

Patenting of life forms may have at least two dimensions. Firstly, there is the ethical question of the extent of private ownership that could be extended to life forms. The second dimension relates to the use of IPRs concept as understood in the industrialized world and its appropriateness in the face of the larger dimension of rights on knowledge, their ownership, use, transfer and dissemination. Informal systems, e.g. the "shrutis" and "smritis" in the Indian tradition and grandmother's potions all over the world get scant recognition. To create systems that fail to address this issue can have severe adverse consequences on mankind, some say even leading to extinction. (World Trade Organization, 1999)

This discussion paper has been ignored by the US and EU although Article 2 of TRIPS allows for the exclusion of patents on life on ethical and ecological grounds (Shiva, 1997 p. 95). However, the right to review has been blocked and diverse perspectives have not been included. Shiva explains that for democratic legitimacy the implications for life patents must be publicized and the views of diverse groups heard prior to implementation.

According to the WTO, developing countries owe IPR royalties in the amount of 
US60 billion per year to developed countries (Finger, 2002, p. 13). A growing body of literature inquires whether patents guarantee financial benefits to developed countries and inhibit economic progress in marginalized societies (Godbole-Chaudhuri, Srikantaiah \& Van Fleet, 2008; Marinova \& Raven, 2006). According to Finger (2002, p. 13-14):

More simply, it (TRIPS) has the effect of creating claims by intellectual property owners against intellectual property users. As developing countries are more often users than vendors of intellectual property, the impact is a significant economic obligation on developing countries - users owe royalties, copyright fees, etc. on the use of knowledge not previously protected in their countries by patents, copyrights, etc.

A common critique of TRIPS is that it is oriented towards the recognition of Western science and societies and thus fails to compensate indigenous peoples for their knowledge (Godbole-Chaudhuri, Srikantaiah \& Van Fleet, 2008; Shiva, 1997; Shiva, 2000b; Siganporia, 2007).

TRIPS does not recognize IK nor protect the needs of indigenous peoples. According to WHO (2001), “(T)he TRIPS standards for IPR protection are largely based on the models for intellectual property protection, which existed in industrialized countries; these models are not necessarily appropriate for developing countries." Shiva (1997, p. 10) comments on the exclusion of indigenous peoples written into TRIPS Article 27.1 which states that IPRs will only be recognized when they are capable of industrial application. This means that knowledge and innovation that is designed to meet social needs is excluded if it does not generate profits. Shiva (1997, p. 10) writes that:

This immediately excludes all sectors that produce and innovate outside the industrial mode of organization. Profits and capital accumulation are the only ends of creativity; the social good is no longer recognized. Under corporate control, there is "deindustrialization" of small-scale production in the informal sectors of society. 
The contradictions between TRIPS and many countries needs are evident in the absence of indigenous livelihoods and perspectives. The most notable absence from the TRIPS agreement is the lack of any mechanism for addressing collectively held intellectual property as is common amongst traditional cultures.

According to former World Bank vice-president and chief economist Joseph Stiglitz (2007), “TRIPS reflected the triumph of corporate interests over billions of people in the developing world." Public health experts and consumer groups have generated mainstream criticism of TRIPS over the consequence of reduced access to modern medicines such as urgently needed anti-retroviral drugs for HIV/Aids in developing countries (WHO, 2001). WHO estimates that a third of the world population lacks regular access to the medicines they need.

A Monsanto representative commented on the TRIPS negotiations calling it: ...absolutely unprecedented in GATT. Industry has identified a major problem in international trade. It crafted a solution, reduced it to a concrete proposal, and sold it to our own and other governments.... The industries and traders of world commerce have played simultaneously the role of patients, the diagnosticians, and the prescribing physicians. (Enyart, 1990, p 54-56)

The comment made by a Monsanto representative, and quoted by Enyart, is indicative of structural violence. When 'industries and traders of world commerce played simultaneously the role of patients, the diagnosticians, and the prescribing physicians' they left little room for dialogue with any stakeholders. The statement indicates a hegemonic decision-making process troubling to the problem of how to engage indigenous peoples in dialogue regarding IPRs over PGR.

Sachs (1999, p. 17) wrote in The Economist that:

The global regime of intellectual property rights requires a new look. The United States prevailed upon the world to toughen patent codes and cut down on 
intellectual piracy. But now transnational corporations and rich-country institutions are patenting everything from the human genome to rainforest biodiversity. The poor will be ripped off unless some sense and equity are introduced into this runaway process.

From Sachs and Stiglitz description of TRIPS we can deduce that the agreement is an example of a global agreement where powerful Multi-National Corporations (MNCs) undermine democratic legitimacy through monopoly control over food resources. The exclusion of diverse constituencies has fatal consequences in the context of limiting access to seeds. In light of the criticisms lodged against TRIPS it may be argued that life form patenting promotes an impoverished understanding of the necessary limits to intellectual property.

\section{The Convention on Biological Diversity: Access and Benefit Sharing}

The framework of the Convention for Biological Diversity (CBD) (Annex I) established a different standard for the protection, usage and access to live resources as an alternative solution to the problems created by the global regime of life form patenting. The convention was signed by 150 States at the Rio Earth Summit in June 1992, and entered into force in December 1993. The CBD evolved out of international recognition for the alarming erosion of biodiversity with the United Nations Environmental Program serving as a key proponent (Siganporia, 2007). The convention is significant for providing a framework for the sustainable use and conservation of biodiversity and also proposing a voluntary benefits sharing mechanism. Although largely seen as ineffective by scholars, the CBD is also depicted as an important breakthrough in IPRs.

To remedy the problems associated with biopiracy and bioprospecting the CBD 
contains a mechanism for Access and Benefit Sharing (ABS) through bilateral contracts to enable indigenous peoples to either maintain control over their knowledge or to benefit from the commercialization of this knowledge (Martin \& Vermeylen, 2005; Siganporia, 2007). The ABS described in the $\mathrm{CBD}$ is a unique approach that differs greatly from TRIPS. Unlike TRIPS, the CBD formally recognizes indigenous contributions to genetic resources as stewards of biodiversity. Article $8(\mathrm{j})$ recognizes the rights of indigenous and local communities in calling for signatories to 'respect and preserve the knowledge, innovations, and practices relevant for the conservation and the sustainable use of biodiversity.' This vague article was clarified during the Fifth Meeting of the Conference of Parties (WHO, 2001).

Business responsibility towards indigenous communities requires intellectual accreditation to indigenous peoples for their contributions to knowledge and biodiversity (Marinova \& Raven, 2006). ABS is an attempt to alleviate the marginalization of indigenous communities by IPR regimes and Biopiracy. ABS is a framework intended to promote the fair distribution of benefits from commercialization of indigenous resources and knowledge. Divergent perspectives emerge from relevant literature on the ABS mechanism (Siganporia, 2007).

ABS agreements are bilateral contracts between users and providers of genetic resources prescribed by the $\mathrm{CBD}$. The $\mathrm{CBD}$ requires that a competent national institution and legal authority preside over ABS negotiations (Singaporia, 2007). Rights and responsibilities outlined in the $\mathrm{CBD}$ for individual citizens and private organizations are only applicable if required by national law. The convention does not describe who should be involved in ABS negotiations nor assign responsibilities to a regulatory body. 
Contracting parties typically assume that only legal authorities need to be consulted in ABS negotiations, not local communities and indigenous peoples directly (Singaporia, 2007). This limitation results in the exclusion of indigenous peoples for several reasons including: government bias, cumbersome bureaucracies, general incompetence and language barriers. This exclusion results in the majority of benefits going to scientists and institutions.

The CBD and ABS require national governments to apply prior informed consent (PIC) to source-country governments on mutually agreed terms in Articles 15.4 and 15.5 (Artuso, 2002; Kate \& Laird, 1999; Siganporia, 2007; Tobin, 2001; Vermeylena, 2007). The consent of local and indigenous peoples is supposed to be obtained (PIC) by national governments before the relevant knowledge can be used and/or patented through bilateral bioprospecting contracts. The Bonn Guidelines (2002) stipulate PIC with resource providers as a precondition for patenting genetic resources. Unfortunately, few countries have proposed laws for PIC procedures and most negotiations take place between the private sector and government agencies. ABS does not provide a mechanism designed to verify if PIC has been obtained.

The CBD encourages indigenous and local communities to participate as providers of knowledge as well as conservers of biodiversity within the IPR framework (Singaporia, 2007). The ABS mechanism aspires to give resource providers benefits resulting from the commercialization of genetic resources. The benefit-sharing mechanism adopted in the $\mathrm{CBD}$ is aimed at the integration of local and indigenous communities into the patenting regime. In other words, the ABS mechanism is an attempt to conform IK systems to the IPR regime. In so doing the convention supports the 
proliferation of IPR regimes through the commercialization and privatization of IK.

ABS in the CBD provides a context in which IPR claims can be critically challenged (Marinova \& Raven, 2006). Through partnerships such as ABS it may be possible for some indigenous peoples to use patents to secure some rights over their knowledge, while gaining economic benefits (Marinova \& Raven, 2006). The Bonn Guidelines outline financial and non-monetary benefits like training and joint research, scientific cooperation, institutional capacity building, employment opportunities and ongoing relations.

Arguably, placing IK within the realm of the capitalist market may provide the recognition and equity necessary for some indigenous communities and individuals to create monetary wealth and poverty alleviation. Finger (2002) argues that the main issue needing to be addressed is to help poor indigenous peoples commercially benefit by using modern methods from their traditional wisdom. The formation of 'indigenous intellectual property' may gain some recognition of indigenous rights to knowledge, while creating opportunities for market- based value of their knowledge, and thus economic stability.

The CBD has been criticized for many reasons. The usefulness of applying IPR language in the movement for biodiversity and IK conservation is a subject of considerable debate. Indigenous peoples have largely warned against developing legal instruments to encourage the commercialization of IK (Tobin, 2009). Rather, they suggest an approach that embraces IK systems by supporting them holistically. In theory voluntary indigenous accreditation through ABS is a fair partnership and holistic approach that actually improves the socioeconomic conditions of indigenous communities. According to Marinova and Raven (2006) and Finger and Schuler (2004), 
'indigenous intellectual property' can be conceptualized as a form of capital, which existing legal, economic and market-based mechanisms are more able to manage. Eisner (1990) and Reid (1993) believe bioprospecting has the capacity to share benefits with indigenous communities and promote sustainable development. Following this logic, engaging communities in the bioprospecting process and compensating them is a way of alleviating poverty. This claim is highly contested in existing literature.

The idea of 'indigenous intellectual property' has been criticized as a reductionist approach that articulates IK systems in terms of 'utility' to market-based approaches (Shiva, 2005a). Vermeylena (2007) has criticized the CBD as a 'Western' construct that promotes the concept of exclusive ownership of knowledge, which negatively impacts indigenous communities. Marinova and Raven (2006, p. 5) inquire whether, "Even if it were possible to fragmentize and capitalize indigenous knowledge, would it be desirable?"

Scholars have argued that indigenous peoples are forced to adopt the language of IP although it is contrary to the very foundations of indigenous cultures and is thus culturally erosive (Godbole-Chaudhuri, Srikantaiah \& Fleet, 2008). WIPO (2005) has stated that the current IPR regime cannot maintain the social and physical environment that perpetuates IK. In other words the commoditization of IK by indigenous peoples themselves may erode the holistic, collectivist foundations important to the survival of indigenous communities.

Agrawal (as cited in Fernando, 2003, p. 69) is a pioneer in research on IK systems and has reflected on the conflicts arising from the CBD writing that:

I believe indigenous peoples are caught on the horns of a dilemma that arises from 
the spreading interest in their knowledge and culture. Without control over their intellectual products, their knowledge stands to be expropriated without any material benefits reaching them. But even with intellectual property, and even if some capture significant material gains, their cultures will inevitably be radically transformed.

Indigenous cultures are impacted by IPR regimes regardless of their ability to maintain control over their intellectual products and obtain material benefits. Understanding the multiple impacts of imposing IPRs over PGR will help to decide if a new intellectual property is capable of maintaining the social, political, cultural and physical environment where indigenous knowledge is created (Marinova \& Raven, 2006).

Siganporia (2007, p. 25) asks the seminal question, "What circumstances impel actors in a position of political and economic marginalization to adopt the language of intellectual property?" Siganporia concludes that most ABS agreements do not fairly compensate indigenous peoples for the value of their traditional knowledge and consequentially suggests amendments to TRIPS and CBD. Siganporia (2007) critiques the $\mathrm{CBD}$ as lacking clarity, requiring high bureaucracy and transaction costs, lacking corporate and indigenous involvement in creating the framework and for creating false hopes amongst indigenous communities for high monetary return. Additionally, the CBD ignores many factors such as third parties like gene banks and research institutions.

The CBD has been widely criticized for failing to define 'fair' and 'equitable' and failing to advance a tangible framework for benefit sharing (Godbole-Chaudhuri, Srikantaiah \& Fleet, 2008; Marinova \& Raven, 2006; Miller, 2010; Sulula, 2006; Sillitoe, 2010; Siganporia, 2007; Vermeylena, 2007). Addressing the question of what constitutes fair and equitable is a complex question (Dutfield, 2004). The concept of justice is subjective (Bourassa \& Strong, 2000). The United Nations Environmental Programme 
(UNEP, 1998) stated that interpretations of what constitutes 'fair' and 'equitable' (used in the $\mathrm{CBD}$ ) depends on the underlying value system on which the judgment is based.

Challenges attributed to the ABS concept include the difficulty in attributing an economic value to genetic resources, the post-patenting/commercialization distribution of benefits, excessive bureaucracy and transaction costs in developing counties, the nonrecognition of indigenous communities and their inability to negotiate bilateral contracts with powerful corporations (Kate \& Laird, 2000). Siganporia (2007) asks: "Is it possible to calculate the value of genetic resources and the research activities that improve the variety at every stage?"

The problem of benefit distribution and identifying individual recipients of benefits is a serious issue facing the ABS (Siganporia, 2007). Many genetic resources that corporations want to patent are used by millions of people as illustrated by the case of Neem. Such a conundrum requires stakeholders to review the laws that give private ownership over genetic resources.

Yet another challenge to creating a financial mechanism to allocate payment to farmers is the unlimited duration of Farmers Rights. IPRs are devised in a temporary time frame (20 years) to balance innovation incentives and public competition. The time frame is relatively minuscule when compared to the collective, intergenerational accumulation of IK over many centuries (Correa, 2000).

Peria (2005) asserts that ABS is misleading. The researcher claims that the ABS mechanism creates false hopes for substantial monetary gains or capacity building. To remedy this fault indigenous communities should have a clear understanding of the ABS process and realistic expectations (Siganporia, 2007). Peria proposes greater participation 
and involvement of indigenous peoples at all levels of negotiations as a remedy to the shortcomings of the ABS mechanism.

Clearly the ABS mechanism is a flawed and tremendous undertaking however only few studies have been conducted on the actual social consequences and experiences of the CBD approach and the ABS mechanism. The debate on creating 'indigenous intellectual property' is limited due to the lack of empirical evidence regarding the experiences of local communities and indigenous groups. The first case of indigenous intellectual accreditation is widely discussed in the relevant literature. Scholars reviewing the Aveda case study acknowledge the attempt at social responsibility, but raise important questions regarding the actual benefit to the community (Siganporia, 2007).

The first application of ABS was created through the partnership between Mt Romance (Australian sandal- wood company), Aveda (US-based multinational cosmetics corporation) and the Kutkabubba community (represented by the Songman Circle of Wisdom) (Marinova \& Raven, 2006). Marinova and Raven (2006) provide a critique of ABS based on analysis of the Aveda case study. The US based Cosmetics Company Aveda accredited the Kutkabubba community and shared profits in the amount of $\$ 50,000$ from the use of sandalwood oil. Marinova and Raven conclude that the voluntary accreditation clearly lacks an adequate framework for ABS and did not fairly compensate indigenous peoples for the value of their traditional knowledge.

Mamen and Whiteman (2002) present an ABS case study of the mining industry. The researchers argue that insufficient attention is given to the perception of procedural fairness in the decision-making process from an indigenous perspective. They conclude in their examination that the indigenous cultural perspective must be included for a fair 
and balanced procedure to exist.

Vermeylena (2007) conducted a case study of power imbalances between indigenous peoples and corporations through a case study of the San community's views of a belated benefit-sharing agreement for the traditional plant Hoodia in South Africa. The San's perceptions of the Hoodia benefit-sharing agreement were collected through the use of participant observation, life stories and over 100 informal and semi-structured interviews. The San people expressed much interest in learning and benefiting from the Hoodia project. However, they were disappointed in the level of cooperation.

The prevailing ethic of egalitarianism and full participation, consensus decisionmaking in San society was ignored during negotiations. Findings included that corporations dominate the development and application of epistemologies, or simple definitions, that are used to shape benefit-sharing agreements and disregarded traditional practices, perceptions and customary law (local governance structures). Divisions were created within San society by the ABS agreement. Vermeylena (2007, p. 17) explained that:

A society that was previously characterized by egalitarianism and avoidance of prestige is now faced with a new sort of San elite who are visibly better off (houses, cattle) and consider themselves superior to other community members ... In short, the way in which the Hoodia benefit-sharing agreement came into being shows that it mainly regulates an economic relationship; the main concern was redistribution of money and no attention was given to the social impacts of the agreement.

Vermeylena concluded that the processes behind the ABS negotiations failed to engage all stakeholders in the decision-making process, which resulted in a schism in the egalitarian structure of San society. Even the seemingly positive benefits that result from granting intellectual property rights to local communities may lead to unintended 
negative consequences.

Moran (2004) agrees that benefit-sharing agreements can only be fair when all stakeholders participate equally in the decision-making process. According to Husted (as cited in Whiteman \& Mamen, 2002, p. 301-302), procedural fairness can be practiced through the choice to participate in a balanced decision-making process, the ability to influence decision-making and legitimate explanatory feedback. The indigenous sensitivities reported by Whiteman and Mamen (2002) might not necessarily be universal, but their findings (in addition to providing a checklist) highlight the importance of going into the field to elicit, explore and reflect on the views of indigenous peoples who are affected.

Sharma (2005) is critical of the ABS mechanism because of the non-recognition of indigenous communities. He writes that, "Such projects should be cancelled or avoided. Otherwise developing countries will be made to sell their "green gold" for little more than benefit-sharing candies and trinkets (p. 10)." Sharma presents a case study of the failed ABS agreement between the Kani tribe of South India and the pharmaceutical company Nutri Science. The Kani tribe developed an anti-stress and fatigue medicine with a commercial value of one billion dollars called Jeeavani. The ABS bilateral contract stipulated that the tribe was supposed to receive $600 \$$ per acre, but only received a one time payment of $\$ 10,000$.

Shiva (2005a) likewise criticizes ABS as a flawed concept because it excludes indigenous people from involvement in the negotiation of bilateral contracts. Shiva asserts ABS is illegitimate because bioprospecting contracts wrongfully claim IPR over 
IK and are thus a form of biopiracy. ABS promotes exploitation by excluding indigenous communities from their rightful share in growing markets.

Greater participation of indigenous communities at all levels of development and implementation of ABS would provide greater legitimacy to the CBD (Siganporia, 2007; Peria, 2005). The Bonn Guidelines (Siganporia, 2007) elaborate on the application of 'fair' and 'equitable' in CBD Article 15 by emphasizing the need for diverse and direct stakeholder's participation in the implementation of the convention (Tully, 2003; Vermeylena, 2007). A participatory process for proposing, interpreting and applying rules and definitions such as 'fair' and 'equitable' will allow for a broader definition of what constitutes justice and thus satisfy more parties.

The CBD and the ABS mechanism do not mandate and describe processes for inclusion through participation of indigenous knowledge holders. The bilateral contracts between providers and receivers of indigenous genetic resources often do not involve the representatives of indigenous communities. The need for PIC is only required from the national governments who are presumed to speak on behalf of indigenous communities. However, the capacity for national governments to accurately represent the interests of indigenous people is questionable considering the continued violation of indigenous rights worldwide.

According to Siebenhuner (et al., 2005), the CBD needs to challenge existing IPR doctrines because of the complexity of pre-existing cultural frameworks. O'Faircheallaigh (1998) asserts that to understand inequality from an indigenous point of view it is necessary to analyze the interactions between indigenous peoples and the companies involved. Posey (1996) argues that working together with communities, to 
study the social impacts and to determine what 'just compensation' should mean, would be more effective than hundreds of national and international laws.

Sen $(2009$, xi) writes that, "The focus on actual lives in the assessment of justice has many far reaching implications for the nature and reach of the idea of justice." The Nobel Laureate goes on to say that:

The need for an accomplishment-based understanding of justice is linked with the argument that justice cannot be indifferent to the lives that people can actually live. The importance of human lives, experiences and realizations cannot be supplanted by information about institutions that exist and the rules that operate. (p. 18)

Few bioprospectors have enacted the voluntary ABS mechanism and less have taken steps to communicate directly with indigenous peoples regarding their experience of ABS when applicable. Rather, researchers and intermediary organizations, like NGOs, pursue justice by facilitating dialogues between indigenous peoples and relevant companies in few instances.

\section{The International Treaty on Plant Genetic Resources for Food and Agriculture}

The International Treaty on Plant Genetic Resources for Food and Agriculture (ITPGRFA) (FAO, 2001) has been signed by 79 countries, including the United States (FAO, 2003), and ratified by 67 countries (28.04.2005). Following eighteen years of political mobilization and seven years of negotiations the ITPGRFA was adopted in November 2001, coming into force June 2004 (Siganporia, 2007). The Governing Body of the Food and Agriculture Organization (FAO) of the United Nations (UN) Commission on Genetic Resources for Food and Agriculture (CGRFA) promulgated the 
treaty. The ITPGRFA revises the International Undertaking on Plant Genetic Resources for Food and Agriculture (IU), adopted in 1983, to harmonize with the CBD.

The treaty was motivated by the fact that the conservation and sustainable use of PGRFA is necessary to solve the problem of world hunger and meet the Millennium Development Goals (MDGs) (FAO, 2001). The treaty recognizes that international cooperation and open exchange of PGR is necessary because of transnational interdependence in terms of genetic resources. The treaty seeks to establish a global system to provide access to PGR, and recognizes the contributions of farmers in developing crop diversity. Finally, the treaty aspires to share the benefits created by PGR with the countries of PGR origin.

To accomplish these goals the treaty obligates signatory countries to create efficient, transparent and effective Multilateral Systems that allow access to sixty-five of the world's main crops (FAO, 2001). Furthermore the treaty requires the fair and equitable sharing of benefits. The benefit-sharing fund supports relevant projects. ITPGRFA benefit sharing agreements are conducted between 'owners' and 'buyers' of plant genetic resources or in other words between stewards of agrobiodiversity and society (Andersen, 2005, Brush, 2007). Some developing countries have created legislation for direct benefit sharing yet none have been enacted. There are many examples of non-monetary, indirect benefit sharing agreements such as those that allow for participatory plant breeding, conservation projects and access to seeds. However, only a small number of direct benefit sharing contracts have been instigated.

Article 9 in the ITPGRFA has initiated the process of international recognition for protection of Farmers' Rights (FAO, 2001). The ITPGRFA is not a binding international 
resolution, but rather allocates the protection of Farmers' Rights to national governments according to their needs and priorities. According to the treaty Contracting Parties are responsible for providing for Farmers' Rights through the protection of traditional knowledge, by providing equal participation in benefits sharing and participation in decision making related to biodiversity conservation.

The forum for Farmers' Rights was established through Food and Agriculture Organization (FAO) Resolution 8/83 in 1983, which encourages recognition of the (preTRIPS) common heritage principle for open access to genetic resources (Brush, 2007). The FAO Resolution defines Farmers' Rights as:

Rights arising from the past, present and future contributions of farmers in conserving, improving, and making available plant genetic resources, particularly those in centers of origin/diversity. These rights are vested in the International Community, as trustee for present and future generations of farmers, for the purpose of ensuring full benefit to farmers, and supporting the continuation of their contributions. (FAO, 1998, p. 278)

Brush (2007) criticizes the FAO definition of Farmers' Rights as problematic because it does not specify what genetic material is covered or who could claim ownership. However, the definition announces the intention to defend Farmers' Rights by ensuring benefit to farmers and supporting their work.

The lack of legislative protection for the misappropriation of IK is a key issue for relevant NGOs in developing countries and public institutions in developed countries (Andersen, 2005). With this in mind the ITPGRFA has been created as a platform to advance Farmers' Rights through acknowledging the world's farmers contributions to conserving, improving and making available plant genetic resources. The treaty suggests measures to protect and promote Farmers' Rights and traditional knowledge. 
For the treaty to successfully defend Farmers' Rights a common understanding of strategies is necessary (Andersen, 2005). Towards this end The Farmers' Rights Project was established at the Fridtjof Nansen Institute in Norway in collaboration with the Norwegian Ministry of Agriculture and Food, the Royal Norwegian Ministry of Foreign Affairs and the German GTZ, with related proponents in Peru, India and Ethiopia. The Farmers' Rights Project provides a platform for proposals of concrete measures to the Governing Body of the ITPGRFA. Additionally, the goals of the Farmers' Rights Project are to encourage stakeholders to actively participate in implementing the provisions of the ITPGRFA on Farmers' Rights and to raise awareness about the importance of Farmers' Rights for biodiversity conservation of PGR and for poverty alleviation.

The Farmers' Rights Project has initiated a document and literature survey of the premise of farmer's knowledge and to draw lessons from efforts to realize Farmers' Rights (Andersen, 2005). The project has conducted an international stakeholders questionnaire survey in 31 countries on the state of Farmers' Rights, which shows that efforts are underway with regard to all measures addressed in Article 9 in the treaty. Four case studies have been conducted on the state of Farmers' Rights in Peru, India, Ethiopia, and Norway. Comparative analysis indicates that the challenges in these diverse countries are similar despite varying socio-political and economic contexts.

The Farmers' Rights Project explores two approaches to Farmers' Rights. The stewardship approach is an overall objective that upholds the need for legislation to protect Farmers' Rights (Andersen, 2005). The ownership approach rewards farmers for genetic material that is obtained from their fields when it is used in commercial varieties and/or protected by IPRs. The purpose of this approach is to provide incentives for 
biodiversity conservation, access and benefit sharing legislation and the granting of IPRs to farmers. However, it is difficult to reward specific farmers because of the collective heritage of genetic resources and ethic of sharing that exists amongst traditional farming communities. Additionally, the limited demand for farmers' varieties would only benefit few farmers. Considering these limitations the ownership approach is intended to be secondary to the stewardship approach.

Although some developing countries have the relevant legislation there are only few examples when farmers actually participated in decision-making process pertaining to PGR (Andersen, 2005). Farmers are more likely to participate in the decision-making process in wealthy nations even though relevant legislation and policies are absent. Yet, even farmers in developed countries have stated that their influence is decreasing.

The Farmers' Rights Project has consulted with a diverse array of stakeholders who have varying expectations about the activities of the treaty's Governing Body (Andersen, 2005). Stakeholders have requested that the Governing Body actively organize and promote the sharing of experiences of mobilization. Stakeholders also demand that the Governing Body of the treaty monitor, support and advocate for the development of communications, national plans, institutional assistance, legislation, standards and models to promote farmers' rights.

\section{Comparison of the Three Treaties}

While the CBD, ITPGRFA and TRIPS are based on opposing rationale and divergent perspectives they do not legally conflict (Siganporia, 2007). The CBD recognizes collective rights, while TRIPS does not. The CBD and ITPGR focus on 
sustainable development while the WTO policies outlined in TRIPS ignore sustainable development. CBD and ITPGRFA use soft law with no follow up agency or system of compliance. However, the WTO can impose sanctions on countries that do not comply with TRIPS. TRIPS is propagated by large multinational corporations and by the demands from certain developed countries, while the initiative to develop legislation for implementing the CBD generally comes from national concerns and interests (WHO). Most countries have ratified both the CBD and TRIPs and so they will have to develop relevant national policies and laws.

Similar to the CBD, the objectives of the ITPGRFA are geared towards the conservation and sustainable use of biodiversity and the fair and equitable distribution of benefits resulting from the use of biodiversity (Brush, 2007). However, the ITPGRFA only applies to plant genetic material that has actual or potential value for food and agriculture, whereas the CBD applies to biodiversity in general. The CBD does not distinguish crop genetics as a special category of biological resources and thus negates the foundational premise of Farmers Rights. In this regard the ITPGRFA is better suited for recognizing the centuries worth of selective breeding to produce valuable genetic traits through the collective action of farmers.

Of particular interest are the processes that enact the TRIPS, CBD and ITPGRFA. Where TRIPS and the CBD are implemented from the top down, the ITPGRFA is applied from the bottom up. The funding strategy of the ITPGRFA mobilizes from the grassroots by supporting local initiatives to defend Farmers' Rights. The CBD is problematic because it is rooted in the same ideological paradigm as the TRIPS agreement. The ABS 
agreement does not designate decentralization in the decision-making process or PIC rather it leaves the final word to centralized governments.

\section{India's Act 53: exempting farmers from TRIPS}

The Indian Protection of Plant Varieties and Farmers' Rights Act of 2001 (Act 53) has created the legal space necessary for the conservation of IK and biodiversity (Andersen, 2005). Meeting the challenge to establish Farmers' Rights would benefit from following the model of the ITPGRFA and India's Act 53. The ITPGRFA and Act 53 both move away from individual contracts for accessing crop resources, or sharing benefits from their use, and instead emphasize multi-community solutions (Marinova \& Raven, 2006).

This important Act is the most liberal legislation worldwide that establishes rights for farmers to save, use, exchange and sell farm-saved seed regardless of IPRs. The Act was created through grassroots mobilization. Under this act farmers are not allowed to sell patented seeds as a packaged brand, but they are aloud to share and save seeds (Andersen, 2005). Farmers' Rights in India are ensured through the Act. The Act also contains provisions for compensation for crop failure. This Act complies with the TRIPS Agreement on the protection of plant varieties.

NGOs and farmers organizations strengthened Farmers' Rights through five revisions of the bill resulting from mass protest (Andersen, 2005). The Act is a stunning example of India's capacity for grassroots mobilization. Dr. Vandana Shiva describes the massive, grassroots effort to protest the unjust seed laws. She explains that:

When we had to fight the seed laws, and the WTO, it was very clear that no 
matter how many coordinators we have in our network we have to have partnerships with others who are involved in these issues so I created a national alliance of all the farmers organizations. And in 1993, before the GATT was finalized in the WTO form, we managed to pull together half a million people on the streets of Bangalore through that alliance. I took a million signatures to the Prime Minister to fight the seed laws, which would have made it illegal for farmers to save their own seeds. To say, 'we do not accept this, like Gandhi did not accept the salt laws! We will not accept laws that will make it illegal for us to have our own seeds'. (personal communication, May, $\left.1^{\text {st }}, 2009\right)$.

India has an enormous civil society that is readily mobilized by the memory of Mahatma Gandhi. Alliance building has proven crucial towards maintaining grassroots efforts to counteract structural violence in India. The successful protest of the WTO seed laws in India is a rare example of citizen's groups effectively amplifying their voices in the global, political-economic sphere.

India's Professor M. S. Swaminathan is another grassroots leader who pursued the idea of Farmers' Rights in the FAO's international negotiations and helped frame Act 53. The M.S. Swaminathan Research Foundation has initiated, with the assistance of the government, a program for capacity-building among farmers, grassroots democratic institutions, non-governmental and community organizations in order to enhance the implementation of Farmers' Rights as provided for in the Protection of Plant Varieties and Farmers' Rights Act of 2001. 


\section{Part IV - International Rights}

\section{Sustainable Livelihoods Approach and Farmers' Rights}

The concept sustainable development was explained in the World Commission on Environment and Development commonly called the Brundtland Commission (Krishna, 2009) as that which 'meets the needs of the present without compromising the ability of future generations to meet their own needs.' Krishna (1996a, p. 224, 252-253) reflects on SLA writing that:

International agencies, governmental departments and NGOs have used SLA variously to deal with access to resources but have generally not been able to cope with issues of resource control and conflict... Sustainable development requires changes in socio-political attitudes and structures, and in the specific instruments of development, which at present are not taking place. So both nationally and internationally, behind all the ... rhetoric of equity, it seems to be business as usual. Indeed sustainable development itself has become big business.

Instead of using the compromised term 'sustainable development' many NGOs alternatively apply the concept of sustainable livelihoods as a perception from 'below'. The view from below means that the concept conveys the perceptions, experiences and needs of the people.

The United Nations Development Programme (UNDP) adopted a 'Sustainable Livelihoods Approach' (SLA) as a central platform (Krishna, 2009). UNDP defines the term as, 'the capability of people to make a living and improve their quality of life without jeopardizing the livelihood options of others, either now or in the future.' The approach links poverty alleviation with social sustainability.

Farmers' Rights have are significant in the struggle to SLA. Farmers Rights seek to specifically recognize farmers for having adapted genetic resources over generations to meet the requirements of specific ecosystems, thus creating biodiversity through the work 
produced through sustainable livelihoods. Saving and exchange of seeds and seedlings ensure that many different climate adapted crop varieties are available to deal with increasingly unpredictable weather conditions. Without selective breeding, seed saving and exchange the quality of urgently needed yields will decrease and deteriorate. Farmers' Rights initiatives such as the ITPGRFA seek to defend these traditional agricultural practices vital to the survival of the rural poor.

\section{Indigenous Rights}

Indigenous peoples' rights to self-determination are legally recognized in the binding International Covenant on Civil and Political Rights (CCPR) and the International Covenant on Economic, Social and Cultural Rights (CESCR). Rights to indigenous self-determination are contingent upon rights to participation. According to Tobin (2009, p. 110), "the extent to which indigenous peoples are incorporated into decision-making processes on IK will be indicative of commitments to realization of rights to self-determination, and to respect and recognition for customary law and governance structures." UNDRIP ensures indigenous rights to participation in the decision-making process, representation selection and requires states to consult with indigenous peoples to obtain PIC before enacting legislation or administrative measures that impact them. If indigenous resources have been taken, used or damaged without PIC then states must provide fair and equitable compensation.

The CBD and WIPO Intergovernmental Committee on Intellectual Property, Genetic Resources, Traditional Knowledge and Folklore (IGC) have adopted measures to guarantee more participation of indigenous peoples in their IK discussions (Tobin, 2009). 
However, indigenous peoples are still marginalized in international forums. To counteract structural violence in the International negotiation on ABS (as a remedy to TRIPS) the full participation of indigenous peoples in all levels of decision-making, implementation and enforcement of relevant law and policy is necessary.

The customs associated with farming and seed saving should be considered institutions just as much as formal state laws according to Eyzaguirre and Dennis (2007). Local institutions governing rights to natural resources are often more effective from the perspective of local peoples than formal laws and regulations. The inclusion of customary law into the ABS mechanism is essential to protecting indigenous rights. Acknowledging the pivotal role of customary law is necessary to lay the foundations of indigenous rights to participation. Tobin (2009) argues that if the ABS mechanism is to protect IK it must be codified in customary law and evolved in the context of self-determination. The WHO agrees that various traditional customary laws that apply to knowledge access should be respected so as to preserve and sustain such knowledge.

\section{Cultural Rights}

The United Nations Declaration on the Rights of Indigenous Peoples (UNDRIP) recognizes the right of indigenous peoples to maintain, protect, and develop their cultures including IK and any intellectual property over it (Tobin, 2009). The Committee on Economic, Social and Cultural Rights (CESCR) has noted that the right to "participation in cultural life" also includes "the right to benefit from cultural values created by the individual or the community... The right to culture incorporates protection for knowledge, beliefs, art, morals, law, customs, and habits as well 'ideological systems." 
The 2001 UNESCO Universal Declaration on Cultural Diversity recognize the significance of cultural pluralism and affirms that respect for the diversity of cultures is vital for international peace and human rights. The Declaration states that the diversity of cultures is as important "as biodiversity is for nature" and that defense of cultural diversity is "an ethical imperative, inseparable from respect for human dignity." 


\section{Part V - Impacts on epistemology and socio-cultural factors}

Patenting of plant genetic resources has provoked a controversial debate regarding the negative impact on the rights of local and indigenous communities (Crucible II Group, 2004). Eyzaguirre and Dennis (2007) argue that IPR regimes need to take account for the impact they have on local and indigenous peoples. According to Calle (1996), the imposition of IPR regimes on indigenous communities and knowledge ignores the implications of important socio-cultural factors and epistemological differences.

IPRs value and impose Western epistemologies over IK systems (Dei et al., 2000). However, IK systems operate outside the realm of conventional knowledge because they are embedded in a unique epistemology (Dei, Hall \& Rosenberg 2000; Nathani-Wane, 2000). Outside efforts to value, promote, and protect traditional knowledge appear inevitably to distort it and its social context (Dove, 1996). Direct payment and royalties for genetic resources may change the traditional collectivist practices of indigenous communities.

IK and IPRs are embedded in contradictory epistemologies where indigenous communities are collectivistic and IPRs are individualistic. The individualism inherent in the framework of TRIPS denies the collectivist culture that holds together much of the developing world and is particularly significant for indigenous peoples (Greaves, 1994). Indigenous peoples have a divergent conceptual understanding of knowledge ownership as compared with proponents of IPR regimes (WHO, 2001).

IPR regimes marginalize IK systems by favoring individualistic modern values over collectivistic traditional practices (Fagerlind \& Saha, 1989; So, 1990). IPR frameworks can only be held by legally recognized entities like individuals and 
corporations, which invalidates the collectivist foundations of indigenous cultures (Siganporia, 2007). The communal ownership of IK is incongruent to patent laws and the underlying principles of exclusion through privatization.

The inherent incompatibility of a holistic, reciprocal transmission of knowledge and the privatization of knowledge through IPRs requires a separate protection mechanism for IK (Godbole-Chaudhuri, Srikantaiah \& Van Fleet, 2008). Calle (1996) insists that any legal patenting mechanism must recognize the socio-cultural components of indigenous cultures when attempting to share the benefits of bioprospecting. Only through extending scientific and legal recognition to IK systems can indigenous cultures be protected from usurpation and unfair exploitation by IPR regimes and the biotechnology industry (Chowdhury, 2004).

\section{Western Reductionism and Indian pluralism}

The impacts of reductionism on epistemology, ethics, ecology, economics and society are vast. Western science interprets the world in small units (reductionism) (Godbole-Chaudhuri, Srikantaiah \& Van Fleet, 2008). IPR regimes are embedded within the Western scientific and cultural trend towards reductionism (Shiva, 1997; Shiva, 2005b). Measuring IK through the reductionist worldview of the IPR regime undermines the holistic framework on which IK is founded.

Shiva refers to molecular biology, which is used to legitimize life form patenting, as a reductionist biology that is biologically deterministic (Shiva, 1997), and that genetic determinism is genetic reductionism. Shiva explains that the belief in the "master 
molecule", or the primacy of genes, is more ideology than science (1997). According to

Shiva (p. 29):

Genes are not independent entities, but dependent parts of an entirety that gives them effect. All parts of the cell interact, and the combinations of genes are at least as important as their individual effects in the making of an organism... Some biologists have gone far in exalting the gene over the organism and demoting the organism itself to a mere machine.

Furthermore, Lewontin (1993) explains that DNA is a dead molecule that has no power to reproduce itself and is one of the most non-reactive, chemically inert molecules in the world. The scientific isolation of genes from the whole organism parallels the Western perception that organisms exist in isolation from their environment.

Cultural reductionism negates diverse ways of knowing and ethical systems (Shiva, 1997). Reductionist thinking ignores the complex relationships between humans and culture, culture and ecology and ecology and economics. Shiva (p. 8) writes that, "Indigenous knowledge systems are by and large ecological, while the dominant model of scientific knowledge, characterized by reductionism and fragmentation, is not equipped to take the complexity of interrelationships in nature fully into account."

Shiva goes on to say that:

Intellectual property rights are supposed to reward and provide recognition for intellectual creativity. Yet knowledge and creativity have been so narrowly defined in the context of IPRs that the creativity of nature and of non-Western knowledge systems has been ignored. IPRs are theoretically property rights to products of the mind. People everywhere innovate and create. If IPR regimes reflected the diversity of knowledge traditions that account for creativity and innovation in different societies, they would necessarily be pluralistic - also reflecting intellectual modes of property systems and systems of rights - leading to an amazing richness of permutations and combinations. (Shiva, 1997, p. 8)

Ignoring the creativity of indigenous peoples in the context of the universal standardization of life form patenting over PGR has a negative deficit when viewed in the 
context of democratic pluralism.

The conservation of diverse cultures (and biodiversity) requires a holistic, longterm framework that recognizes the importance of non-market factors such as spirituality, local customs and the environment. According to McGrath et al. (2005),

Indigenous people, whose spiritual practices connect with country and have the potential to provide a foundational ethic for sustainability generally have much to offer the Eurocentric rationalists who have separated themselves from ecological cycles between the earth, air and water and are thus disconnected from the spiritual self.

IPR regimes, in their current form, value only specific types of knowledge and fail to protect or value the cultural, spiritual or ecological components of IK.

Visionary peace pilgrim Satish Kumar teaches about the importance of recognizing interdependence in understanding sustainability. Kumar (2006) challenges the Western Cartesian rationale 'I think therefore I am' in the revealingly titled to his book "You Are Therefore I Am". Kumar explains that when he first heard the Cartesian ethos, that epitomizes Western thought, he was confused. He explains:

...in India we have been speaking of the dissolution and even the nonexistence of the self for many centuries. But here was an eminent European philosopher basing the very foundation of existence on the self! As I learnt more about Western culture, I realized how Cartesian dualism was an essential feature of a thought process which divided mind and matter, separated soul and body and looked at the world as a collection of objects to be analysed, compartmentalized, classified, and controlled. This Cartesian subject-object dualism or mind-matter split has become the dominant paradigm of Western culture.

Kumar actively seeks to alter the dominant, reductionist paradigm as a renowned Gandhian activist.

Kumar (2006) was a walking, Jain monk who escaped to follow Gandhi, and walk with Satyagraha leader Vinoba Bhave, to share spirituality with common people. Kumar 
originates from Rajasthan and has many accomplishments including having walked 8,000 miles from Delhi to D.C. on an anti-nuclear peace pilgrimage without using or having money, is the editor of Resurgence magazine, author of numerous books and the director of Schumacher college where a master in holistic science is offered for 'transformative learning for sustainable living'.

Apffel-Marglin and Parajuli (2000) write that the Cartesian rationality necessitates an 'individual knower' disembodied from the human collectivity and place. In other words, the ontology of Western science assumes that it is given and not constructed. The Cartesian rationality, underscoring Western science, epitomizes the assumption that it is possible to separate facts from values by disembedding knowledge. However, the authors assert that Western science is culturally embedded in modernity and the modern market.

Apffel-Marglin and Parajuli (2000, p. 300) describe Western scientific ontology as possessing, “... an inert and mechanical nature radically separated from humans.” They go on to say that the inert mechanism enables an extractive attitude, "...(that) violates biogeochemical cycles of nature necessary to allow regeneration and renewal" (p. 302). They go on to explain that the violation of natural cycles is a mobilizing force amongst politically active ecological ethnicities.

Indigenous peoples as ecological ethnicities apply a "post-Descartian rationality" by engaging in practices that embed the individual and knowledge in place and community (Apffel-Marglin \& Parajuli, 2000). Interestingly in the "post-Descartian" rationality of ecological ethnicities, "The body and the place are not separated from what one might call mindfulness or consciousness" (p. 303). This ontology of ecological 
ethnicities has produced, “ ... remarkably stable, sustainable ways of life with a low level of technology" (p. 302). The field of ecology, and several sustainable agricultural techniques (permaculture and biodynamic farming for example), testify to the resilience of traditional farming practices, which is contrary to the colonial idea that indigenous cultures are 'backwards'

Shiva (1997) comments on diversity and science in writing that:

Since creativity has diverse expressions, I see science as a pluralistic enterprise that refers to different "ways of knowing." For me, it is not restricted to modern Western science, but includes the knowledge systems of diverse cultures in different periods of history... Recognition of diverse traditions of creativity is an essential component of keeping diverse knowledge systems alive. This is particularly important in this period of rampant ecological destruction, in which the smallest source of ecological knowledge and insights can become a vital link to the future of humanity on this planet. (p. 8)

Restricting legitimized ways of knowing to Western science excludes diverse groups and thus the cultivation and evolution of biodiversity. The exclusion of diverse ways of knowing also excludes the possibility of biodiversity conservation. The value of plant genetic resources is not in any single variety, but in the bundle of varieties that create possibilities for biodiversity and ecological stability.

Sen (2005) expresses dismay that Western society falsely claims to have inventing rational science. He explains that, "The diagnosis of a thought as "purely Western' or 'purely Indian' can be very illusory. The origin of ideas is not the kind of thing to which 'purity' happens easily... Western Science' is not the special possession of Europe" (p. 132-133). Sen writes that the West vindicates itself and redefines diverse cultures in alien terms. Westerners exaggerate their own rational secularism and underestimate India by overemphasizing the supposed 'irrational spiritual', religious 
facets of India. To disprove this assumption Sen explains that Sanskrit and Pāli have a larger atheistic and agnostic body of literature than any classical tradition. 


\section{Part VI - Reciprocity and the Selfish-Model}

Burger, Field, Norgaard, Ostrom \& Policansky (1999) disprove Garret Hardin’s popular metaphor in The Tragedy of the Commons that predicts 'rational users' will inevitably overuse and destroy an open-access commons. Hardin's prediction leads to the solution that external authorities must control the commons. Scholars and policy makers commonly cite The Tragedy of the Commons to rationalize centralized governmental control of natural resources (CPRs). According to Burger et al, Hardin's theory depends on the worldview that people are selfish, norm-free and will favor short-term results over long-term sustainability.

Burger et al. (1999, p. 1) reassesses and challenges Hardin's theory as a limited, disempowering, pessimistic vision that denies the possibility of change. The Tragedy of the Commons depends on the 'selfish-model' to explain why the market institution effectively distributes private goods and services. However, Burger et al. explains that the 'selfish-model' is not supported by relevant empirical, field research or laboratory experiments. Rather, in real life reciprocity is often implemented to overcome social dilemmas (p. 22).

Burger et al. (1999) point to empirical studies that show no single property regime can work efficiently, fairly and sustainably in relation to all CPRs. The economist points to design principles that have managed CPRs for multiple generations with success.

Burger et al. (p. 279) writes that:

When interactions enable those who use reciprocity to gain a reputation for trustworthiness, others will be willing to cooperate with them to overcome CPR dilemmas, which leads to increased gains for themselves and their offspring... Thus groups of people who can identify one another are more likely than groups 
of strangers to draw on trust, reciprocity, and reputation to develop norms that limit use.

The researchers emphasize the importance of trust. Low cost methods of monitoring and sanctioning CPRs can more easily be implemented when trust is established.

Additionally, organizational experience and local leadership are important features to reducing costs and finding solutions. The researchers go onto say that farmers are more likely to manage CPRs effectively than government ownership, which has a negative overall impact on the system of productivity.

A scholarly consensus has emerged demonstrating that local and regional CPR management is the most effective method. Local regimes are more likely to adopt effective rules than macro-regimes. According to Burger et al. (1999):

Users who depend on a resource for a major portion of their livelihood, and who have some autonomy to make their own access and harvesting rules are more likely than others to perceive benefits from their own restrictions, but they need to share an image of how the resource system operates and how their actions affect each other and the resource. (p. 281)

Some challenges associated with the global control of CPRs include: the shear size of the problem, the decreased likelihood of shared interests and understanding (cultural diversity), rapid rates of change, the inability to implement past lessons to current problems, the decreased likelihood for collective-choice or unanimous agreement and the magnitude of repercussions resulting from errors.

Burger et al. (1999) advocates for analysis of the history of CPRs that guarantee fair-access and sustainable use. The researchers highlight examples of how government ownership and privatization are both subject to failure. They compare the degradation that takes place when traditional management is replaced by centralized control. 
However, this is not to say that resources are not difficult to manage at the village level because ecosystems are interdependent such as with the case of large-scale watersheds.

Burger et al. (1999) explains that the management of the global commons depends on cooperation between national, regional and local institutions. New issues emerge from the transfer of small systems to global systems. Effective rules that limit access and define rights and duties will preclude against the phenomenon known as 'free riding' where one person abuses the CPR by promoting his or her short term interest over the long-term interest of the group.

Solutions to CPRs go beyond universal solutions or policy panaceas through diligent analysis of diverse socio-economic systems (SES), and their impact on ecosystems. According to Sillitoe (2010) developmental agencies assume that strictly standardized solutions can be imposed and result in benefits to impoverished communities. Conversely, the argument presented by many NGOs is that if development is to be sustainable, it must be embedded in the local knowledge systems (Fernando, 2003).

According to Ostrom, blueprint solutions and approaches to SES problems are dangerous because they negate the learning process by imposing final solutions without due consideration. To move beyond extensive policy panaceas it is necessary to build a strong field of sustainable science based on well-documented scholarship, interdisciplinary and theoretically sound study (Ostrom, 2007). Ostrom (p. 2) writes that, "We should stop striving for simple answers to complex problems. Social-ecological systems are complex, and the problems of over harvesting and misuse of ecological systems are rarely attributed to a single cause." Ostrom, who is the first woman to win 
the Nobel Prize in Economic Sciences, has conducted extensive field research on the significance of reciprocal cooperation in managing Common Pool Resources (CPRs).

Ostrom (2007) has advanced and implemented diagnostic methods to examine the attributes, system units, incentives, rules, interactions and outcomes for users and officials to experiment with adaptive policies and gain feedback. The diagnostic methods needed to overcome policy panaceas have extensive variables needing to be considered within complex nested frameworks (developed by ecologists) and nested conceptual maps for analyzing interactions and outcomes. The diagnostic methods will help scholars of sustainability with their long term goal to identify which combinations of variables tend to sustain productive use and which result in collapse and high costs. However, despite the complexity of variables and frameworks to be considered Ostrom insist that face-to-face communication creates the conditions necessary for socially optimal harvesting levels as opposed to extensively over harvested CPRs.

Ostrom (1999) concludes that protecting institutional diversity related to how diverse peoples manage CPRs may be as salient for our long-term survival as the protection of biodiversity. Sen (2009) likewise comments on the importance of diversity and sustainable development. He writes more generally that:

In assessing our lives, we have reason to be interested not only in the kind of lives we manage to lead, but also in the freedom that we actually have to choose between different styles and ways of living. Indeed, the freedom to determine the nature of our lives is one of the valued aspects of living that we have reason to treasure... This is an important issue in addressing such questions as the demands of environmental responsibility and of 'sustainable development'. (p. 227)

It may be deduced from Ostrom and Sen's ideas that protecting institutional diversity in the context of IK systems may be crucial to our long-term survival and freedom. 
Sen $(2009$, p. 83) comments on policy panaceas in writing, “... none of these grand institutional formulae typically deliver what their visionary advocates hope." Institutions and rules cannot replace the significance of human lives, experiences and realizations (p. 18). According to Sen (p. 82), "We have to seek institutions that promote justice, rather than treating the institutions as themselves manifestations of justice, which would reflect a kind of institutionally fundamentalist view." Sen writes that the principles of justice need to be defined in terms of ordinary lives not institutions. In other words, it is inadequate to focus on institutions when seeking to advance justice rather it is necessary to focus on actual lives as they are lived and experienced.

Sen elaborates on the problem of institutional fundamentalism by explaining the classical distinction in Indian jurisprudence and ethics between 'Niti' and 'Nyaya':

Niti is an inflexible arrangement, institutional centered approach to justice. Niti prevents critical examination by ignoring the adverse effects and the voices of affected people. Nyaya comprehensively takes into account broader perspectives through an inclusive process. "The more general issue of course is the basic unreliability of not being constantly sensitive to what actually happens in the world, no matter how excellent the institutions are taken to be. (p. 85)

Patent laws are an example of the restrictive quality of Niti or the institutional triumph over society.

Sen explains that (p. 409) patent laws are one of several issues that would benefit from global dialogue with criticisms emerging from far and near. Paying attention to civil society and less powerful people in different countries from far and near avoids the pitfalls of exclusionary neglect. Sen $(2009$, p. 408) writes that:

Giving serious consideration to distinct and contrary arguments and analyses coming from different quarters is a participatory process that has much in common with the working of democracy through public reasoning ... if 
democracy is seen in terms of public reasoning, then the practice of global democracy need not be put in indefinite cold storage.

Sen theorizes that grappling with the complexity of human perspectives and interests is fundamental to generating social justice and fairness.

Sen $(2009$, p. 153), demands that we reconsider the typical trite capitalist rendering of Adam Smith's work by reviewing A Theory of Moral Sentiments in which Smith advocates for the consideration of a wide variety of view points to overcome parochial, institutional rigidity. According to Sen, Smith is wrongly thought to be an advocate for the exclusive pursuit of self-interest, or 'the selfish-model', in the form of the so-called 'economic man'. Smith identified self-interest as one of many motivations including: sympathy, generosity and public spirit (Smith, 1790, p. 191). Interestingly, Smith advocates that we should develop procedures to examine our bias by hearing diverse perspectives that remove ourselves from our 'natural station' through the eyes of others. If we neglect all voices from elsewhere we are subject to a deteriorating parochialism. 


\section{Chapter II - Methodologies}

\section{Overview}

This study was completed in two different but interrelated stages to explore the research problem of how to engage indigenous peoples in dialogue regarding life form patenting over PGR. The first stage was completed over six months interning with the non-governmental organization Navdanya in India from October through March 20092010 (excluding December). During this time I conducted participant observation and interviews with Garhwali farmers who work with Navdanya. The data I collected was intended to answer the question: how do Garhwali farmers experience grassroots mobilization for biodiversity and IK conservation? The second stage of the study involved writing the thesis and analyzing data, for which Navdanya and Portland State University's library resources were instrumental.

My study merges diverse disciplines including socio-cultural anthropology, law, economics and politics. Interdisciplinary research is necessary to grapple with the complexity of social forces that converge to create structural violence. Complex global problems increasingly require solutions resulting from collaborations between disciplines and cultures (Pandey, 2001). Shiva insists that interdisciplinary research and thinking is fundamental to understand the current state of ecological destruction and alleviate poverty (National conference on climate change in the Himalaya, 2009). 


\section{Part I - Participatory Action Research}

Paulo Freire's Pedagogy of the Oppressed (1970) inspired participatory

methodologies to shift the focus of research to action (Krishna, 2009). Fals-Borda and Rahman created the approach known as Participatory Action Research (PAR). The action research paradigm is directed towards studying, reframing and reconstructing specific social practices, processes and interactions (Creswell, 2009). Participatory action research (PAR) is a social process characterized by collaborative learning in groups (Kemmis \& Mctaggart, 2000).

The PAR process necessitates a sense of development in research practices and an evolving understanding of these practices. PAR often explores the linkages between socialized attitudes, disciplinary knowledge, policy approaches and institutional practices (Krishna, 2009). Participatory methodologies are more able to engage the researcher in relationship building, which is fundamental to dialogue and peace building. According to Thamizoli (2004), participation is a goal unto itself because the process is empowering. Through participatory methodologies at the grassroots level people become agents who define their own agenda and priorities.

Smith et al (2010) reviews the best practices from a coded analysis of PAR literature. They define PAR as:

... an approach to research in which local perspectives, needs, and knowledge are prioritized through collaborations with community members throughout the research process. In PAR, research is not conducted on community members, youth, or other parties usually excluded from knowledge making; rather, research is conducted with community members or youth, challenging conventional distinctions between researcher and the researched. (p. 5) 
The other best practices of PAR include: raising critical consciousness, promoting change, fluidity, learning, reflection, investigation, interpretation and action. PAR is an interpersonal perspective and process that works towards collective efficacy in creating and implementing social change. The PAR process also seeks to enhance the social and emotion well-being of the researcher.

Krishna (2009) demonstrates the reach of PAR in her multiple experiences of fieldwork and meticulous, feminist analysis of Natural Resource Management (NRM) entitled, Genderscapes: Revisioning Natural Resource Management. According to Krishna, participatory research should create a power-shift so that the 'other' voices are emphasized as 'the voices'. In the case of India PAR was spun into Participatory Rural Appraisal (PRA) in the 1980s to bring farmers into the process of development (Chambers, 1995). There is an expansive body of literature and tools available regarding PRA. PRA is the most widely used method by NGOs, development agencies and the government in India today. Navdanya coordinators also implement PRA as my interview with Pramod Kimoti reveals.

Krishna (2009) critiques participatory methodologies in India as 'diluted'. She writes that, "When participatory tools are used without skill and sensitivity, or only to fulfill project requirements and as a means to achieving project goals, such 'participation' may itself be disempowering..." (p. 261). In some cases participation is only used to fulfill the imposed goals of the intervening agencies rather than to assess the needs of communities and empower them.

Participatory research is frequently used in social movements. Dr. Vandana Shiva's research is a preeminent example of PAR, and PRA, since she is vigorously 
engaged in the field combating multiple injustices with her mighty voice. The Right

Livelihood Award recognizes Dr. Shiva as one of the most articulate international spokespersons of people-centered, participatory processes for counter-development.

According to Shiva (2009) and Krishna (2009) participatory methodologies are the most effective method to mobilize from the grassroots and create sustainable livelihoods. The need for indigenous peoples participation at all levels of policy-making and implementation of biodiversity conservation is highlighted by multiple social and environmental rights movements and academic scholars. Participatory approaches to research challenge existing hierarchical dichotomies and are thus potentially transformative through engagement with the issue of indigenous marginalization.

Engaging small-scale farmers as experts in their fields, long-term participant observers and knowledge subjects highlights the significance of engaging local people as experts. Shiva explains that:

When it comes to local ecosystems, when it comes to understanding the impact of destruction on local ecosystems, and when it comes to finding solutions and alternatives to that destructive activity nobody is a better expert than local communities. They are knowledge subjects, they are experts in their own right because their expertise is multi-disciplinary and it comes from experience. And there is no knowledge more reliable then experiential knowledge. There is no knowledge more reliable then knowledge in which you have to suffer the consequences. (National Conference on Climate Change in the Himalaya, 2009)

Experiential knowledge possessed by local communities is a huge source of knowledge. Rendering a dynamic picture of people's knowledge situates knowledge in a real-world context. 


\section{Part II - Ethnography}

According to Mac Ginty (2008) the fields of anthropology and conflict resolution would benefit from an interdisciplinary merger. The diverse field of anthropology has produced a tremendous body of work examining diverse cultures. Conflict resolution scholars and practitioners have emphasized the significance of culture in transforming conflict. Traditional and indigenous conflict resolution is based on diverse, local cultural practices and customs. Indigenous approaches to peace building are participatory and relationship-focused. Similarly, the field of conflict resolution emphasizes the salience of ongoing relationship building and participation.

This study applies the ethnographic strategy of inquiry. According to Berson (2010) ethnographic studies would help to address various ethical and legal questions regarding IPRs and cultural appropriation. The objective of ethnographic research is to describe a holistic picture of the research subject that focuses on the experiences of individuals to reveal how people express and construct their worlds (Creswell, 2009). The ethnographic methodology has advanced the tenet of holism by analyzing knowledge in a cultural context. Anthropological holism, that considers diversity, transcends the reductionism epitomized by the IPR regimes as they seeks to universally impose the IPR over PGR agenda.

IPRs are a significant area of study in the field of anthropology, including political, cultural and linguistic anthropology (Hayden, 2003; Escobar, 2008). Eyzaguirre and Dennis (2007) explain that the goal of IPR research should be to identify how different rules and institutions can be mobilized to ensure more equitable access and sustainable use of genetic resources. They go on to say that scientists, developmental 
experts and policy makers must take into account local perceptions, institutions and collective action that allow farmers to protect the environments through sustainable livelihoods.

Indigenous environmental knowledge is the 'entry point' for anthropological research into biodiversity according to Pandey (2001) in his dissertation on ethnoforesty. Ethnographic study requires constant participant observation and in-depth interviewing. Using the ethnographic strategy of inquiry allowed me to gain access to knowledge about the process of grassroots mobilization. The ethnography also allowed me to collect and analyze data to better understand the practice of seed saving as an expression of indigenous environmental knowledge in the broader epistemological context of sharing and reciprocity.

Krishna (2009) explains that ethnography is a tool for PAR that can empower marginalized communities through capacity building within the community. A portion of Krishna's expansive work is dedicated to ethnographic accounts that depict the 'reality' of women's lives on the ground by listening to the 'voices' of the women themselves. She situates ethnographic accounts in a socio-cultural and political context to understand the divergent perspectives and power imbalances experienced by rural women.

Sillitoe (2010) identifies several demanding tasks needed to advance and refine ethnographic methodologies for trust building. These tasks include: making socio-cultural issues more accessible, overcoming prejudicial science that discriminates against local knowledge, and advancing interdisciplinary work. Trust must be fostered to include alternative views in a meaningful way in developmental discussions. Trust will bridge epistemic cultural differences and help to overcome the shortcomings of 'expert' views 
when 'experts' impose their perceptions and processes on local people. One challange to building trust is that development agencies tend to work with short-term politically driven agendas. Fieldworkers know that trust building requires time.

Farmer (1996) writes that case studies are insufficient to explain structural violence. According to Farmer, ethnography is the best method to render a greater comprehension of structural violence because this method embeds research analysis in the larger social, cultural, historic, political and economic matrix. Farmer (1996) asks anthropological research questions to understand the problem of structural violence. One question he poses is: how do social forces such as poverty and discrimination become embodied in individual experiences? To explore this question Farmer shares stories from the field, not as anecdotes, but to recognize the large-scale social forces that mold the faces of suffering in daily life. 


\section{Part III - Data Collection and Analysis}

Twice during the course of research I obtained permission from the Human Subjects Review committee at Portland State University to proceed with data collection. I conducted interviews and participant observation with a notebook, laptop computer, photography and digital video recording in Garhwali villages in the Himalaya, Navdanya's biodiversity farm, Navdanya's offices and at various conferences in New Delhi. My interview subjects were Navdanya, Garhwali coordinators, employees and members.

I adapted the interview protocols according to the individual being interviewed. However, the core questions I asked dealt with the grassroots process, seed saving, farming, culture as well as personal questions. It is important to note that the notion of TRIPS and IPRs over PGR are not part of most people's experiences anywhere in the world despite the indelible impact they have on our lives. Garhwali farmers are experts in their fields, but not in international politics and IPRs. It would be culturally insensitive to ask farmers about the TRIPS agreement directly. Thus, it was necessary to ask questions relative to the actual experiences of Garhwali farmer's lives as they are lived to derive relevant data.

The interviews developed spontaneously according to the flow of emerging dialogue. Notes taken for participant observation and my interviews were often formulated into articles for Navdanya's website, organizational records and bi-monthly magazine Bija. Over twenty of my high resolution photographs were featured in Navdanya's new 2010 publication The Story of Seed: Navdanya and the Struggle for Seed Sovereignty. 
I collected and analyzed data that focuses on understanding participants' meanings of the mobilization process, values and interests to identify five themes in an emergent design (Creswell, 2009). Collecting data in agricultural settings with Navdanya members required forming relationships with many members of the community. Those relationships, and the research process, were personally transformative because I was able to engage with remarkable, strong, determined and skilled conflict resolvers in difficult conditions and an inspiring context.

\section{Research Sites and Activities}

My three purposefully selected research sites were villages in the district of Uttarkashi (mostly in the village of Sankrit), the Navdanya agro-ecological, biodiversity, experimental farm and learning center in the Doon Valley (at the foot of the Himalayas) and in New Delhi at Navdanya's offices and conferences. The activities that occurred at the three research sites were varied.

\section{Navdanya's agro-ecological, experimental farm and learning center}

During my six month research period I was based at Navdanya's experimental farm and learning center at the foot of the Himalaya in the Doon Valley, North India in village Ramgarh. The farm is a popular destination for tourists, volunteers and various national and international programs. The farm serves as a base for Navdanya coordinators and researchers. Many activities take place on the farm including: workshops, courses, research, trainings, organic certification preparation, meetings, farming, seed saving and distribution. The farm produces more than 600 varieties of plants, including 250 rice 
varieties, 30 wheat varieties, and diverse varieties of millet, pulses, oilseeds, vegetables and medicinal plants.

The farm was transformed into a Earth University in 2001 to promote Gandhian philosophy with the support of visionary, peace pilgrim Satish Kumar. The learning center offers many courses instructed by visionary leaders such as Sunderlal Bahuguna and the Prime Minister of Tibet in Exile Venerable Samdhong Rinpoche. My experiences in courses such as Gandhi and Globalization, Seed Saving and the Grandmother's University supported my research.

Several male farmers and coordinators live on the farm. They come from diverse locations including: Bihar, Uttar Pradesh, Himachel Pradesh and the Uttrakhand. Male and female day laborers come to work on the farm in the fields from the nearby villages. I was able to build meaningful relationships with the farmers and engage them in the research process. At Navdanya's biodiversity farm I acted as a participant observer and conducted interviews. The activities I participated in included: workshops and events, writing reports and articles, managing the library, photographing for The Story of Seed publication, mentoring other interns and volunteers, farming, seed saving and food preparation.

\section{District Uttarkashi and Sankrit Village}

I collected data over three separate occasions totaling four weeks in the district of Uttarkashi (8016 sq. kms, population 295,000). Uttarkashi is only accessible through a few nauseating and poorly maintained dirt and stone roads at least eight hours drive from the plains and up to twelve hours depending on the destination. Distances in the region 
are deceptive because of the rugged terrain. Glaciers, mountain meadows and glacial lakes characterize the area. The Harkidun valley in the sanctuary is a popular destination for trekkers. The sanctuary includes snow leopard, black and brown bear, musk deer, thar wild goat, blue sheep, serow, monal, tragopan, koklas and kallej pheasants. The village of Sankrit in the district Uttarkashi is located near the river Tons and inside of the Govind Wildlife Sanctuary

When I acted as a participant observer in the village settings of Uttarkashi activities included: farming, seed saving, family life, the distribution of donations, evaluation of farmer's goods, procurement of farmer's goods, farmers trainings, the maintenance of Navdanya's 'presence' in the communities, relationship building and dialogue. During my time in the villages I participated, observed, filmed, photographed, wrote and conducted interviews.

In the village of Sankrit I was welcomed warmly because of my relationship with Navdanya and the Indian belief that 'Guest is God'. I toured 10 villages and met with over twenty Navdanya farmers during my first research trip to the district of Uttarkhashi in Uttrakhand, North India. The second time I visited I filmed several interviews in the village of Sankrit. The third time I visited was for a nine-day trek over 96 kilometers into the wildlife sanctuary with ten Navdanya, Garwhali farmers. We past through several extremely remote villages and ended at 4,500 feet. Balbeer Singh Rawat was the leader of our trek. Balbeer is a Navdanya coordinator and professional mountaineer as well as a high altitude medicinal plants specialist. I was able to have informal interviews with Balbeer over this time and learn about his work with Navdanya and passion for biodiversity and IK conservation. 


\section{Navdanya's New Delhi Offices}

In Navdanya's New Delhi offices I helped coordinate events, participated in meetings, documented conferences with digital recording and notes, conducted research and produced reports and articles. The conferences I participated in included: The Sir Alfred Howard Lecture Series, The National Conference on Climate Change in the Himalaya, The International Conference on Two Decades of the GMO Free Movement and the Indigenous Peoples Tribunal.

\section{Data Analysis}

In the following chapter I present and interpret my ethnographic case study. To analyze my data I first compiled twenty interviews and my journals. I then reviewed, identified and organized the data for analysis according to emergent themes (Creswell, 2009). I represent the data in five emerging themes including: Experiences and Strategies in Grassroots Mobilization, Culture and Sharing, The Seed, Climate Change and Women.

Within each theme I discuss the data in the context of the literature review to validate my research findings. I interrelate the themes and interpret the meanings of the themes. The goal of data analysis is to better understand participant's meanings about grassroots mobilization for biodiversity and IK conservation. This data may be used to better understand the problem of how to engage indigenous peoples in dialogue regarding IPRs over PGR. 


\section{Translators}

I was fortunate to have several translators work with me at different stages of the project. Shravan Rawat from the village Sankrit, who was studying at Shivalik Engineering College near Navdanya's biodiversity farm, aided me on several occasions translating interviews both on the farm and in the village Sankrit over the course of two visits totaling three weeks. Navdanya volunteer Aditya Barry from Mumbai acted as my translator for interviews conducted with the farmers on Navdanya's biodiversity farm. Senior Navdanya Coordinator from the Garhwal Darwan Singh Negi acted as my translator over a week's time in the village Sankrit in November 2009 and during a group interview at the Grandmother's University in 2010. During various conferences and workshops Dr. Vandana Shiva translated on different occasions, as did Navdanya director Dr. Vinod Bhatt.

\section{Study Limitations}

This is a small experiment to advance my understanding and experience of conflict resolution and social justice. I hope that the work sheds light on the theory of structural violence. The difficulty in accessing the terrain, speaking the language and the brief 6 month research period limited my ability to collect extensive data. Additionally, my novice status as a first time field research, with no experience analyzing data, hindered the dynamics of research analysis. 


\section{Part IV - The Role of the Researcher}

My previous experiences studying, working and living with people from diverse cultures equipped me to engage in meaningful, cross-cultural relationship building through Navdanya's grassroots network. My studies in the field of conflict resolution, colonialism and geopolitics informed my research approach. Most importantly, my experiences studying and traveling in North, South and West Africa over eighteen months prepared me for conducting research in rural India.

I first became aware of Dr. Vandana Shiva's work as an undergraduate student in the course called Gandhi, Zapata and New Agrarianism at Portland State University. This course was offered through the graduate program Portland International Initiative for Leadership in Ecology, Culture and Learning. Since this course I have become an advocate for local, organic agriculture as a solution to the problem of ecological destruction. I decided to intern with Navdanya and conduct my graduate research exploring farmer's experience of the grassroots processes.

As a high school student I participated in a peace studies course on nonviolence at Portland Community College (PCC) instructed by Portland State University Department of Conflict Resolution Professor Tom Hastings. This college level course was available to me through the PCC partnership with local high schools. In this course we studied Mahatma Gandhi and the nonviolent liberation struggle in India. Since this time I developed an interest in conflict resolution and the power of grassroots mobilization in India.

India's prolific, contemporary and historic grassroots mobilization provides an immense pool of wisdom to draw from in the field of conflict resolution. During the 
Gandhi and Globalization course annually offered through Navdanya at Bija Vidyapeeth an emphasis on transforming the personal self in the interest of the larger society emerged. Likewise, in the field of conflict resolution it is suggested that personal transformation proceeds structural transformation. The meaning of this idea has a profound impact when put into practice.

Lederach (1995) explains that the pursuit of personal transformation and systematic transformation are not exclusive options. Rather they are mutual and interdependent. Furthermore, personal transformation and structural transformation must be pursued together to produce real social change. Lederach explores the "Gandhi Dilemma" by asking which is more important, the means or the ends? The transformative approach adopts the Gandhian solution of peace by peaceful means embodied in the famous saying, 'my life is my message to the world'. 


\section{Chapter III - Analysis}

\section{Introduction}

In this chapter I present a small, ethnographic case study of how Garhwali farmers experience grassroots mobilization for biodiversity and IK conservation. This study explores the problem of how to engage indigenous peoples in dialogue regarding the universal standardization of life form patenting over PGR. I have collected and analyzed data in response to the research question (how do Garhwali farmers experience grassroots mobilization?) in order to yield insights into how local people act as peace builders to transcend conflicts arising from the loss of biodiversity and IK.

Navdanya has pioneered a model of participatory research and positive peace building. Exploring how participants experience this participatory, grassroots process provides a model for how to engage indigenous peoples in dialogue for positive peace building. Additionally, understanding how local people experience an authentic participatory process will highlight the gross inadequacy of unilaterally imposed decision making epitomized by the TRIPS agreement.

In the context of peace building indigenous farmers must be engaged in dialogue for social justice to prevail. Understanding the experience, perspectives and interests of Garwhali farmers is necessary to establish a legitimate dialogue on the subject of IPRs over PGR. More specifically, democratic legitimacy requires participation of Garwhali seed-keepers in IPR agenda setting, decision-making and policy formation processes. 


\section{Part I - Setting}

"In these hills, Nature's hospitality eclipses all men can ever do. The enchanting beauties of the Himalaya, their bracing climate and the soothing green that envelope you leaves nothing more to be desired. I wonder whether the scenery of these hills and the climate are to be surpassed, if qualified, by any of the beauty spots of the world." - Mahatma Gandhi

The Garhwal is an administrative division in the North Indian state of Uttrakhand (population 8.48 million), which was formed out of Uttar Pradesh in the year 2000 (Govt of Uttarakhand, 2011). Garhwali people also live in Uttar Pradesh today. Uttrakhand is bordered by the Tibet Autonomous Region to the north, Nepal to the east, the Indian states of Uttar Pradesh to the south, Haryana to the west and Himachel Pradesh to the northwest. The ecosystem of the Garhwal Himalaya is incredibly distinctive. Severe agro-climatic variations occur within a small geographical area (Dutta, et al, 2004). Forests, rugged mountains and high glaciers divided by narrow valleys, deep gorges and ravines characterize the Garhwal. There are 175 rare species of aromatic and medicinal plants in Uttrakhand.

The Himalayas are under increasing threat due to climate change and the largescale exploitation of natural resources. Drought and other natural disasters are increasingly common occurrences and have a tremendous impact on the local populations. Himalayan glaciers sustain seven of Asia's most important rivers that provide water for hundred of millions of people (p. 13). The Himalaya supports almost half of humanities ecological needs (40\%) as the third largest body of snow on earth (Bhatt \& Shiva, 2009, p. xi).

The damage to the ecosystem resulting from things such as the 'green revolution', big dams, deforestation, and climate change make living conditions very difficult on even 
a subsistence level (Dutta, 2004). Climate change is the most significant threat to the Himalayan ecosystem (Bhatt \& Shiva, 2009, p. xi). Climate change has resulted in plant species moving to higher altitudes, alterations in plant flowering and fruiting behavior, erratic rainfall, decreased snowfall and the quick drying of perennial streams.

Yamunotri and Gangotri in the Garhwal's Uttarkashi District are the sources of two of India's mightiest and holiest rivers, the Yumuna and Ganges. The monsoons give rain in the peak season, while the snow melt and perennial springs and streams give much needed water in the lean season (Bhatt \& Shiva, 2009, p. xi). The impact of climate change in the Himalaya is most felt in the lean season. Climate change reduces snowfall and the accumulation of snow. As atmospheric temperatures increase the zero temperature line elevates, which results in the phenomenon known as glacial retreat. The melting of the glaciers due to higher temperatures has severe repercussions for humanity.

Agarwal writes about the crucial axes of the 'people-ecology' interface in India saying that:

I gradually realized that in a densely populated, poor country like India, people were dependent for their daily survival on the gross nature product, the benefit that nature gives them for free, rather than the gross national product. In India, no understanding of ecology can be complete without understanding the relationship between people and their landscape. This led me to see the interface between culture, people, and ecology. I could not understand ecology without understanding people, and I could not understand people without understanding their culture, including their religious faith. (2000, p. 171)

This ethnography explores the 'people ecology' interface experienced by Garhwali farmers and the relevance of this interface to cultivating an experience of positive peace. 


\section{Part II - Actors}

Surprisingly little information is available about Garhwali people. What has been written is fragmentary and episodic. The inhabitants of this region and subject of this study are from the ancient Garhwali ethnic group also known as Paharis (of the mountains) (Govt of Uttrakhand, 2011). The Indo-Aryan, Garwhali language is categorizes as 'unsafe' in the UNESCO Atlas of the World's Languages in Danger and thus requires conservation efforts. Some areas of the Garhwal are classified as belonging to the Other Backward Classes (OBC) governmental category.

The Garhwal state was founded in 823 AD and the Garhwal Kingdom was founded in $1358 \mathrm{AD}$ (Govt of Uttarakhand, 2011). The Garhwal kingdom continued in an uninterrupted line until being temporarily taken by the Gorkhas in 1803 . The British defeated the Gorkhas in the Anglo-Nepalese War (1814) and established the British Garhwal (1815) in the eastern half of the Garhwal region. The heir of the Garhwal dynasty was granted the western half. The British were defeated through non-violent resistance in 1947.

Uttrakhand and the Garhwal region are known for containing many sacred Hindu pilgrimage spots (Bhatt \& Shiva, 2009, p. xi). These places are featured in many sacred ancient Indian texts. India's four sacred Himalayan sites, significant for all Hindus, are located in Uttrakhand. Badrinath, Kedarnath, Gangotri and Yamunotri are together known as Char Dham. The four sacred sites are visited on pilgrimage by many Hindus.

Garhwali people follow a Brahmanical Hindu code. Agarwal considers the ecological virtues of Hinduism explaining that (2000, p.172): 
Hindus clearly believe in and act upon a form of "utilitarian conservationism," as opposed to any sort of protectionist conservationism: they value and protect those features of nature that have gained significance within the ritual cycle of human flourishing. The sad fact is that these practices and beliefs are rapidly breaking down under the onslaught of Western-style technological modernization and social concepts of secularism. Rather than sustainability, the modern ethos driven by science and technology calls for high productivity, Rather than seeing people within the context of a life-style that has been developed over hundreds or thousands of years, the modern world seek to rush them into a money economy driven, in Gandhi's words, not by need but by greed.

Hinduism has encouraged many ecologically sound beliefs. Rivers and their origins, cows and their power to sustain lives (by fertilizing and plowing the fields), and medicinal plants (such as tulsi) have taken on central religious functions and are declared sacred.

The Garhwal Himalayas are sparsely populated (Dutta, 2004). Around $80 \%$ of the population lives in rural areas. There is very limited communication and many areas are not accessible. Garhwali communities have major settlements in about 3,580 small and medium sized villages located on slopes or in plain areas. The villages are often located near watercourses surrounded by agricultural fields.

The severe agro-climatic variations, and other factors, result in a plurality of socio-economic lifestyles amongst Garhwali people (Dutta, et al, 2004). However, most Garhwali people maintain a subsistence lifestyle. Garwhali villages maintain a traditional caste structure of labor distribution. Most work activities are forest-based and there are 54,047 handicraft units in the state (Govt of Uttrakhand, accessed online). Agriculture, cattle farming and a few cottage industries constitute the major part of the subsistence economy.

Garhwali communities are readily identifiable as village communities. The local 
extended family is the basic economic, social, and religious unit. Berreman (1999, p. 259) wrote in a rare ethnography of Garhwali people that, "The community is the most relevant manageable unit of analysis if one's aim is to achieve an over-all understanding of the way of life of the people in a limited time... Like all Indian villages, Pahari villages are not static isolated or autonomous."

Berrmen conducted his research in 1962, and updated it in 1973. He wrote that: Participation in common enterprises, ownership of common property, and preoccupation with common problems and common antagonisms further bind the community together despite caste, sib, and clique alignments... Cooperative work on village-owned trails, on the water source, and in certain phases of house building and agriculture also contribute to community identification. Indicative of a degree of village unity and interdependence is ownership by the village in common of large cooking vessels and a few large tools available to all community members as needed. (p. 259)

I confirmed Berrmen's description of Garhwali communities as fundamentally cooperative during the course of research. Understanding the socio-cultural and political significance of common property and cooperation in Garhwali culture is crucial to evaluating the cross-cultural impact of imposing IPR regimes on indigenous peoples.

In the Garhwal there are many variation in wealth and land ownership. However, there are no 'big' landowners as compared to in the Indian plans (Dutta, 2004). The varied agro-climatic situations result in different agricultural practices and socioeconomic lifestyles that could likely affect the nutritional status of the people living in this region. Dutta conducted a rare study of the Body Mass Index (BMI) nutritional status of 1,030 subjects in three agro-climactic regions of the Garhwal Himalaya (406 from the high hills, 292 mid and 332 low). Body mass index is calculated as the individual's body 
weight divided by the square of his or her height. The researchers found that one third of the Garhwali population have a low BMI.

The researchers further found that the percentage of healthy people is similar in the mid and high hills (54.7\% and 55.1\%, respectively) (Dutta, 2004). Only 52.4\% of the population is nutritionally normal in the high hills. The largest percentage of mildly and moderately undernourished people (18.2 and $12.1 \%$, respectively) is found in the low hills. However, most of the severely undernourished people are present in the high hills (11.1\%). The highest number of severely undernourished as well as the lowest number of nutritionally normal individuals are found in the high hills. Dutta concluded that the residents in the high hills are most nutritionally vulnerable.

Ehrlich and Ehrlich (1970) describe malnutrition and starvation as consequences of structural violence. Dubee (2006) writes more specifically that the malnourishment of 852 million people, (of which 815 live in developing countries), and 9 million annual hunger related deaths ( 5 million children) is a symptom of structural violence. Adequate nutrition for all people is feasible if current socio-economic structures change by challenging the dominant logic. Dubee describes the dominant logic as an information filter, a funnel for perceptions and a lens that restricts future possibilities and strategic actions that needs to be questioned in the context of structural violence. 


\section{Part III - Events: Chipko and nonviolent resistance in the Garhwal.}

The Garhwal region is known for leading important environmental movements including the Chipko movement (Dwivedi, 2000). The Chipko movement was India's first environmental movement. Since then India has spawned the world's largest environmental movement with more than 950 NGOs (Chapple \& Tucker eds., 2000). The Chipko movement was part of a protracted struggle, recorded since the 1950s, taken on by Garwhali people to change forestry practices that were injurious to local people (James, 2000). The Chipko movement consisted of hundreds of decentralized, local initiatives and was primarily led by village women.

The Chipko movement officially commenced in 1973 in the town of Gopeshwar in the district of Chamoli when Garhwali women villagers linked arms and created protective circles around trees earmarked to be cut down (O.P. Dwivedi, 2000). This nonviolent resistance was repeated in other villages when forest contractors brought licenses to fell trees from the Government Department of Forests. The actions of the villagers resulted in the contractors being forced to leave. Chipko leaders and activists have primarily been village women. In 1980 the Chipko protests resulted in a 15-year ban on the green felling in the Himalayan forest of Uttar Pradesh, Uttaranchal and Himachel Pradesh and halted the clear felling in the Western Ghats and the Vindhyas. Overall, the movement contributed to a natural resource policy more sensitive to people's needs and the environment.

The most famous Garhwali activist and farmers is Sunderlal Bahuguna a leader of the Anti-Tehri Dam and Chipko movements. Sunderlal Bahuguna is a famous and accomplished Gandhian activist who practices non-violent resistance or Satyagraha. He 
was awarded the Right Livelihood Award (1987) and India's second highest civilian honour, the Padma Vibhushan (2009). I was fortunate to meet and receive teaching from Sunderlal Bahuguna and his wife on two occasions at Bija Vidyapeeth. Bahuguna has had considerable political success in achieving his demands for environmental protection through the Gandhian practice of fasting. His longest fast was for 74 days resulting in the Prime Minister's commitment to review the Tehri dam project.

Dr. Vandana Shiva was also a leader in the Chipko movement that took place in the hills near her birthplace in the Doon Valley (Dehradun) (James, 2009). Dr. Vandana Shiva's visionary leadership has brought together millions of people around the world to understand and support biodiversity and IK conservation. Dr. Shiva is what Lederach (2002) calls a 'middle-range leader'. A middle-range leader is vital to peace building because of their talent for networking and relationship building. These leaders know toplevel leadership, but also are connected to the grassroots.

Dr. Shiva was awarded the Order of the Golden Ark, Global 500 Award of the UN, Earth Day International Award, The Lennon Ono Grant for Peace and the 2010 Sydney Peace Prize (Right Livelihood Award, 2011, accessed online). In 1993 Dr. Shiva was awarded the Right Livelihood Award, "...for placing women and ecology at the heart of modern development discourse.” In 2003, Time Magazine called Dr. Shiva an environmental "hero" and Asia Week identified her as one of the five most powerful communicators of Asia. Dr. Shiva serves on the board of the World Future Council, the International Forum on Globalization and Slow Food International. 


\section{Part IV - Processes}

In 1982 Dr. Shiva founded the Research Foundation for Science Technology and Ecology (RFSTE) as a public interest group. The RFSTE led to the formation of the participatory, grassroots network Navdanya. The Navdanya program is a participatory research initiative that provides guidance to environmental activists and is also the largest fair-trade, organic network in India. Navdanya empowers farmers through processes such as: community development projects, targeted trainings, educational programs, providing access to markets, fair prices and involvement in many special events, conferences, participatory research projects, protests and petitions where farmers are recognized as experts and peace builders.

Navdanya seeks to improve the wellbeing, and defend the rights, of small and marginalized farmers through a variety of processes related to biodiverse organic farming and fair trade (Navdanya, 2006). Navdanya has established 54 community seed banks in 16 states in India and has collected thousands of varieties of seeds in different working areas. Navdanya's 500,000 community members can borrow seed for the season, but they must return seed of the same quality and in an amount exceeding the seed received to the village seed bank upon harvest. Navdanya members are encouraged to bank local varieties in the community seed bank. Community seed banks build a stock of diverse seed varieties and provide farmers simple access to local seeds.

Navdanya carries forth the message of local, sustainable, decentralized, selforganization epitomized in the work of Sunderlal Bahuguna and Mahatma Gandhi. Navdanya has formed hundreds of Jaiv Panchayats (Navdanya, 2006). The Jaiv Panchayat is an important grassroots movement to reinvigorate the traditional Panchayat 
(decentralized community committees) with the mission of defending biodiversity as a commons. Farmers working with Navdanya experience Earth Democracy through Navdanya's Jaiv Panchayat Living Democracy movement. The concept of Earth Democracy for seed, food and water sovereignty promotes an educational and organizing strategy for local grassroots development.

According to Navdanya's (Navdanya, 2006) mission statement, "Navdanya is born of a mission based on peace and non-violence... the human wellbeing especially of the poor and marginalised communities is directly dependent on the health and wealth of our biodiversity... We are therefore committed to resist patents on seeds and life forms promoted by the TRIPS agreement of WTO which leads to the privatization of biodiversity and the piracy of traditional knowledge..." Navdanya has successfully challenged patents on Neem, Basmati and Wheat through the legal system.

Navdanya has organized over twelve hundred farmers meetings that tens of thousand of farmers participate in (Navdanya, 2006). Navdanya holds hundreds of training programs each year in which thousands of farmers participate. Navdanya also has converted over ten thousand farmers to organic methods each year, numbering tens of thousands of acres. Through various Yatras (marches) hundreds of thousands of people receive Navdanya's message. 


\section{Part V - Findings}

I have presented select data collected from twenty-one structured interviews. I have categorized the data in five themes including: Experiences and Strategies in Grassroots Mobilization, Culture and Sharing, The Seed, Climate Change and Women. I present findings in three groups within each theme (whenever applicable) including: A.) internal Navdanya farmers and coordinators, B.) Navdanya farmers from Sankrit Village and C.) Navdanya farmers from other parts of the Garhwal. Please note that internal refers to a vested and sustained participation as a hired employee or volunteer. Following the presentation of each theme I analyze the data in the context of relevant literature. Finally, I identify major findings. 
Theme I - Experiences and Strategies in Grassroots Mobilization

\section{A.) Internal Navdanya farmers and coordinators}

1.) Bija Devi: lead farmer and seed keeper at Navdanya's agro ecological, biodiversity farm.

Bija Devi is from Tehri, a district that reputedly has strong and outspoken women.

She began working with Navdanya seventeen years ago as the lead farmer and seed keeper at Navdanya's biodiversity farm. Bija came to Navdanya when she heard that Dr.

Shiva was looking for women with knowledge about seeds. She heard this through her daughters, friend's mother.

Bija is a leading grassroots figure in Navdanya's movement. International programs wanting to learn about indigenous seed keeping often visit her and she is featured in various publications and campaigns. As Satish Kumar has said, she is the fire behind Dr. Vandana Shiva and Navdanya (personal communication, 2008). Bija embodies the connection between indigenous knowledge and biodiversity conservation. She inherited her traditional knowledge from her mother and then, after she was married, from her mother in law.

2.) Pramod Kimoti: Navdanya coordinator.

Pramod Kimoti has worked with Navdanya for two years as a regional coordinator creating SHGs in the Garhwal Himalaya. Kimoti had already created over 120 organic SHGs in the Garhwal, especially in Rugapya districts, while working with another program prior to Navdanya. His specialization is farmer's groups, women's groups and children's groups. The groups are made with the goal of creating sustainable livelihoods and entrepreneurial business developments. Kimoti prepares farmers for organic certification through training such as in composting. He helps groups to create 
various natural products such as in food processing to make pickles and chutneys. He helps his groups to establish direct, fair trade linkages so that they can sell their products for a fair price.

Kimoti explains that:

We especially work on sustainability. In my heart I have sustainability! I feel good doing my job... My vision is that sustainability is the one thing that matters. I make sure that all the groups I form sustain and do organic self-sufficient farming. They are making model villages, a model region and district. This is my priority for these groups. I am in a position of advantage because I am able to give to these groups.

3.) Anand Kumar: Navdanya coordinator and agro ecological, experimental farm manager.

Anand Kumar has dedicated ten years in service to Navdanya farmers. The kind and soft-spoken man from Uttaranchal is the coordinator for the Dehradun region and the farm manager at Navdanya's biodiverse farm. His job duties include crop planning, mapping, labeling, course arrangement, stock inventory, seed organization and categorization, register maintenance and working in the soil lab. Anand avidly works with 80 Certified Organic Farmers and 5,000 total farmers. He explains that Garhwali farmers working with Navdanya save seeds so that they can maintain intact ecosystems, adapt to changing climate conditions and develop local, sustainable food-systems. Anand says that his experience working with Navdanya has been life enhancing.

4.) Dr. R.S. Rawat: Navdanya coordinator

Dr. R.S Rawat has worked with Navdanya for ten years. He is the coordinator for all of Uttrakhand, Rajasthan and the large state of Uttar Pradesh. Dr. Rawat works voluntarily with Navdanya. Dr. Rawat is a Graduate in Botany and Earth Science from the University of Garhwal in Sri Nagar. He has worked in the high Himalayas, in the 
Sankrit area, with high-altitude medicinal plants. Dr. Rawat also has a commercial business with medicinal plants.

Dr. Rawat explains that before he was introduced to Navdanya he believed that only industrial, scientific agriculture was good for the development of the farming community. He explains his experience that:

When I came to Navdanya and visited the developed areas slowly, slowly I came to know this is not the way of development. Organic ways of farming are the main need of the century. The whole issue of climate change is related to chemical farming and the fuels - causing global imbalances by emitted a lot of nitrous and carbon dioxide. I feel that if the world goes for organic farming, we will get rid of $50 \%$ of the carbon problem in the air. It will reduce our fuel use in the industrialized farming system.

Dr. Rawat's work is multifaceted. He works in the fields and generates reports. At the time of interview he was coordinating a special project related to biodiversity and conservation in the field. He is involved in procurement, management for grains, pulses and other food items: not only from Uttrakhand, but Rajasthan and Uttar Pradesh. Dr. Rawat is also involved in organic certification. Additionally, he contributed to Navdanya's recent, participatory study called Climate Change at the Third Pole.

Dr. Rawat explains that all Navdanya members in the villages are organic, but they are not all certified organic. When farmers have excess product to sell and demand for that product then Navdanya aids them in the process of organic certification. The farmers needing certification are identified and helped to make required documents like the field diaries. Navdanya collects data and inspects the fields. Dr. Rawat explains that this is a long process that is accomplished by maintaining relationships with the farmers.

The organic certification is granted by a worldwide agency known as SDS. SDS is an organization based in Switzerland for global level certification. Navdanya bypasses 
the two or three Indian organic certification bodies by working with SDS. The process of certification requires: soil testing, land survey and interviews with the farmer about production. Dr. Rawat and his team have ongoing dialogue with the farmers to check the farmer's fertility maintenance, which crops they are growing, what the benefits are, how they feel, whether they feel chemical farming is good among other things.

5.) Vinod Chamoli: Navdanya coordinator.

Vinod Chamoli has been working with Navdanya as a grassroots coordinator for nearly eleven years. Chamoli is the head of his area's Panchayat (local democratic body), which holds community meetings and makes decisions through discussion. The Panchayat also provides seeds to farmers. He explains that:

At this young age they call me 'the wise one'. When I began my role as coordinator I called a meeting with the Panchayat heads in twenty-eight villages. I asked them, 'Why are you eating poison? Why do you want to kill yourselves?' They all agreed and have virtually stopped the use of urea chemical fertilizers. They have asked me to stand for election, but I do not want to enter politics. I want to continue as a grassroots community organizer.

Chamoli met Dr. Shiva at the world environmental day in his district of the Garwhal Himalayas. At this time he was the president of a cooperative society selling chemical pesticides, fertilizers and hybrid seeds. The cooperative society is a group of elected people who support agricultural production by providing seeds and loans to farmers. Chamoli's dialogue with Navdanya director Dr. Vinod Bhatt initially led him to attend several Navdanya workshops to learn about organic farming and the negative impact of agrochemicals. Chamoli was inspired by what he calls his "inner self" to organize around organic farming. He returned to his colleagues at the cooperative society 
and discussed his new found knowledge and they decided to prevent the selling of hybrids and pesticides. The group then changed the mission of the elected body.

Chamoli first mobilized by calling farmers to a meeting to explain the unsustainable nature of hybrid seeds (Hybrid crops produce sterile seeds). Chamoli says, "Our native seeds are sustainable so the people slowly changed and began to save their native seeds." Chamoli works diligently to mobilize people by raising awareness about the government's role in society, providing new information about the negative impact of chemical farming and new techniques in organic farming.

Chamoli explains that the government representatives, promoting government policy, disagree with Navdanya and the Panchayat. As community president Chamoli is invited to government inaugurations to announce new programs and policies. According to protocol Chamoli and the Panchayat give the closing speeches. During the closing speeches they testify about the negative impacts of corporate industrial agriculture. He says, "We tell people to think before we implement about what is wrong and what is right." Chamoli and the Panchayat prevent corporate fairs that promote industrial, chemical agriculture from coming into their areas.

Chamoli explains that:

I learn a lot from Navdanya. The big benefit to farmers is their fight against patent law and to save their native seeds, water conservation, water harvesting, soil conservation. Navdanya brings allot of national and international issues to the local level; new technical issues like the changing climate. The farmers are aware of these things and tell others about these future problems.

Chamoli organizes groups of farmers to grow traditional crops such as millets, ragi, foxtail millets and barley. Navdanya purchases the surplus grain from the farmers at a fair price to sell in Delhi and other local places. 
6.) Rukmani Rawat: Navdanya coordinator.

Rukmani Rawat didn't grow up farming where she is from in the Tehri District of Uttrakhand because she was in school, but she chose to focus on farming in her adult life and career. She is a grassroots activist who works to raise awareness, establishes seed banks, distributes seeds and trains farmers in organic methods. Rukmani remarks that Garhwali farmers are aware of the negative impact of the green revolution and the epidemic of farmer's suicides in Punjab. She explains that, "Farmers know that deforestation leads to land change and environmental problems. They are very aware of this information."

7.) Balbeer Singh Rawat: Navdanya coordinator and high altitude medicinal plants specialist.

Balbeer Singh Rawat has worked with Navdanya for eleven years. He is the coordinator in 42 villages where an estimated 18,000 people live in the high Himalayas and is based in the village known as Sankrit (sometimes called Sour). Balbeer provides seeds, trainings, and marketing support. He has also lead trekking and mountaineering expeditions for forty years. Balbeer says he is proud to teach the people and give them the benefit of organic farming. He lives by his statement that, "If we want to life a life close with nature we have to go and be with nature: go and see and identify plants. You must live with nature, walk into nature and invite nature into ourselves."

Balbeer explains that Navdanya gives seed to farmers free or for exchange. Either the farmer has to return the seed or give it on to two more farmers. Navdanya farmers take a pledge to stay organic before becoming members. Navdanya gives awards to farmers who grow special things and to recognize farmers for excellent work. Balbeer 
coordinates women's groups and the granting of donations including: buffalo, equipment (like juicers) or, for example, when one village entirely converted to organic they were given a watermill.

8.) Ghanshyam Prasad: Navdanya coordinator.

Ghanshyam Prasad has worked with Navdanya for eight years. He is the trainer and coordinator for sixteen villages and over one thousand farmers (forty of whom are certified organic) in the district of Porola. Prasad previously worked with Dr. R.S. Rawat's organization Share where he taught about high altitude medicinal plants. He says that he is very proud to teach people seed saving because it is the most important work for the farmers.

9.) Sheila Godiyal: Navdanya farmer

Sheila is a Garwhali farmer who has worked with Navdanya for five years at Navdanya's biodiversity farm and learning center. She is from Ganeshpur village in the Doon Valley at the foot of the Himalaya and now lives in Jaivaradi. Sheila learned farming when she was twelve while she was in school from her mother, who has more than five acres in Ganeshpur. She explains that, "I do feel like part of a community. If any members need knowledge we would be more than willing to learn from them and share knowledge."

\section{B.) Navdanya members in Sankrit Village}

10.) Meenakh Rawat: Navdanya seed keeper and farmer.

Meenakh Rawat is from Sankrit Village in Uttarkhashi. I interviewed her while she was sorting through seeds as they had mixed in varieties. Meenakh attended training 
at the Navdanya farm and enjoyed it. She said she met new people and acquired new knowledge. When she returned to her village she was able to share this new knowledge with her friends and family. Her status in the community changed after the Navdanya training because she gained new insight into her work. Meenakh said that her perspective on her life's work in agriculture changed after the training and she became more appreciative and aware of the importance of agriculture as a result.

11.) Shurveer Singh Rawat, Navdanya farmer and Panchayat leader.

I interviewed Shurveer Singh Rawat who is the president of the Jaiv Panchayat and a Navdanya farmer. He told me that Navdanya came and renewed the compost and other organic practices in the village of Sankrit after chemicals began to infiltrate the region and destroy the soil. He explains that, "Productivity decreased after a few years of using chemicals, but now it has been renewed since converting back to organic.” He goes on to say of his experience that:

Farming is the one thing you can rely on: that knowledge is essential!... Farmers have incredible power. India lives by the farmer. He is everything. If we have good crops there is nothing more important than that. Farming is the first and highest role. Like Gandhi said, 'farming is the superior act.' We are very proud of our work. Mahatma Gandhi taught us to organize, to share, love and care for everyone.

12.) Rena Rawat, Navdanya seed keeper.

Rena Rawat, Shurveer's sister, is the head seed keeper in Sankrit village. She supplies seeds to the villagers and explains that after two years the farmers will return the seed to the seed bank if they have a good crop. Rena explains that this is a mutual exchange to help one another. She teaches others what she has learned through training with Navdanya at the biodiversity farm far below in the Doon Valley. Rena used to be 
adept at farming, but now due to health problems she has had to cut back on her time in the fields. Now she mainly focuses on cooking and keeping seeds.

\section{C.) Navdanya members from other parts of the Garhwal}

13 \& 14.) Jhadidevi Thalwan and Bachnidevi Thalwan are Navdanya seed keepers from Tehri. They explain the intergenerational transfer of knowledge and skills pertaining to agriculture. However, while Jhadidevi's family had lost the skill of seed saving, Bachnidevi's family retained the practice. Jhadidevi learned seed saving from Navdanya. She explains that, "We used to buy seeds and now we know it is supposed to be saved and kept in a cool dry place so if there is a shortage we can distribute the seeds." 


\section{Theme I - Analysis}

In this section I review the relevant experiences described by Garhwali farmers and coordinators. It is clear that Garhwali farmers working with Navdanya use local agricultural development as a tool for social transformation through biodiversity and IK conservation. Their experiences reveal various strategies and processes that have strengthened Navdanya's grassroots network and empowered local agents of change through engaged dialogue.

The data shows how Garwhali farmers act as peace builders. The creation of SelfHelp Groups (SHG), the restructuring of the Panchayat, trainings in biodiversity conservation and organic farming, research and grassroots actions are some examples emerging from the data. These examples demonstrate the strategies that Garhwali farmers use to enter into dialogue and cultivate an experience of positive peace. The manifestations of the peace building process are dependent on a strong sense of community and relationship-based dialogues.

It is evident from the data collected that the process of grassroots mobilization for biodiversity and IK conservation has been positive for participants. The data sheds light on how the daily grassroots experiences of Garhwali farmers are fundamental to their lives and livelihoods. Navdanya provides much needed access to pertinent resources such as trainings, education and seeds. However, the farmers are not passive recipients of preconceived plans. Rather they are active participants in an organic process that validates and engages their knowledge systems. 
Theme II - Culture and Sharing: the significance of relationship building

\section{A.) Internal Navdanya farmers and coordinators}

1.) Bija Devi explains that if a village or farmer doesn't have good seeds, other villages will share with them. Bija Devi explains that, "Seeds are given freely; we don’t ask farmers to return them when in small quantities. If the seeds are excellent they will return to us with additional seeds."

2.) Balbeer Singh Rawat mobilizes farmers through a system of relationship building to spread the message of seed saving. Balbeer says that without relationships you cannot accomplish anything.

3.) Ghanshyam Prasad emphasizes the significance of community unity where everyone is one family so that everyone is in good health. He says, "All problems can be solved when you share them."

4.) Vinod Chamoli explains the strength of the Garwhali community:

When problems arise the people unit to help one another. For example, if someone is injured the community will collect money and donate it to get the injured person to the hospital. Later this favor will be reciprocated.

Chamoli explains that Garwhali farmers have their personal resources to solve problems in the local community.

5.) Rukmani Rawat explains that:

The knowledge passes through generations. If someone is unwell grandmothers prepare a concoction and her daughter will watch and learn. Maintaining these relationships is important to pass down knowledge. One mother is everyone's mother and one auntie is everyone's auntie.

6.) Dr. Rawat explains that Garhwali culture is a peaceful culture:

This is our culture. We don't want to kill. The chemicals kill everything; it kills soils, bees, pollinators, birds, etc. This is not our culture. Our culture says give life to others also. People feel we are doing good work. We are organic. We are holy 
people. Organic is basically a philosophy. Fifty years ago we were all organic, only due to the industrial model did we start using chemicals. In Garhwal, the whole area is under organic cultivation. Three hundred and eighty farms, or more in Garhwal, that we work with are all organic.

7.) Pramod Kimoti explains that:

Farmers living in the Garhwal Himalaya experience inequality. I determine who in my groups is in need because we want there to be equality. The rich and poor must unite. There are rich, poor and ordinary men in my groups who save their money and create a treasury and strategies for sustaining the work. Some groups are growing herbs, prepare food products and explore fruit products.

\section{B.) Navdanya members from Sankrit Village}

8.) Shurveer Singh Rawat explains that, "I feel like I have helped a lot of people working with Navdanya. This is the right of every human being to share knowledge." In the mountains of the Garhwal Himalaya the context of IPRs over PGR is greatly skewed because survival requires cooperation and sharing. Garhwali cultural values are deeply intertwined with the community's daily existence and functioning in the mountains and tied to the mountainous environment.

Shurveer goes on to explain that:

Garhwali is our local culture, our language, our dress are distinction. The natural environment influences our culture. The mountains shape our culture. Mountains can't describe us, but it gives an indication. The best part about living in the mountains is the peace and space for meditation. Up on the mountain in the meadows we feel so good. Puja is a prayer for good crops. Puja is important for our emotional lives and our hearts. If we pray then we fell motivated. Serving our Guru also helps us to express our love. Love is God.

\section{C.) Navdanya members from other parts of the Garhwal}

9.) Group Interview Grandmothers University, during this interview the women spoke collectively, interjecting wildly so that the translation was portrayed as a whole.

The group of women discuss sharing and the barter system:

The Barter system is a beautiful system that does not rest on currency exchange because in the village it is a shame if we talk about money. It is a shame to talk about money because it is a community. Suppose one person has a lot of onions so she will automatically distribute them around. Any surplus food will be distributed amongst the community freely. There is no question to talk about money. There is no commercial concept because everything in excess is shared. It is in the spirit of sharing that a barter system still remains. This is how we live and 
think. However, if people become consumed by the market mentality they become the odd ones out. People will remark, 'what a strange person.'

10.) Bachnidevi Thalwan from Tehri comment in a group interview that:

The unique feature of Garwhali culture is sharing: We teach our children when they are young that they should share and help when others are in times of need and Rukmani Rawat teaches the small children also.

11.) Sunderalal Bahuguna explains that:

Collectivistic societies are founded on organizations of relationships that provide immense strength for self-sufficiency and Satyagraha (the force of truth), and thus freedom. Farmers may also demand a fair price through strong associations. 


\section{Theme II - Analysis}

This section presents data collected on the emerging theme of a Garhwali culture of sharing. The data shows that Garhwali farmers regularly experience relationship building, dialogue and reciprocal knowledge sharing as they live their lives and mobilize from the grassroots. This is significant when we focus the lens of conflict resolution on the research question: how do Garhwali farmers experience grassroots mobilization? Their experiences clearly are imbued with spiritual, philosophical and practical appreciation for the right to share.

Garhwali farmers, who have been trained with Navdanya, identify reciprocal knowledge sharing as foremost in the process of creating sustainable livelihoods, solving problems and conserving their knowledge. The Garhwali knowledge system is maintained and transmitted through community cooperation and an ethic of sharing. The interview subjects insist that community unity and strong relationships are necessary for the community's success, health and strategic problem solving.

In my interview with Dr. Vandana Shiva I inquired about the significance of relationship building and culture in the Garhwal. She replied:

The beauty of Garhwal is that, because it is a mountain region, it still has elements of what I would call a nature's economy functioning. And in nature's economy everything is in the commons: the seed is in the commons, your forest is in the commons, the water is in the commons. That is the legacy we built on. All conflict comes out of trying to own in divisiveness what belongs to everyone in the common good. By holding in the common good, the seed the biodiversity, the communities of Garhwal are able to understand much more quickly what the alternative to privatization is...

They have a very strong community spirit, and that is what we built on because Navdanya's philosophy is based on saying patents on seeds and patents on life are wrong. Biodiversity and seeds are in the commons and they belong to the community. It is not something you have to teach from outside. We have to 
help people remember this, and that remembrance then becomes the basis of creating perpetual peace (personal communication, May $1^{\text {st }}, 2009$ ).

The data I collected pertaining to the culture of sharing highlights the substantial conflict between Garhwali culture and IPRs over PGR. Garhwali people's preference for reciprocal knowledge sharing, embodied in the practice of seed saving, conflicts with the standardization of life form patenting.

The ability of indigenous peoples to conserve, recover, develop, and transmit their inherited knowledge is contingent upon a traditional worldview that promotes an ethic of sharing. The practice of reciprocal knowledge sharing and sharing of resources is present throughout indigenous cultures. The WHO (2001) explains that, "most members of traditional and indigenous communities were -and probably still are- very generous in sharing their knowledge." However, IPR regimes are fundamentally incongruent to the ethic of sharing and reciprocity typical of indigenous cultures because they promote exclusive rights and monopoly control through exclusion.

Krishna (2009) conducted a participatory, ethnographic study to understand the caring practices of the Kunbi women who are forest dwellers in the Western Ghats, India. The study found that caring occurred in the context of needs, interests and values that emerge from a situated, socio-political and economic history. Krishna identified the love of children and trust in elders as core values that shape the intergenerational transfer of knowledge of plants and herbal medicine skills. The Kunbi's spiritual beliefs and economic rationality encourage co-existence with nature and the sustainably regulated use of the forest for productivity.

Krishna summarizes the significance of caring and reciprocity in writing: 
From this small case study of the Kunbi in Joida, we can surmise that the capacity to care reflects processes of socialization and learnings that are passed on - from father to daughter and from mother to son, as Annapurna has done. Caring is more than the giving of material objects in a system of deferred reciprocity. Caring involves giving of oneself, one's knowledge and skills, giving time, giving space, often without weighing this in a balance of exchange. The carer derives satisfaction (and some power) from the self-recognition that she (or he) is performing a vital function and that by fulfilling a social need has gained the esteem of the community. (Krishna, 2009. P 138)

Commercial and industrial pressures, and governmental changes in the forest and land use policies, have impacted the practice of caring by weakening the natural resource base. Krishna found that despite the inability to practice time-honored traditions, due to ecological exploitation, the knowledge of herbal medicine is prevalent amongst adults 
Theme III - The Seed

\section{A.) Internal Navdanya farmers and coordinators}

1.) Bija Devi explains that, "We may die, but the seeds must be left for the next generation."

2.) Anand Kumar explains how because of Navdanya the ancient practice of seed saving has proliferated. He remarks that:

Navdanya farmers all keep their own seeds. Seeds are also supplied from the Navdanya seed bank. The farmers are now self-sufficient in seeds through seed saving and an exchange amongst themselves. They don't depend on the market. Vegetable and pulses are sometimes bought in the market. The seed is very important for agriculture. We discuss seed sovereignty with the farmers so they will keep seeds at home. It is best to keep your own seed so you can carefully check the quality - the quality of the seeds from the market is unknown. We teach seed selection. (For example) the wheat fields are examined and selected in separate bunches, thrashed by hand, cleaned and kept for seed saving for next year. Other plants are used for food.

6.) Dr. Rawat and the team of farmers and researchers at Navdanya's experimental, biodiversity farm are making trials of (currently) eighty varieties of wheat and over five hundred varieties of rice. Navdanya then distributes these varieties to Navdanya members, especially in the Garwhal, and especially those varieties that are drought resistance. Navdanya's research team and farmers have conducted field trails in the Garwhal and found that millets such as: ragi, foxtail, barnyard and bajra are more resistant to harsh drought. Also, they found that local varieties of wheat and local varieties of rice are drought resistant. The varieties imported by the government have failed.

Dr. Rawat explains the significance of biodiversity and intercropping multiple varieties through an example in the district of Parola where the farmers experienced a total failure of tomato crops. Dr. Route explains that: 
They earn a high income with tomatoes and they are totally dependent on tomatoes. They should not be dependent on a single crop, but biodiversity. In the village of Sankrit they grow three or four varieties in a single field. If there is drought or two much rain there are different options. This is the security people have devised against climate change. That will come from the community, not outside. Maybe this year there will be so much change in climate. Climate change means variability, not just drought. Last year in the month of March there was one or two days drastic temperature loss so that it was almost zero in Sankrit, this effected all our apple crop. So there was a total failure of apple crop in the state due to the sudden decrease in temperature. We need crops that are not susceptible to high fluctuation of temperature and moisture.

He goes on to say that:

Farming should be naturalized and farming products should not be commercialized like it is being commercialized by monopolies like Monsanto. The big corporations want to kill all the diversity in seeds of the world to get some monetary benefit, some money. To have this monopoly on natural seeds, and their seeds, they want that no farmers have a sustainable seed supply - so they have to buy their seeds.

7.) Balbeer Singh Rawat emphasizes the importance of seed saving. He says that, "Saving seeds makes us self-sufficient. Self-sufficiency is necessary for our freedoms so we do not go to others like a beggar." He explains that the government brings chemicals and hybrid seeds free to these areas to try to create a dependency. However when the farmers realize that the hybrid seeds do not germinate to produce new seeds (because they are sterile) then they discard them because the price is more and they do not grow.

Balbeer explains that:

I have talked with the people about Monsanto that they want to steal our seeds and genetically take the traits and characteristics we have developed. I tell them that they should not take genetically engineered seeds. They ask me, "if they are destroying our seeds what can we do?' We tell them to save the seeds. Many people know me because I am the only one who goes to talk to them about farming. They trust me and say, 'you are the only person who cares about the farming'. They do not trust in the government because they send pesticides with low prices trying to trick them. We have opposed many times the government distribution of internationally acquired seeds. 
8.) Genshyam Prasad and Balbeer both explain how they raise awareness amongst the farmers about transnational seed corporations like Monsanto because the farmer's situation will be further impaired if their seed is taken from them. Genshyam remarks that:

If they take the seed from them then they cant save their seeds. Seed saving is important because the farmer will not have to buy the seed from outside and it will be better for him. If he has no money then how can he grow his crop next time?

When asked why it is important that farmers have the right to seeds Prasad responds frankly that, "Asking this question is as simple as answering why you eat food." Prasad elaborates in saying that the farmers whom would use GMO seeds and Monsanto's seeds don't own their land, they are only leasing it and they don't know about the future consequences. He explains that, "They are thinking that this time we will have a good crops, then after that we will leave our farming. They want to leave farming to go to into hotel management for example."

\section{B.) Navdanya members from Sankrit Village}

9.) Shurveer Singh Rawat says that:

Seed saving is necessary because everyone needs the seed. We exchange the seeds if people are in need. Then we supply them. Depending on the production they will repay one and a half times in return. We help people in our community save the seed. Seed saving is an ancient practice.

10.) Rena Rawat explains that the melting of glaciers and reduces snowfall in the Himalaya is devastating to local agricultural production because the snow is needed to kill the insects and provide moisture to the soil and replenish the water supply. She explains that:

We keep enough seed varieties to deal with the changing weather conditions. We save around forty or fifty types of varieties of seeds. What we need the most is help with seed saving. I taught my daughters how to keep the seed and they help me learn about modern things. 
11.) Sulochna Rana explains that, "Navdanya means saving seeds. When there is a shortage of seeds in the village then we distribute them as needed."

12.) Vinod Chamoli explains that the impact of new agricultural policies is negatively

impacting Garwhali farmers because new regulations are being built according to

corporate demands. Chamoli remarks that:

The farmers are starting to become aware that we are in dangerous times. So they are documenting biodiversity and registering the seeds on the village levels. Garwhali farmers in the hill areas are small-scale, local and marginalized farmers who have been practicing organic methods since ancient times. These farmers don't often take loans or export. 


\section{Theme III - Analysis}

For this theme I have isolated segments from the data that focus explicitly on seed and seed saving. Understanding the significance of seed saving from the perspective of the Garhwali is intended to clarify why restricting farmer's access to seed is structurally violent. Furthermore, understanding how farmer's access genetic resources, how they exchange seed and how they improve local crop varieties are important to revealing the adverse effects of cultural and genetic erosion on farmers. The free exchange of seed and sharing of knowledge is integral to promoting biodiversity and IK conservation.

Seed saving is necessary to maintain diverse cultures, sustainable livelihoods and protect biodiversity (Shiva, 1997; Shiva, 2005b). However, IPR regimes obscure the practice of seed saving and the supporting socio-cultural framework. Farmers' Rights to save, use, exchange and sell farm-saved seed are increasingly affected by IPR regimes over PGR (Andersen, 2005). Interestingly the very practices being banned by life form patenting are the same practices that transform the conflict of how to engage indigenous peoples in dialogue regarding IPRs over PGR. A process of inclusion based on the ethic of sharing provides the necessary framework for conflict transformation.

The traditional practice of seed saving, use and exchange exists within the sociocultural ethic and practice of sharing. Seeds and knowledge are shared reciprocally to maintain continuity in relationships in farming villages, with nature and expand outwards to benefit the earth's ecosystem (Brush, 2007). Free seed exchange represents the reciprocal exchange of ideas and knowledge as recognition of interdependence.

In Sub-Saharan Africa and South Asia 80-90\% of planting materials are produced on the farm (Andersen, 2005). Also, farm saved seeds provide for half the seeds used in 
Germany, France and the EU. IPR regimes are most restrictive in developed countries, however developing countries are increasingly targeted to conform to TRIPs. IPRs ensure that the seed initially created by the farmer is sold back to her at higher prices as the property of the company that patents the seed (Shiva, 2002). According to Shiva, patents on seeds and the adjoining restrictions render the farmer both the source and the client in the chain of seed development.

IPR regimes over PGR increasingly impact the social institutions, cultural mechanisms and local production systems that provide access to and distribution of genetic resources through seed access and exchange (Siganporia, 2007; Shiva, 2005). Natural resource polices at the macro level indelibly impact peoples lives in the micro context (Krishna, 2009). Chowdhury (2004) explains that indigenous livelihoods and survival depend directly on PGR.

Eyzaguirre and Dennis (2007, p. 1496) write that:

Plant genetic resources are still largely in the hands of the rural poor, as biological assets for their livelihoods. They are the raw materials that allow farmers to resist shocks and climatic variation. Although farmers' assets can be enhanced by greater access to commercial germplasm, loss of access and rights to local germplasm takes power away from farmers and limits their contribution to future diversity and evolution in the plants and animals that sustain humanity.

Most farmers use farm-saved seeds (GRAIN, 2007). Local institutions at the village level determine how individuals coordinate to gain access and use diversity in genetic resources. Genetic material are shared in many ways including among villages in the exchange of gifts of seed, wage payment in kind to agricultural labor, through regional trade of commodities and seed, and farmer experimentation (Brush, Perales, \& Qualset, 2003; Louette, 1999). 
Indigenous peoples have developed sustainable livelihoods and genetic biodiversity over many centuries through the practice of selective breeding, which includes seed saving. The break down of sustainable livelihoods occurs when farmers are forced to rely on costly external inputs and unable to adapt local varieties to rapidly changing weather conditions (Berson, 2010). Eyzaguirre and Dennis (2007, p. 1491) write that:

The exchange of locally adapted varieties, the introduction of new varieties, and the movement of seed through its exchange, sale, or saving from past harvests contribute to a robust seed system that is more likely to maintain optimal amounts of diversity.

The evolution of crops is created through the "conscious" selection of desirable traits. Selective breeding is to improve on varieties and adapt them by identifying various properties such as drought, disease and pest resistance.

Local crop varieties can survive in a greater range of environmental conditions as compared to varieties distributed by corporate and government vendors (Bhatt \& Shiva, 2009). Bhatt and Shiva (2009, p. 23) explain that, "With the disappearance of folk varieties, the very genetic base for crop breeding and improvement is irretrievably lost." Traditional farmers evolve genetic traits that are resistant to different pests, pathogens and environmental conditions.

The patenting of genetic life forms by the biotechnology industry is enacted through the criminalization of seed saving (Shiva, 1997). Various national legislation, recently influenced by the biotechnology industry, require that farmers not legally be allowed to save their seeds if they are patented. Forcefully imposed patenting laws require seeds to be sold with licenses that prohibit the act of seed saving among farmers. The licensing agreements and contracts that forbid farmers from using farm saved seeds 
have immense socio-cultural, economic and ecological repercussions (Siganporia, 2007;

Shiva, 2005).

From the indigenous perspective the seed is embodied culture, the symbol of life and continuity, thus it cannot be commercialized (Shiva, 2001, Shiva, 2005). Bhar and Shiva (2005, p. 167) that:

The seed, for the farmer, is not merely the source of future plants and food. It is the storage place of culture, of history. Seed is the first link in the food chain. Seed is the ultimate symbol of food security. Seed is sacred... Seed is the embodiment of the ideas and knowledge, of the culture and heritage of a people. It is an accumulation of philosophy, of tradition, of knowledge of how to work the seed... For the farmer, the field is the mother; worshipping the field is a sign of gratitude to the earth, who as mother, feeds the millions of life forms who are her children.

They go on to explain that the seed and new crops are worshipped before being planted and consumed. The festivals surrounding the agricultural cycle are integral to maintaining the foundational organization of society. The festivals symbolize the people's intimacy with nature and that, "For the farmer, the field is the mother; worshipping the field is a sign of gratitude to the earth, who as mother, feeds the millions of life forms who are her children" (p. 168). 


\section{Theme IV - Climate Change}

\section{A.) Internal Navdanya farmers and coordinators}

1.) Genshyam Prasad expressed concern regarding climate change because of the devastating experiences of drought. In the rainy season in 2008 there was no rain. Prasad attributes the climate change and the drought to deforestation. The farmers experience global forces through the changing weather patterns due to climate change. He says, "Water is the main problem, if we do not have water we cannot have farming. So the disruption to the water cycle has serious impacts."

2.) Chamoli observes that:

The climate is changing very rapidly, snowfall is less, and rain is less. Chemical agriculture needs more water and more moisture and when we talk about both systems: which is more beneficial? - organic farming is beneficial and chemicals have a bad impact. People slowly, slowly change to organic farming and they find good results.

3.) Balbeer says that:

In some places in the Garhwal Himalaya there is no water. We know this because we talked to people in the Climate Change Yatra in June this year.... On the yatra march we talked with different villagers carrying water far to their villages. Crop decrease and water are the major problems. In our place two and three years ago there were streams and in many places now the water has dried up. The women work more then the men, so the women have more information, so we were communicating with the women.

Navdanya did the yatra because they wanted to know how the water cycle was being affected: in terms of crops, water, deforestation and glacial retreat. The results of deforestation showed that if there would have been enough snow the forest would not catch fire in some cases. Balbeer goes on to explain that there is a problem with the Buckwheat because the outer wall is developed, but the seeds is not mature because of climate change. The farmers see the effects of climate change in the crops. Balbeer says 
that, "Many of the people know already about the climate because they have seen in the last year the effect of the climate the effect of the snow and the rain."

4.) Pramod Kimoti explains that:

Climate change is a natural disaster. We have mock drills for natural disasters caused by climate change. The water level has decreased and there is no rain and sometimes there are flash floods. The main cause of climate change is the human being. The deforestation and construction of roads and big dams by humans is the main cause of climate change. I survey climate change in the Garwhal.

\section{B.) Navdanya Members from Sankrit Village}

5.) Shurveer Singh Rawat observes that:

This year is better than last year. We have seen many changes to the environment. Last year we experience global warming. We understand global warming. Last year there was not enough snowfall. It was the only year in my life there was no snow! This year there was some snow, but it was much less than in previous years. When there is no snow there are no crops or apples. Everyone was indebted after that. They had to take loans from the bank for their food. Everyone is indebted in the Living Democracy. 


\section{Theme IV - Analysis}

The interview data showed that the issue of Climate Change is immensely relevant to local farmers whose livelihoods depend on intact ecosystems. The drought that has befallen the Garhwal Himalaya due to Climate Change has immense repercussions for the malnourished Garhwali people. The 2008 drought had a devastating impact on the community. The farmers have an intimate relationship with their environment and have observed the ecosystem closely over many years. The observations allow for climate related comparisons over the decades. My findings on climate change are inconsequential compared to Navdanya's participatory study.

Navdanya conducted a participatory study on climate change, then concurrently published a 2009 report entitled Climate Change at the Third Pole: The Impact of Climate Instability on Himalayan Ecosystems and Himalayan Communities and then held the National Conference on Climate Change in the Himalaya (Bhatt \& Shiva, 2009). The study found that biodiverse farming systems reduce vulnerability to drought and increase climate resilience.

The study also resulted in the drafting and presentation of a People's Participatory Climate Adaptation and Mitigation Plan called the People's Charter on Climate Change. The participatory study qualitatively interviewed and quantitatively surveyed 755 people from Uttrakhand in 165 Garhwali villages from 2008-2009. The researchers also verified interviews by assessing the ground realities. Interviews and surveys were also were collected during the 'Himalayan Climate Yatra (march)' through three Himalayan states, which generated awareness amongst society at large. 
The extensive study came to several conclusions (Bhatt \& Shiva, 2009). The researchers findings for Uttrakhand include: a drastic reduction in snowfall, glacial retreat, disruption to seasonal rainfall, the drying of springs and related drinking water crisis, failure of agricultural crops, increased forest fires that accelerate loss of animal and plant diversity, rapidly changing forest structures, displaced wild animal as a menace to agriculture, reduced livestock due to depleted fodder and water resources and the disturbance to seed formation due to temperature variation.

The study emphasizes the connection between biodiversity conservation, reduction of climate change impact and poverty alleviation (Bhatt \& Shiva, 2009, p. xii). Biodiverse, local, organic systems reduce water use and risk of crop failure due to climate change in addition to producing more food and higher farm incomes. The priority of global trade for GMO corn, soya, canola and cotton increases climate vulnerability. Production of drought resistant, local varieties of millets, that are nutritionally superior and use only 200-300 mm water, could produce four times more food that Green Revolution rice farming.

The People's Charter on Climate Change was based on detailed surveys and 765 interviews collected at different altitudes and locations in five river valleys of the Garhwal Himalaya (Bhatt \& Shiva, 2009). Thirty 'veteran intellectuals' or Climate Guardians (Ritu Praharies), six from each valley, were invited to participate to prepare a valley level climate adaptation and mitigation plan. The five valley level plans were adapted into a People's Charter on Climate Change for Garhwal Himalaya. The charter was given to the minister of environment and forests Shri Jai Ram Ramesh, the Ministry 
of Environment and Forests, Government of India and the Chief Secretary, Uttrakhand on September $6^{\text {th }}, 2009$. 


\section{Theme V - Women}

\section{A.) Internal Navdanya Farmers and Coordinators}

1.) Dr. Rawat explains that:

We work with the farmers as families. There is a lot of community diversity and social taboos in various areas depending on the region. In some areas they do not want us to talk with the women, but in Teri the women are very frank and hundreds of women come to talk with you. They are very social: it is all cultural...

Garhwali, female farmers are also hampered by the men - socially speaking. They have more of a workload in Garhwal, especially Garhwal women, but the organic practices we teach them helps. The women carry the manure on their backs to the field, which was too heavy. Now they are making good quality manure like Vermi compost and they are taking to the fields ten times less weight because it is better quality, less in weight and well made. We teach them how to use manure: usually they use manure during the preparation of the field. We taught them to use compost after germination of the seed. When they use it in preparation stages it will be used by the weeds and plants. The weeds will grow simultaneously. We suggest not using compost too early in the fields.

2.) Rukmani Rawat explains that:

Four years back I was not that happy because my parents kept pressuring me to get married. After I started working they were very happy with me to see what I have done for my community. If I don't feel like getting married then how can I? Even if I have to leave and get my own house then I will. I will not be pressured into marriage.

In our religion there is a saying that a woman cannot take care of herself unless she is married. I told them even if I am not married I could take care of myself financially and mentally. In Indian families the men are supposed to take care of the daughters. It is everyone's right to stay in his or her family and take care of their parents. I have two elder sisters and one brother but I am the one to take care of my parents. When my parents die it will be customary for the man to light the fire because he takes care of the parents.

Now I am free to move around because my brother supported me for the good of my community, but this was not always the case. My brother said, ' I will support you in your cause.' Now it is a ripple effect, people see what I am doing so they will allow the women to move freely. Now they can go where they like when previously they were restricted. 
3.) Bija Devi says that, "Seed keeping is the role of women." 


\section{Theme V - Analysis}

Sen (2005) explains that 'survival inequalities' in India result in 37 million

missing women. That means that if the inequalities were diminished there would be 37

million more women alive because their chances of survival would increase. Sen (p. 244)

explains economic development and modernization variables have no significant effect

on gender bias in child survival, but when not accompanied by empowerment, increase

gender bias in child survival. Rather, it is the deliberative agency of women that increases their survival chances.

In the mountain economy of North India women play a dominant role. Women compose the population of subsistence farmers in the mountains. According to Dwivedi (2000, p. 17), "In the Himalayan areas, the pivot of the family is the woman. It is the woman who worries most about nature and its conservation in order that its resources are available for her family's sustenance." He goes on to write that:

The more innovative NGO strategies attempt to extend women's mobility and their ability to reclaim public spaces. This requires improving women's access to and control of productive assets.... It is women's collective strength in grassroots organizations that could give them the confidence to cope with discrimination and violence, whether in the community or the family. (p. 240)

A gendered approach to development is crucial to alleviate poverty. Navdanya maintains programs for women including Diverse Women for Diversity.

A cross-analysis with the theme of a Culture of Sharing shows that women work together in small groups to accomplish their goals in the Garhwal. According to Krishna:

The more innovative NGO strategies attempt to extend women's mobility and their ability to reclaim public spaces. This requires improving women's access to and control of productive assets.... It is women's collective strength in grassroots organizations that could give them the confidence to cope with discrimination and violence, whether in the community or the family. (2009, p. 240) 
However, the culture of the Garhwal, which is rooted in traditional crops and cropping systems, is impacted by the changing crop patterns.

Women play a pivotal role in the use and management of natural resources including food production, land use, the provisioning of water and fuel supply (Dankelman et al., 2005). Women are instrumental in land use methods including: natural fertilizers, seed selection and soil conservation, crop rotation, mulching and terracing. Women adapt these methods to meet environmental conditions. Dankelman et al. show that the labor inputs of women are the most critical to the functioning of the mountain economy. Women work more than 16-hour days, without breaks, in the mountain areas. Singh (1987) showed that on a one-hectare farm in the Uttrakhand a pair of bullocks' works for 1064 hours, a man for 1212 hours and a woman for 3485 hours in a year.

Bhat and Singh (1987) demonstrated that, in addition to household chores, women in the mountains of Himachel Pradesh did 69\% of animal tending, $66 \%$ in harvesting, $59 \%$ of trenching, $59 \%$ in intercultural and $37 \%$ of sowing. A case study in Tehri district found that a woman on average will walk $5460 \mathrm{~km}$ annually to gather fire wood and can spend up to eight hours a day in collecting fodder. Thus, women are responsible for a disproportionate amount of the workload.

'Green revolution' chemically intensive, dwarf varieties planted in the Garhwal have impacted the local ecosystem and thus impact women. Dankelman et al. (2005) explore how the replacement of indigenous varieties with corporate controlled seeds is directed towards men and commercial interests for industrial food processing. Cashoriented agriculture is male-dominated. 
The gender dichotomy is apparent in that men plan, make decisions, and primarily participate in the commercial transformation of traditional mountain agriculture. A study conducted by Manju Mehta (ICIMOD, 1989) in the Garhwal shows that the change to commercial agriculture for cash crops reduces women's sphere of influence. Women's dependence on men increases when they are forced to purchase seeds, take on debt and use money. The collective power of women is eroded in this context.

The displacement of local crop varieties (such as millets, mustard and potato) for local consumption with commercial crops for export increases the malnourishment of local people. The work of women increased in the instance of increased weeding requirements due to the needs of chemically intensive, 'green revolution' high yield varieties (HYV). HYV varieties do not leave biomass for fodder thus impacting women and animal-husbandry practices. According to Dankelman et al. agricultural changes have aggravated women's problems, drudgeries and misery.

Mountain women are very critical of commodity-based agriculture. Women's perception of the agricultural transformation needs to be considered. Dankelman et al. (2005, p. 26-37) list the concerns of women:

The erosion of biodiversity due to export-oriented production of limited varieties at the expense of locally adapted varieties, the neglect and destruction of common property resources through resource privatization, the erosion of community-based agriculture systems, the impact on girls education due to increased labor demands on women, the alienation of women from agro-technologies and activities, the displacement and devaluing of women's traditional knowledge and skills related to resource conservation, environmental management and biodiversity management, soil erosion and soil infertility due to agro-chemicals, human exposure to chemical toxicity, greed embodied by the endless pursuit of cash, the extinction of highnutritive, local varieties and the increased consumption of alcohol by men due to the availability of cash. 
The articulation of these concerns is a crucial enterprise. Rural women's interests must be considered in the decision-making processes that impact them such as in the case of IPRs over PGR.

The Navdanya publication Biodiversity, Gender and Technology in Mountain Agriculture (Dankelman et al., 2005) identifies a particular 'feminine perception', associated with the interests of women. The researchers claim that the feminine perception allows for a holistic approach to biodiversity conservation as compared to a reductionist, masculine approach that promotes monocultures. Dankelman et al. (2005) describe women's 'autonomy' to make their own life choices as an important indicator of their position in society. They identify the following criteria as indicative of a woman's autonomy: access and control over means of production, internal cooperation and organization of women's groups, reproductive and sexual control, women's right to selfdetermination, dignity and self-respect. The researchers claim that in the traditional agroecosystem of the Garhwal Himalaya women possess 'obvious autonomy'.

Krishna (2009) calls for a gendered approach to participatory action research in Natural Resource Management. Her work Genderscapes envisions a developmental process that considers the immense marginalization of women in society. She writes that:

My concern has been that the new and emerging environmental rights ... cannot be separated from the gender and caste biases in old rights to land and equal wages and that not recognizing this is to further male domination in resources management. (p. 11)

Krishna critiques Dr. Vandana Shiva and other 'ecofeminists' as romanticizing poverty. She goes on to say that:

I have also held that the picturesquely seductive images of India's unchanging, self-contained village communities is naïve and a historical. This imagined 
landscape, which was shaped in colonial times by foreign anthropologists and Indian nationalists, now serves as a powerful symbol for eco-activists. (p. 15)

The belief that women have a biologically inherent special relationship with nature that is biologically superior to men's relationship is biologically deterministic and precludes the possibility that men too are capable of having a 'intimate' relationship with nature. 


\section{Conclusions}

My research captures the perceptions, practices and experiences of Garhwali farmers as they seek to build positive peace through dialogic relationships premised on reciprocal knowledge sharing. Furthermore, my study reveals some of the methods, principles and models implemented by local people working with Navdanya as well as the participant's relevant perceptions. The Garhwali farmer's overall focus on reciprocal knowledge sharing and seed saving indicates the seminal importance of seed to rural farmers. Thus, the debate on IPRs over PGR must include the voices of indigenous peoples like the Garhwali since their survival depends on access to seeds.

The study shows that Navdanya has created space for an emergent and dynamic dialogue. Navdanya has pioneered a contemporary model of participatory research and development rooted in dialogue with indigenous peoples. Dialogue has changed the meanings and perceptions that create the conflict explored in this thesis. Navdanya has created a much-needed bridge between elite, expert scientists and local farmers by recognizing local farmers as ecological experts in the process of empowerment.

Seeking to understand the actual experience of people who are silenced, oppressed and marginalized has multiple implications. Sen (2009, p. 130) writes that:

We do not live in secluded cocoons of our own. And if the institutions and policies of one country influence lives elsewhere, should not the voices of affected people elsewhere count in some way in determining what is just or unjust in the way a society is organized, typically with profound effects - direct or indirect - on people in other societies?

Following Sen, participatory methodologies and results, that seek to understand and validate the experiences of local people, should be included in institutional agendas and policies. 
Dr. Shiva remarks that:

When you can sit in a room far away and just write policies, where you never have to suffer the consequences, you don't have any tests to figure out: are you holding knowledge that is authentic or are you holding superficial knowledge? (National Conference on Climate Change in the Himalayas, 2009)

Navdanya' disseminates participatory research, tested in the field, pertaining to a wide variety of subjects including farmer's suicides, the impacts of chemical agriculture, the threat of climate change and political and corporate schemes and institutions. My interviews show that Navdanya encourages local people to be agents of social change in their communities by granting them agency to solve local problems and engage in local, regional, national and international political action.

John Paul Lederach (2002) identified four stages needed in the peace building process. These stages may be summarizes as: 1) the process of conscientization, 2) direct confrontation that recognizes disputant parties, 3) mutual negotiation to achieve goals and balance power and 4) additional negotiation and mediation to restructure relationships. Analyzing Navdanya's progress according to Lederach's four stages for peace building is difficult because it operates on both the local, regional, national and international level with staggering levels of success.

Navdanya's struggle has immense proportions and so it is difficult to quantify the organization's success. However, Lederach's four stages shed light on the Navdanya case study in peace building. It is evident that Navdanya has greatly contributed to the concientization of Garhwali farmers, built relationships between disputant parties and successful negotiated through many legal and political problems. Navdanya has helped to propel the voices of marginalized communities into the global policy sphere through 
successful legal battles, grassroots mobilization, alliance building and visionary leadership.

Participating in the successful rejection of the Seed Laws with India's Act 53 is one example of how Navdanya has contributed to restructuring international relationships through negotiation and mediation. The significance of India's Act 53 and the international political dimensions of the conflict are further explored in the literature review section of this thesis. However, analysis of how Navdanya has progressed in restructuring relationships internationally is beyond the scope of this thesis.

Yet, the work of Dr. Shiva has undoubtedly been incredibly influential in the international community. The undeniable power imbalances in the conflict between IPRs over PGR and indigenous peoples' rights and Farmers' Rights hinder the possibility for a genuine global positive peace to emerge. For the conflict over IPRs over PGRs to be addressed it is crucial that intermediary organizations and actors create space to elevate the voices of marginalized indigenous peoples. 


\section{Chapter IV - Overall Conclusion}

The apparent injustices unfolding in a nuanced analysis of life form patenting require serious consideration. Patents on seeds impact the basic needs and livelihoods of indigenous peoples. The prohibition and criminalization of seed saving has led to genetic erosion, erosion of local environmental expertise and biopiracy. The 500-800 billion dollar annual global market for products derived from genetics was made possible through the intergenerational work of small-scale farmers and indigenous peoples like the Garhwali (Kate \& Laird, 2000). However, the 300 million indigenous peoples in the world today do not benefit from the commercialization of genetic resource (IFAD, 2003, p. 5).

The forces behind the universal standardization of life form patenting are depicted in a large body of literature as indirectly conspiring to marginalize indigenous peoples as non-dominant sectors of society. Indigenous peoples continue to experience gross inequality and oppressive poverty that results from a hegemonic decision making process, which enables the centralized control of natural resources. This thesis applies the theory of structural violence to answer the question, why have indigenous peoples not benefited from the commercialization of genetic resources considering the economic viability of IK?

This thesis explains structural violence as phenomenon that exist when groups are marginalized and denied the agency necessary to participate in the decision making process at which time they would be able to advocate for their interests. The existence of structural violence precludes a genuine global positive peace because it indicates a high level of oppressive inequality. Analyzing the conflicts arising from the universal 
standardization of life form patenting over PGR in the context of structural violence highlights the complexity of the problem.

My study shows the many reasons why Garhwali people experience structural violence through the exclusionary processes that impose IPRs over PGR. Garhwali people have not been included in the decision-making process pertaining to IPRs over PGR. Some reasons that explain their exclusion include the WTO and the biotechnology industries observed tendency towards reductionism, exclusionary neglect and preference for a hegemonic decision-making process. Unfortunately these tendencies regularly deny local people the agency they need to survive because survival requires cooperation, reciprocal knowledge sharing and a holistic treatment of biodiversity and IK systems.

My study clearly shows that TRIPs is structurally violent. To better understand the multiple and interrelated impacts of TRIPS this study reviews the erosion of IK and biodiversity, the phenomenon of biopiracy and socio-cultural differences. TRIPS have been widely critiqued in multiple forums as a western tool for consolidating economic power that ignores the plight of impoverished people. According to the UN SubCommission on the Protection and Promotion of Human Rights (now the Human Rights Council) there is a conflict between TRIPS and the realization of economic, social and cultural rights (Tobin, 2009).

The industries and traders of world commerce left little room for dialogue with diverse stakeholders since they simultaneously acted as 'patients, the diagnosticians, and the prescribing physicians' when they created TRIPS (Enyart, 1990, p 54-56). The denial of India's right to review incorporated in TRIPs and the misappropriation of IK through bioprospecting (biopiracy) indicates levels of structural violence. The non-participation 
of indigenous peoples in any aspect of the decision-making process regarding the universal standardization of life form patenting supports the argument that TRIPS is structurally violent.

The Convention on Biological Diversity (CBD) and the International Treaty on Plant Genetic Resources for Food and Agriculture (ITPGRFA) provide alternative frameworks to TRIPS (Siganporia, 2007). The CBD has a broader agenda than the ITPGRFA, which exclusively focuses on PGR for food and agriculture. The CBD encourages the formation of bilateral contracts between users of biodiversity and national governments for fair and equitable sharing of benefits. The goal of the $\mathrm{CBD}$ is to promote the conservation and sustainable use of biodiversity as well as the fair and equitable sharing of benefits resulting from the commercialization of genetic resources.

Criticisms of the CBD demonstrate that imposing 'indigenous intellectual property' onto indigenous peoples has a negative impact. Vermeylena (2007) showed that the San community's egalitarian ethic and consensus-decision making process was eroded by the Hoodia ABS agreement. The non-participation of indigenous peoples in the $\mathrm{ABS}$ and PIC mechanisms of the CBD indicates levels of structural violence. However, the CBD indicates a shift in global awareness about the salience of biodiversity and IK conservation

The overall objectives of the ITPGRFA are in line with the CBD. The goals of the treaty are the sustainable use and conservation of PGR for food and agriculture and the fair and equitable sharing of benefits resulting from their use. The treaty diverges from the bilateral CBD by implementing a multilateral system for access and benefit sharing. Farmers' Rights, advanced through the ITPGRFA, more accurately describes the 
plight of marginalized indigenous peoples who are struggling to conserve their knowledge and biodiversity.

Preventing the biopiracy of IK is a prerequisite for promoting indigenous communities as important knowledge holders and stewards of biodiversity (GodboleChaudhuri, Srikantaiah \& Van Fleet, 2008). Policies need to be evolved to insure that biopiracy be reduced and eliminated and benefits be returned to indigenous peoples. Alternatives should be holistic and improve the socioeconomic conditions of marginalized indigenous communities. IK and biodiversity conservation requires that sustainable livelihoods be supported and not compromised by national and international policies.

Alternatives exist that validate western knowledge systems and simultaneously protect IK. These alternatives are necessary because IPRs have been used to promote growth in rich countries while impeding development and increasing poverty in many indigenous communities. A successful alternative is embodied in Costa Rica's much celebrated Biodiversity Law that protects indigenous populations and epistemologies (Fernando, 2003). The law requires no prior declaration or knowledge registration and the law protects cultural practices and knowledge related to the use of biological and genetic resources.

Godbole-Chaudhuri, Srikantaiah \& Van Fleet (2008) provides alternatives to IPRs that embrace the purposes of knowledge ownership mechanisms while promoting ecological sustainability. One proposed alternative is to use pre-existing indigenous social structures and cultural conventions such as those extensively developed within traditional Indian Ayervedic medicine. Indian Ayurvedia medicine includes systems of 
codification, rituals and secrecy that serve to protect medicinal knowledge from unlawful appropriation (Oguamanam, 2004).

This alternative requires a paradigm shift to value and legitimate traditional protocols for IK protection. Another alternative would be to provide incentives through affirmative awards and prizes instead of patents that undervalue prior knowledge (Godbole-Chaudhuri, Srikantaiah \& Van Fleet, 2008). This proactive alternative of incentives does not restrict access to knowledge, but would discourage false innovators from seeking claims over IK that already exists.

According to Henrik Magga the Chariman for the UN Forum on Indigenous Issues:

Indigenous people have a dynamic living culture and seek their place in the modern world. They are not against development, but for too long they have been the victims of development and now demand to be participants - and to benefit from - a development that's sustainable. (UNDP, 2004)

Social justice initiatives that link the local with the international through participation and dialogue are essential in addressing structural violence and to build positive peace.

Literature and social movements pertaining to the Rights of indigenous peoples reveals the seminal need for participation. Sen $(2009$, p. 25) asks in the context of patent laws: "what international reforms do we need to make the world a bit less unjust? As an alternative to TRIPS, scholars and practitioners from diverse backgrounds have supported participatory methodologies, the Sustainable Livelihoods Approach (SLA), Farmers Rights, Indigenous Rights and Cultural Rights.

Sen (2009, p. 409) writes that patent laws are one of several issues that are, “...eminently discussable issues which could be fruitful subjects of global dialogue, 
including criticisms coming from far as well as near." Paying attention to civil society and less powerful people in different countries around the world avoids the pitfalls of exclusionary neglect elaborated on in The Idea of Justice. Sen writes that:

In today's world, global dialogue, which is vitally important for global justice, comes not only through institutions like the United Nations or the WTO, but much more broadly through media, through political agitation, through the committed works of citizens' organizations and many NGOs, and through social work that draws not only on national identities but also on other commonalities ... (p. 151)

Local institutions and customs for the collective management of biodiversity are aided by NGOs like Navdanya.

It is clear from the literature that any remedy to the problem of biodiversity and IK erosion requires that all stakeholders need to actively participate in creating the framework equally (Siganporia, 2007). Limitations to monopoly control over biological resources can be accomplished through the recognition and inclusion of indigenous communities. Participation at all levels of decision-making and management is necessary. Indigenous peoples need to be represented on advisory boards and planning bodies.

The IK initiative over the past twenty years has attempted to give local voices and practices more prominence in developmental contexts. Although IK initiatives paired with the participatory movement gained some headway the overall results have been disappointing (Sillitoe, 2010). However, my research shows that Garhwali farmers working with Navdanya have experienced a greater degree of positive peace as a result of participatory methodologies. Navdanya engages indigenous peoples in constructive dialogue, meaningful relationship building and grassroots action on an extensive and regular basis. Navdanya's methodology provides a model with features that could be replicated by other IK initiatives. 
The need for dialogues on IPRs over PGR is a central element of Navdanya's grassroots initiative. Navdanya has pioneered a model of participatory research and development. Navdanya emphasizes local participation, local skills and local institutions as relevant forums for conflict resolution. Understanding how this participatory process grows in the field has yielded insights into the gross inadequacy of unilaterally imposed decision making epitomized by the TRIPS agreement.

Understanding the experiences, perspectives and interests of Garwhali farmers is necessary for the functioning of a legitimate dialogue in the interest of conflict transformation. This thesis demonstrates that Indian farmers from the Garhwal Himalaya are crucial to developmental methodologies because they are experts in their fields, longterm participant observers and knowledge subjects. Their vital experiences, interests and perspectives on sustainability in agriculture must be included in the global decision making process on the future of food and seed for a living democracy to flourish. My research shows that Navdanya effectively counters structural violence in the context of IPRs over PGR because Garhwali people are actively cultivating an experience of positive peace to counteract marginalization. Garhwali people are able to build positive peace through grassroots mobilization that is rooted in dialogic relationship building. My findings confirm the hypothesis that indigenous peoples experience a greater degree of positive peace when they are recognized and included, through a dialogic relationship, in the process of biodiversity and IK conservation. 


\section{References}

Agrawal, A. (2000). Can Hindu beliefs and values help India meet its ecological crisis? In Chapple, C., \& Tucker, M. (Eds). Hinduism and Ecology. Harvard University Press. pp. 165-179. Cambridge, MA.

Alcock, N., \& Köhler, G. (1976). An Empirical Table of Structural Violence. Journal of Peace Research, 13(4), 343-356.

Alcock, N., \& Köhler, G. (1979). Structural Violence at the World Level: Diachronic Findings. Journal of Peace Research (3)(XVI), 255-262

Andersen, R. (2005). Realising Farmers' Rights under the International Treaty on Plant Genetic Resources for Food and Agriculture: summary of findings from the Farmers' Rights project (Phase 1). Lysaker, Norway. Retrieved from, www.fni.no/farmers/main.html

Apffel-Marglin, F., Parajuli, P. (2000). "Sacred Grove" and Ecology: ritual and science. In Chapple, C., \& Tucker, M. (Eds). Hinduism and Ecology. Harvard University Press. Cambridge, MA. pp. 292-312.

Artuso, A. (2002). Bioprospecting, benefit sharing, and biotechnological capacity building. World development (0305-750X), 30(8), 1355.

Barash, D. \& Webel, C. (2009). Peace and Conflict Studies ( $2^{\text {nd }}$ eds). Sage Publications Inc. Thousand Oaks, CA.

Berreman, G. (1999). Hindus of the Himalayas: ethnography and change. Oxford University Press. New Delhi, India.

Berson, J. (2010). Intellectual Property and Cultural Appropriation. Reviews in anthropology. 39(3) 201-228.

Bhar, R.H., \& Shiva, V. (2005). An ecological history of food and farming in India: diversity the Hindustan way (Vols 1). Research Foundation for Science Technology and Ecology/ Navdanya. New Delhi, India.

Bhatt, V., \& Shiva, V. (2009). Climate Change at the Third Pole: the impact of climate instability on Himalayan ecosystems and Himalayan communities. Research Foundation for Science Technology and Ecology/Navdanya. New Delhi, India

Bongo, A. Intellectual Property Rights in Biotechnology and the Fate of Poor Farmer's Agriculture. Journal of World Intellectual Property. 9(1), 97.

Bourassa, S. \& Strong, A. L. (2000) Restitution of fishing rights to Maori: representation, 
social justice and community development, Asia Pacific Viewpoint, 41(2), 155-175.

Brush, S.B. (2007). Farmers' Rights and Protection of Traditional Agricultural Knowledge. World development (0305-750X), 35 (9), 1499.

Brush, S.B., Perales, H.R., \& Qualset, C. (2003). Dynamic management of maize landraces in central Mexico. Economic Botany, 57(1), 21-34.

Burger, J., Field, C., Norgaard, R., Ostrom, E., \& Policansky, D. (1999). Revisiting the Commons: Local Lessons, Global Challenges.

DOI:10.1126/science.284.5412.278. Science, 278-282.

Calle, (1996). Juridical and sociocultural problems on the definition of a law concerning property, usage and access to genetic resources in Colombia. Journal of EthnoPharmacology 31(1), 127-146.

Cardinato, G., Moutinho, P., Nepstad, D., Ray, D., \& Tohver, I. (2007). Mortality of Large Trees and Lianas Following Experimental Drought in An Amazon Rainforest. Ecology Society of America, 88(9), 2007, 2259-2269

Chambers, R, (1995). Poverty and Livelihood: Whose Reality Counts? Environment and Urbanization. 7(1), 173-204.

Chapple, C. Evelyn, T. (Eds.) (2000). Hinduism and Ecology: the intersection of earth, sky and water. Harvard University Press. Cambridge, MA.

Chowdhury, N. (2004). Patents Bill: Protecting Indigenous Knowledge. Economic and Political Weekly, 39(46/47), 4984-4986.

Correa, C. M. (2000). Options for the implementation of farmers' rights at the national level, trade related agenda, development and equity. Working Papers no. 8, South Centre, Geneva.

Creswell, J. (2009). Research design: Qualitative, quantitative and mixed methods approaches. Sage Publications. Thousand Oaks, CA.

Crucible II Group. (2004). Seeding solutions. Policy options for genetic resources: people, plants, and patents revisited (Vols 1). Rome and Ottawa: International Plant Genetic Resources Institute and IDRC.

Dankelman, I., Negi, B., Singh, S., Singh, V., \& Shiva, V. (2005). Biodiversity, gender and mountain agriculture: glimpses of the Indian Central Himalayas. Navdanya. New Delhi, India.

Dei, G.J., Hall, B.L., \& Rosenberg, D.G. (Eds). (2000). Indigenous knowledge in global 
contexts: multiple readings of our world. University of Toronto Press. Toronto, Canada.

Di Falco, S., Perrings, C., 2003. Crop genetic diversity, productivity and stability of agroecosystems. A theoretical and empirical investigation. Political Economics. 50, 207-216.

Dove, M. R. (1996). Center, periphery, and biodiversity: A paradox of governance and a development challenge. In S. B. Brush, \& D. Stabinsky (Eds.), Valuing local knowledge: Indigenous people and intellectual property rights. Island Press. Washington, DC. pp. 41-67.

Dubee, F. (2007). Structural violence and productivity: the role of business and the United Nations Global Compact. International Journal of Productivity and Performance Management. 56(3), 252-258.

Dutfield, G. (2004) Intellectual Property, Biogenetic Resources and Traditional Knowledge. Earthscan. London, England.

Dutfield, G., \& Posey, D. (1996). Beyond intellectual property rights: towards traditional resource rights for indigenous peoples and local communities. International Development Research Centre. Ottawa, Canada.

Dutta, A., Kumar, P., Pant, K., \& Singh, R. (2004). Impact of agro climatic and socioeconomic variability on the nutritional status of inhabitants in the Garwhal Himalayas. ????

Dwivedi, O. (2000). Dharmic Ecology. In Chapple, C. \& Tucker, M. (Eds). Hinduism and Ecology. Harvard University Press. Cambridge, MA. pp. 5-22.

Eisner, T. (1994) Biotic Exploration Fund-Protecting Biodiversity through Chemical Prospecting. Journal of Bioscience. 44(2), 95.

Ellen, R. \& Harris, H. (2000). Introduction. In Ellen, R.F., Parkes, P. \& Bicker, A. (Eds). Indigenous Environmental Knowledge and its Transformations. Hardwood Academic Publishers. Amsterdam, The Netherlands. pp. 1-34.

Enyart, J. (June, 1990). A GATT Intellectual Property Code. Les Nouvelles. 54-56.

Escobar, A. (2008). Territories of difference: place, movement, life, redes. Duke University Press. Durham, NC.

ETC Group. (2010). Gene giants stockpile patents on "climate-ready" crops in bid to become "Biomassters". Patent Grab Threatens Biodiversity, Food Sovereignty. Issue \# 106. 
Eyzaguirre, P., \& Dennis, E. (2007). The Impacts of Collective Action and Property Rights on Plant Genetic Resources. World Development. 35(9),1489-1498

Fagerlind, I., \& Saha, L.J. (1989). Education and national development: A comparative perspective $\left(2^{\text {nd }}\right.$ ed.). Pergamon. Oxford, England.

FAO (1998). The state of the world's plant genetic resources for food and agriculture. FAO. Rome, Italy.

FAO (2001). International Treaty on Plant Genetic Resources of Food and Agriculture. Commission on Genetic Resources for Food and Agriculture. FAO, Rome. $<$ http://www.fao.org/ag/cgrfa/itpgr.htm>. 21 st century. Oxford University Press. NYC, NY.

Farmer, P. (1996). On Suffering and Structural Violence: A View from Below. Daedalus: Social Suffering. 125(1). 261-283. MIT Press. Cambridge, MA.

Farmers' Rights Resource Pages for Decision Makers and Practitioners. (2010). Best Practices: India's Protection of Plant Varieties and Farmers' Rights Act. Retrieved December 2010 from, http://www.farmersrights.org/bestpractices/success_seed_1.html

Fernando, J. (2003). Rethinking Sustainable Development: NGOs and production of indigenous knowledge under the condition of postmodernity. The Annals of the American Academy of Political and Social Science (0002-7162), 590, 54.

Finger, M. J. (2002) The Doha agenda and development; A view from the Uruguay round. Manila, The Philippines. Asian Development Bank. Retrieved 15 September 2009 from, www.adb.org/Economics/pdf/doha/Finger paper.pdf,

Finger, M.J. \& Schuler, P. (Eds) (2004). Poor People's Knowledge: promoting intellectual property rights in developing countries. World Bank and Oxford University Press.

Freire, P. (1970). The Pedagogy of the Oppressed. Herder and Herder. NYC, NY.

Galtung, J. (1969). Violence, Peace, and Peace Research. Journal for Peace Research 6(3), 167-191.

Galtung, J. (1990). Cultural Violence. Journal of Peace Research 27(3), 291-305.

Godbole-Chaudhuri, P., Srikantaiah, D. \& Fleet, J. (2008). Indigenous Knowledge and Intellectual Property Rights: confronting modern norms to promote sustainability. Diaspora, Indigenous, and Minority Education. 2(4), 276-294. 
Government of Uttrakhand, India. (2011). Utrrakhand At A Glance. Retrieved from, http://ua.nic.in/uk.gov.in/pages/display/115-about-us

GRAIN. (2007). GRAIN Briefing: end of farm saved seeds? Retrieved December 10 2010, www.grain.org/briefings/?id=202

Greaves, T. (ed.). (1994). Intellectual Property Rights for Indigenous Peoples' a Sourcebook. The Society for Applied Anthropology, 10. Oklahoma City, OK.

Greene, S. (2004). Indigenous People Incorporated? Culture as Politics, Culture as Property in Pharmaceutical Bioprospecting. Current Anthropology. 45(2), 211 237

Gupta, A. (2005). Human Rights of Indigenous Peoples (vols 2). Isha Books. New Delhi, India.

Hamilton, C. (2006). Biodiversity, Biopiracy and Benefits: What Allegations of Biopiracy tell us About Intellectual Property. Journal of Developing World Bioethics. 6(3), 158.

Hayden, C. (2003). When Nature Goes Public: the making and unmaking of bioprospecting in Mexico. Princeton University Press. Princeton, NJ.

Hoivik, T. (1977). The Demography of Structural Violence. Journal of Peace Research $1(\mathrm{XIV}), 59-73$.

Ho, K. (2007). Structural Violence as a Human Rights Violation. Human Rights Review. $4(2)$.

Indigena, F., \& Kothari, B., (1997). Rights to the Benefits of Research: Compensating Indigenous Peoples for Their Intellectual Contribution. Journal of Human Organization 56(2), 127.

International Fund for Agricultural Development (IFAD). 2003. Indigenous Peoples and Sustainable Development. 5.

International Labour Organization (ILO). (1989). Convention Concerning Indigenous and Tribal Peoples in Independent Countries, No. 169.

James, G. (2000). Ethical and Religious Dimensions of Chipko Resistance. In Chapple, C. \& Tucker, M. (Eds). Hinduism and Ecology. Harvard University Press. Cambridge, MA. 499-527.

Kate, K., \& Laird, S. (2000). The commercial use of biodiversity. Earth Scan Publications. London, England. 
Khor, M. (2003) IPRs, biodiversity, and the theft of indigenous knowledge. Interdisciplinary Science Reviews. 28(1), 7-10.

Krishna, S. (2009). Genderscapes: revisioning natural resource management. Zubaan. New Delhi, India.

Lederach, P. J. (1995). "Introduction" and "A Framework for Building Peace," chapts. in Preparing for Peace: Conflict Transformation Across Cultures. Syracuse, New York: Syracuse University Press. 3-23

Lederach, P. J. (2002). Building Peace: Sustainable Reconciliation in Divided Societies. Washington, D.C.: United States Institute of Peace Press.

Lewontin, R. (1993). The Doctrine of DNA. Penguin Books. NYC, NY.

Louette, D. (1999). Traditional management of seed and genetic diversity: What is a landrace? In S. Brush (Ed.), Genes in the field: On-farm conservation of crop Diversity. Lewis Publishers. Boca Raton, FL. 109-142.

Maman, K. \& Whiteman, G. (2002) Examining justice and conflict between mining companies and indigenous peoples: Cerro Colorado and the Nga' be- Bugle' in Panama, Journal of Business and Management, 8(3), 293-329

Mac Ginty, R. (2008). Indigenous Peace-Making Versus the Liberal Peace. Cooperation and Conflict, 43(139). Retrieved Online January $3^{\text {rd }} 2011$, http://cac.sagepub.com/content/43/2/139

Marinova, D. \& Raven, M. (2006). Indigenous Knowledge and Intellectual Property: A Sustainability Agenda. Journal of Economic Surveys 20(4), 587.

Martin, G. \& Vermeylen, S. (2005) Intellectual property, indigenous knowledge, and biodiversity, Capitalism Nature Socialism, 16(3), 27-48.

Mauro, F., \& Hardison, P. (2000). Traditional Knowledge of Indigenous and Local Communities: International Debate and Policy Initiatives. Ecological Applications $10(5), 1267$.

May, C., \& Sell, S.K. (2006). Intellectual Property Rights: A critical history. Reinner. Boulder, CO.

McGrath, N., Flatau, P., \& Marinova, D. (2005), Institutionalising a participatory culture for indigenous sustainability in Western Australia, Proceedings of the International Conference on Engaging Communities, Brisbane, Queensland (in press, acceptance date 4 August 2005). 
McNeely, J.A., Miller, R.K., Walter, V.R., Mittermeier, R.A., \& Werner, T.B. (1990). Conserving the World's Biological Diversity. World Bank, World Resource Institute, IUCN, Conservation International and WWF. Gland, WA.

MEIN, E. (2009). Literacy, Knowledge Production, Grassroots Civil Society: Constructing Critical Responses to Neoliberal Dominance. Anthropology \& Education Quarterly. 40(4), 350-368.

Mgbeoji, I. (2006). Global biopiracy: patents, plants and indigenous knowledge. Cornell University Press. Ithaca, NY.

Miller, M. (2010). Biodiversity Policy Making in Costa Rica: pursuing indigenous and peasant rights. The Journal of Environment \& Development. 15(4). 359-381.

Moran, K. (2004) Benefit sharing under the Convention on Biological Diversity, In Riley, M. (Ed.) Indigenous Intellectual Property Rights. Legal Obstacles and Innovative Solutions. AltaMira Press. Walnut Creek, CA.

Nathani-Wane, N. (2000). Indigenous knowledge: Lessons from elders - A Kenyan casestudy. In Dei, G.J.S., Hall, B.L., and Rosenberg (Eds)., Indigenous knowledge global contexts: Mulitple readings of our world. University of Toronto Press, Toronto, Canada. 54-69

Navdanya, (2006). Seed Sovereignty, Food Sovereignty \& Water Sovereignty. Annual Report: 2005-2006. New Delhi, India.

Navdanya, (2011). Biopiracy. Retrieved January $1^{\text {st }}, 2011$ from, http://www.navdanya.org/campaigns/biopiracy

Norton, J.B., Pawluk, R.R., \& Sandor, J.A. (1998). Observation and experience linking s cience and Indigenous knowledge at Suni, New Mexico. Journal of Arid Environments, 39, 331-349

O'Faircheallaigh, C. (1998) Resource development and inequality in indigenous societies, World Development, 26(3), 381-394.

Oguamanam, C. (2004). Localizing intellectual property in the globalization epoch: The integration of Indigenous knowledge. Indiana Journal of Global Legal Studies, 11, 135-169.

Ostrom, E. (2007). A Diagnostic Approach for Going Beyond Panaceas. PNAS : Proceedings of the National Academy of Sciences (0027-8424), 104 (39), 15181..

Pandey, D.P. (2001). Practices for Biodiversity Conservation and Management in Mewar 
Region of Rajasthan. Forest Research Institute: Deemed University. Dehra Dun, India.

Parsons, K.A. (2007). Structural Violence and Power. Peace Review, 19(2), 173-181.

Peria, E. (2005). Real Myths or Mythical Realities. In Beth Burrows (Ed.). The Catch Edmonds Institute. Washington, DC. pp. 163.

Pimbert, M. (1999). Agricultural biodiversity: background paper 1. Paper presented at the $\mathrm{FAO} /$ Netherlands conference on the multifunctional character of agriculture and land. Food and Agriculture Organization. Rome, Italy.

Posey, D. (ed) (1996) Traditional Resource Rights: international instruments for protection and compensation for indigenous peoples and local communities. International Union for the Conservation of Nature and Natural Resources. The World Conservation Union. Gland, Switzerland.

Reid, W. (1993). Biodiversity Prospecting: Using Genetic Resources for Sustainable Development. World Resource Publications. 3. Baltimore, MD.

Right Livelihood Award. (2011). Dr. Vandana Shiva. Retrieved January 5 2011, (http://www.rightlivelihood.org/v-shiva.html).

Sachs, J. (1999, August 14). Helping the World's Poorest. The Economist, 352. 17-20.

Sachs, J. (2005) Ending Global Poverty: a guide to what works. Palgrave Macmillian. NYC, NY.

Sahai, S. (2004). The Green Revolution and the Gene Revolution. Journal of Biospectrum. 2(2), 34.

Sarangapani, P.M. (2003). Indigenising curriculum: Questions posed by Baiga Vidya. Comparative Education, 39, 199-209

Schnase, J. L., \& Cunnius, E. L. (Eds.). (1995). Proceedings from CSCL '95: The First International Conference on Computer Support for Collaborative Learning. Erlbaum. Mahwah, NJ.

Sen. A. (2009). The Idea of Justice. Allen Lane. London, UK.

Shankar, D., \& Venkatasubramanian, P. (2005). The evolution of global standards for traditional medicines. Science and Development Network Policy Briefs. Retrieved from http://www.scidev.org/en/policy-briefs/the-evolution-of-global-standardsfor-traditional. Html 
Sharma, D. (2005). Benefit-Sharing a Dead Concept. In Burrows, B (Eds). The Catch. Edmonds Institute. Washington, DC.

Shiva, V. (1997). Biopiracy: The plunder of nature and knowledge. South End Press. Cambridge, MA.

Shiva, V. (2000a). North-South Conflicts in Intellectual Property Rights. Peace Review $12(4), 502$.

Shiva, V. (2000b). Stolen harvest: The hijacking of the global food supply. South End Press. Cambridge, MA.

Shiva, V. (2002). Protect or Plunder? Understanding Intellectual Property Rights. Zed Books. London, England.

Shiva, V. (2005a). Bioprospecting as Sophisticated as Biopiracy. In The Catch, ed. Beth Burrows (Washington, DC: Edmonds Institute) 16

Shiva, V. (2005b). Earth Democracy: Justice, sustainability and peace. South End Press. Cambridge, MA.

Shiva, V. (2009). National conference on climate change in the Himalaya. Navdanya. Indian International Center. New Delhi, India.

Siebenhuner, B., Dedeurwaerdete, T. \& Brousseau, E. (2005). Introduction and overview to the special issue on biodiversity conservation, access and benefit-sharing and traditional knowledge. Ecological Economics 53, 439-444.

Siganporia, A. (2007). Sharing the Benefits of Traditional Knowledge: an analysis of the Access and Benefit-Sharing Mechanism. Depaul Univeristy. Chicago, IL.

Sillitoe, P. (2010). Trust in Development; some implications of knowing in indigenous knowledge. The journal of the Royal Anthropological Institute. 16(1)12-30.

Smith, A. (1770/1790). The Theory of Moral Sentiments. (1976 edition), Clarendon Press. Oxford, England.

So, A.Y. (1990). Social change and development: Modernization, dependency, and world-system theories. Sage Publications. Beverly Hills, CA.

Stiglitz, J. (2007). Making Globalization Work. Norton Paperback. NYC, NY.

Sulula, S. (2006). Developing indigenous knowledge databases in India. The Electronic Library. 24(1), 83-93 
Thamizoli, P., (2004) Mainstreaming Gender Concerns in Mangrove Conservation and Management. In Sumi Krishna (ed.). Livelihood and Gender: Equity in Community Resource Management. Sage Publications. New Delhi, India. 92-108

Thrupp, L. A. (2003). The central role of agricultural biodiversity: trends and challenges. Conservation and sustainable use of agricultural biodiversity: a sourcebook. Manila, The Philippines.

Tobin, B. (2009). Setting Protection of TK to Rights - Placing Human Rights and Customary law at the Heart of TK Governance. In Evanson, C.K., \& Gerd, W. Genetic resources, traditional knowledge and the law: solutions for access and benefit sharing. Earthscan. London, England. Chapter 6.

United Nations Declaration on the Rights of Indigenous Peoples. (2007) Article 8, ILO convention 169.

United Nations Declaration on the Rights of Indigenous Peoples. (2007). UN General Assembly Resolution A/RES/61/295, Article 11(1).

United Nations Declaration on the Rights of Indigenous Peoples. (2007). UN General Assembly Resolution A/RES/61/925, Article 18 and 19.

United Nations Department of Economic and Social Affairs. (2004). Workshop on Data Collection and Disaggregation for Indigenous Peoples. PFII/2004/WS.1/3. NYC, NY.

United Nations Development Program. (1995). Consultation on the Protection and Conservation of Indigenous Knowledge, 24-27. Sabah, East Malaysia.

United Nations Development Programme Report, (2004). Globalization and Cultural Choices. Henrik Magga Chariman for the UN Forum on Indigenous Issues. Retrieved November $1^{\text {st }}$ 2006, http://hdr.undp.org/2004/

United Nations Economic and Social Council (ECOSOC) Sub-Commission on Promotion and Protection of Human Rights, Intellectual Property Rights and Human Rights, Resolution 2000/7, UN Doc. E/CN.4/Sub.2/Res/2007/7 (17 August 2000).

United Nations Educational, Scientific and Cultural Organization. Atlas of World Language's in Danger. Retrieved February 2011, http://www.unesco.org/culture/languages-atlas/

United Nations Environmental Program. Indigenous Knowledge in Africa. Retrieved, January 2011, http://www.unep.org/ik/Pages.asp?id=About\%20IK 
Vermeylena, S. (2007). 'Contextualizing 'Fair' and 'Equitable': The San's Reflections on the Hoodia Benefit-Sharing Agreement', Local Environment, 12(4) 423-436.

Watal, J. (2001). Intellectual Property Rights in the WTO and Developing Countries Kluwer Law International, 170. Hague, The Netherlands.

World Health Organization. (2001). TRIPS, CBD and Traditional Medicines: Concepts and Questions. Retrieved December $5^{\text {th }} 2010$, http://apps.who.int/medicinedocs/en/d/Jh2996e/

World Intellectual Property Rights Organization, (2005). Intellectual Property and Traditional Knowledge. WIPO Booklet. 2(25). NYC, NY.

World Intellectual Property Organization (WIPO). (2010). Intergovernmental Committee on Intellectual Property and Genetic Resources, Traditional Knowledge and Folklore. Sixteenth Session. Submission of Kenya. Accessed Online.

World Trade Organization. (1999). Review of the Provisions of Article 27.3(b). Discussion Paper IP/CW/161 by India at the TRIPs Council, 2.

Worster, D. (1995). The Wealth of Nature: Environmental History and the Ecological Imagination. Oxford University Press. NYC, NY.

Xanthaki, A. (2010). Multiculturalism and International Law Discussing Universal Standards. Human Rights Quarterly, 32(1), 21-48. The Johns Hopkins University Press 